\title{
Drug Delivery of Natural Products Through Nanocarriers for Effective Breast Cancer Therapy: A Comprehensive Review of Literature
}

Kah Min Yap,' Mahendran Sekar, (D) Shivkanya Fuloria, ${ }^{2}$ Yuan Seng Wu, (D) Siew Hua Gan, (iD) 5

Nur Najihah Izzati Mat Rani, ${ }^{6}$

Vetriselvan Subramaniyan, ${ }^{7}$

Chandrakant Kokare, ${ }^{8}$ Pei Teng Lum,

M Yasmin Begum, ${ }^{9}$ Shankar Mani, ${ }^{10}$

Dhanalekshmi Unnikrishnan

Meenakshi,"

Kathiresan V Sathasivam, ${ }^{12}$

Neeraj Kumar Fuloria ${ }^{2}$

'Department of Pharmaceutical Chemistry, Faculty of Pharmacy and Health Sciences, Universiti Kuala Lumpur Royal College of Medicine Perak, Ipoh, Perak, 30450, Malaysia; ${ }^{2}$ Faculty of Pharmacy, AIMST University, Kedah, 08I00, Malaysia; ${ }^{3}$ Centre for Virus and Vaccine Research, School of Medical and Life Sciences, Sunway University, Selangor, 47500, Malaysia; ${ }^{4}$ Department of Biological Sciences, School of Medical and Life Sciences, Sunway University, Selangor, 47500, Malaysia;

${ }^{5}$ School of Pharmacy, Monash University Malaysia, Bandar Sunway, Selangor Darul Ehsan, 47500,

Malaysia; ${ }^{6}$ Faculty of Pharmacy and Health Sciences, Universiti Kuala Lumpur Royal College of Medicine Perak, Ipoh, Perak, 30450, Malaysia; ${ }^{7}$ Faculty of Medicine, Bioscience and Nursing, MAHSA University, Selangor, 42610 , Malaysia; ${ }^{8}$ Department of Pharmaceutics, Sinhgad Technical Education Society's, Sinhgad Institute of Pharmacy, Narhe, Pune, 4I I04I, India; ${ }^{9}$ Department of

Pharmaceutics, College of Pharmacy, King Khalid University (KKU), Asir-Abha, 6I42I, Saudi Arabia; ${ }^{10}$ Department of Pharmaceutical Chemistry, Sri Adichunchanagiri College of Pharmacy,

Adichunchanagiri University, Mandya, Karnataka, 57/418, India; " College of Pharmacy, National University of Science and Technology, Muscat, 130, Oman; ' ${ }^{2}$ Faculty of Applied Sciences, AIMST University, Kedah, 08I00, Malaysia

Correspondence: Neeraj Kumar Fuloria; Shivkanya Fuloria

Faculty of Pharmacy, AIMST University, Kedah, 08I00, Malaysia

Tel +60 I6 4037685; +60 I43034057

Email neerajkumar@aimst.edu.my;

shivkanya_fuloria@aimst.edu.my

\begin{abstract}
Despite recent advances in the diagnosis and treatment of breast cancer (BC), it remains a global health issue affecting millions of women annually. Poor prognosis in $\mathrm{BC}$ patients is often linked to drug resistance as well as the lack of effective therapeutic options for metastatic and triple-negative BC. In response to these unmet needs, extensive research efforts have been devoted to exploring the anti-BC potentials of natural products owing to their multi-target mechanisms of action and good safety profiles. Various medicinal plant extracts/essential oils and natural bioactive compounds have demonstrated anti-cancer activities in preclinical BC models. Despite the promising preclinical results, however, the clinical translation of natural products has often been hindered by their poor stability, aqueous solubility and bioavailability. There have been attempts to overcome these limitations, particularly via the use of nano-based drug delivery systems (NDDSs). This review highlights the tumour targeting mechanisms of NDDSs, the advantages and disadvantages of the major classes of NDDSs and their current clinical status in BC treatment. Besides, it also discusses the proposed anti-BC mechanisms and nanoformulations of nine medicinal plants' extracts/essential oils and nine natural bioactive compounds; selected via the screening of various scientific databases, including PubMed, Scopus and Google Scholar, based on the following keywords: "Natural Product AND Nanoparticle AND Breast Cancer". Overall, these nanoformulations exhibit improved anti-cancer efficacy against preclinical BC models, with some demonstrating biocompatibility with normal cell lines and mouse models. Further clinical studies are, however, warranted to ascertain their efficacy and biocompatibility in humans.
\end{abstract}

Keywords: breast cancer, drug delivery, molecular mechanisms, nanoparticles, natural products, phytomedicine

\section{Introduction}

Breast cancer $(\mathrm{BC})$ has been recognised as a global health issue, as it is the most common type of cancer and the major cause of cancer death in women. ${ }^{1}$ In 2020 , BC recorded high global incidence (2,261,419 cases) and mortality $(684,996$ deaths) rates. ${ }^{2}$ Advancements in technology (eg, mammography, ultrasound, magnetic resonance imaging, computerised tomography and positron emission tomography) have enabled the early detection of $\mathrm{BC} .^{3}$ Nevertheless, approximately $30 \%$ of patients with early-stage $\mathrm{BC}$ eventually relapse with metastases. ${ }^{4,5}$ Metastatic $\mathrm{BC}$ is considered to be largely incurable, with a 5-year survival rate of only $26 \%$ despite currently available treatment options. ${ }^{6}$ 


\section{Graphical Abstract}

\section{Nano-Based Drug Delivery Systems of Natural Products in Breast Cancer Therapy}
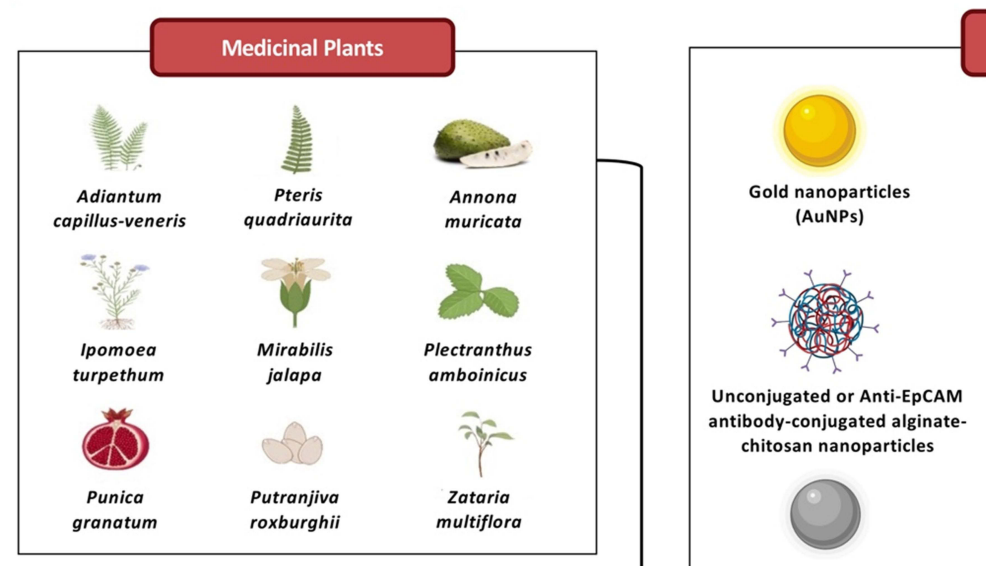

Natural Bioactive Compounds

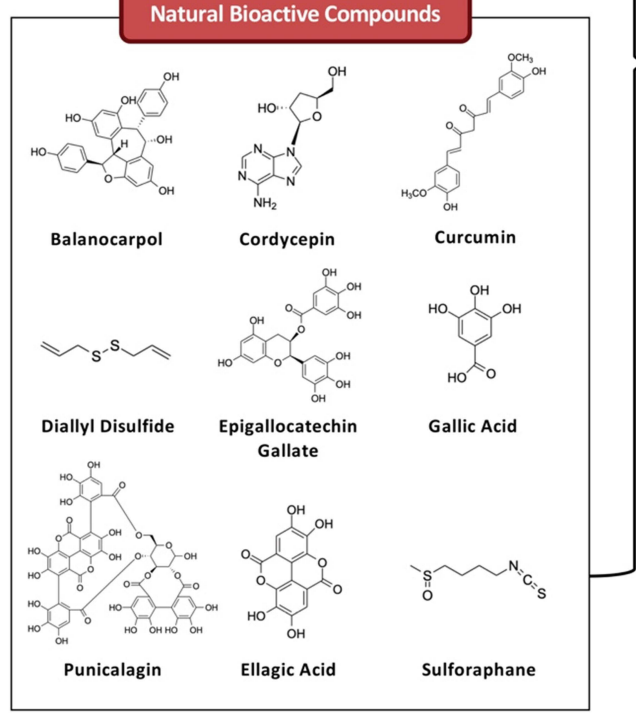

Silver nanoparticles

Nano-Based Drug Delivery Systems

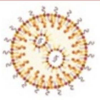

Unconjugated, Anti-RAGE antibody-or boly(N-isopropylacrylamide), $\mathrm{N}$-vinyl solid-lipid nanoparticles (SLNs) VP-AA) co-polymeric nanoparticles

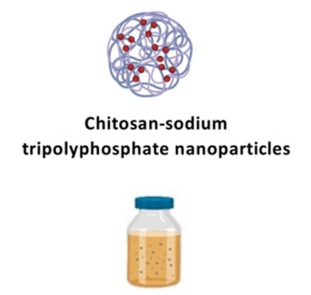

Citrus pectin-based nanoemulsion

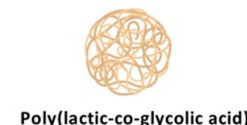

Poly(lactic-co-glycolic acid) (PLGA) nanoparticles

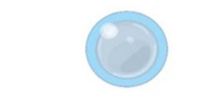

Gum arabic aldehyde-gelatin (GA Ald-Gel) nanogels

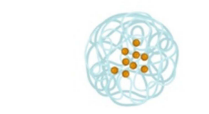

Water-soluble nanomicelle formed by self-assembly of pectin-curcumin conjugates

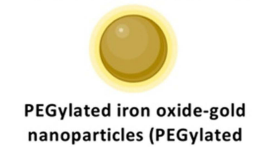
nanoparticles (PEGylated $\mathrm{Fe}_{3} \mathrm{O}_{4} @ \mathrm{AuNPs}$ )

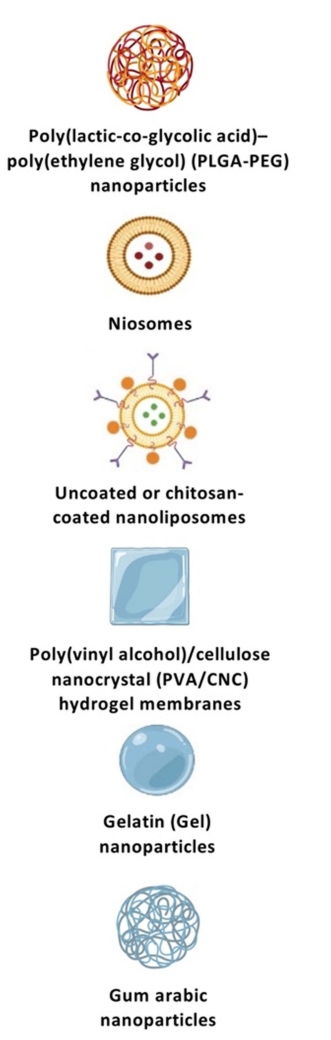

$\mathrm{BC}$ is a disease of heterogenous nature. ${ }^{7}$ Based on the receptor expression status, $\mathrm{BC}$ can primarily be categorised into three major subtypes, including luminal A/B, human epidermal growth factor receptor 2 (HER2)-enriched and triple-negative subtypes ${ }^{7}$ (Figure 1). Different BC subtypes exhibit distinct biological features, with variabilities in their prognosis and treatment response. ${ }^{8}$ In particular, triple-negative breast cancer (TNBC) is associated with worse prognosis, more aggressive behaviour, lack of validated molecular targets and limited therapeutic options (ie, chemotherapy), thereby rendering its management challenging. ${ }^{9,10}$
A multimodal approach is often employed for BC treatment, whereby a combination of surgery, radiotherapy, endocrine therapy, HER2-targeted therapy or chemotherapy may be included in the treatment plan depending on the stage and subtype of $\mathrm{BC}$ as well as the tolerance of patients. ${ }^{11}$ Table 1 summarises the typical systemic therapeutic options for the three major BC subtypes. ${ }^{12,13}$ However, there have been reports of resistance to endocrine therapy, HER2-targeted therapy and chemotherapy clinically. ${ }^{14}$ Both drug resistance and the lack of effective therapeutic options for metastatic BC and TNBC represent the major obstacles in treating $\mathrm{BC}$. Therefore, $\mathrm{BC}$ remains a medical area with unmet needs and has attracted 
Stages of Breast Cancer

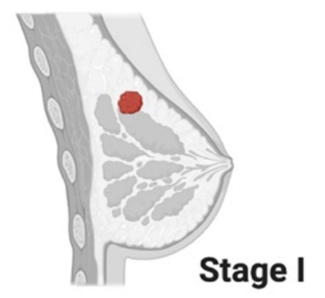

$<2 \mathrm{~cm}$ Localised

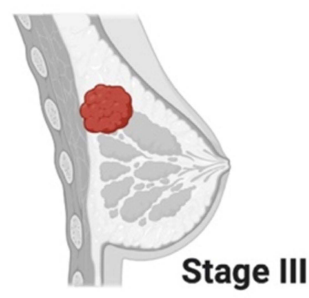

$>5 \mathrm{~cm}$

Metastasised to axillary lymph nodes
Subtypes of Breast Cancer

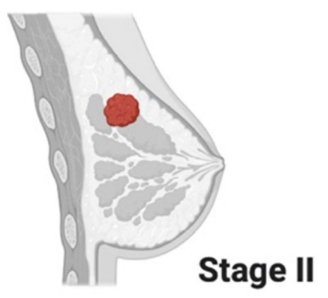

$2-5 \mathrm{~cm}$

May have metastasised to lymph nodes

\section{Any size}

Metastasised to distant organs (preferentially

bones, lungs, brain and liver)

Figure I Stages and subtypes of breast cancer.

Note: Created with BioRender.com.

Abbreviations: ER, Estrogen receptor; HER2, Human epidermal growth factor receptor 2; HR, hormone receptor; PR, progesterone receptor.

researches into the discovery of novel anti-BC drugs that offer higher efficacy with minimal toxicity.

Historically, different forms of natural products (eg, oils, potions, remedies and traditional medicines) have been used to treat various diseases and injuries. ${ }^{15}$ The medicinal properties of natural products have subsequently attracted attention into identifying the bioactive compound(s) of interest, making natural products a vital source for drug discovery in various therapeutic areas, especially in cancer and infectious diseases. ${ }^{16}$ For instance, the majority $(>60 \%)$ of clinically available anti-cancer drugs are natural product-derived. ${ }^{17}$ Of these drugs, paclitaxel from Taxus brevifolia, vinca alkaloids from Catharanthus rosea, etoposide from Podophyllum peltatum as well as topotecan and irinotecan from Camptotheca acuminata represent some of the most effective chemotherapeutic agents in clinics. ${ }^{17}$ There was a decline in the pursuit of natural product-based drug discovery by the pharmaceutical industry in the 1990s, mainly due to challenges in highthroughput screening, bioactive compound identification and synthesis as well as lead optimisation. ${ }^{16}$ However, recent technological advancements have helped to address these challenges and thereby revitalised the industry's interest to re-explore natural products as a potential source of new drugs. ${ }^{16}$

Natural products are often tested for desired bioactivities in the form of extracts. ${ }^{18}$ Extracts demonstrating the bioactivity of interest are then subjected to fractionation for the isolation and identification of bioactive compound(s). ${ }^{18}$ Plants, in particular, represent a natural source that has been heavily explored for their anti-cancer potentials. ${ }^{19}$ Studies have reported anticancer activities of various plant extracts and isolated phytochemicals, which are the biologically active non-nutritive plant chemicals, in preclinical BC models. ${ }^{20,21}$ More recently, studies have also suggested the potential of using essential oils to treat various cancers, including $\mathrm{BC} .^{22,23}$ Essential oils, which are produced and secreted by specialised secretory structures of plants, are complex mixtures of lipophilic and volatile plant secondary metabolites. ${ }^{24,25}$ Natural extracts, essential oils and their bioactive compounds are known to exhibit multi-target mechanisms of action with minimal side effects, of which would be advantageous for cancer treatment. $^{22,26}$ 
Table I Systemic Therapeutic Options for Three Major Breast Cancer Subtypes

\begin{tabular}{|c|c|c|c|c|}
\hline & Luminal A/B & HER2-Enriched & $\begin{array}{l}\text { Triple- } \\
\text { Negative }\end{array}$ & References \\
\hline $\begin{array}{l}\text { Endocrine Therapy } \\
\text {-Selective estrogen-receptor modulators (SERMs; eg, } \\
\text { tamoxifen) } \\
\text {-Aromatase inhibitors (Als; eg, exemestane, anastrozole and } \\
\text { letrozole) }\end{array}$ & $\begin{array}{l}\text {-Used in all } \\
\text { patients }\end{array}$ & $\begin{array}{l}\text {-Used only in patients with } \\
\text { HR-positive breast tumours }\end{array}$ & $-\mathrm{N} / \mathrm{A}$ & [13] \\
\hline $\begin{array}{l}\text { HER2-targeted Therapy } \\
\text {-Trastuzumab } \pm \text { pertuzumab }\end{array}$ & $-N / A$ & -Used in all patients & $-N / A$ & [13] \\
\hline $\begin{array}{l}\text { Chemotherapy } \\
\text {-Cyclophosphamide + methotrexate + 5-fluorouracil (CMF) } \\
\text {-Doxorubicin + cyclophosphamide (AC) } \\
-5 \text {-Fluorouracil + epirubicin + cyclophosphamide (FEC) } \\
\text {-Cyclophosphamide + doxorubicin + 5-flurouracil (CAF or FAC) } \\
\text {-Doxorubicin + cyclophosphamide + paclitaxel (AC-T) } \\
\text {-Docetaxel + cyclophosphamide (TC) }\end{array}$ & $\begin{array}{l}\text {-Used only in } \\
\text { some patients }\end{array}$ & -Used in all patients & $\begin{array}{l}\text {-Used in } \\
\text { all patients }\end{array}$ & {$[12,13]$} \\
\hline
\end{tabular}

Despite the promising preclinical findings, the physicochemical properties of natural products generally lead to poor stability, aqueous solubility and bioavailability, all of which can hinder their clinical application. ${ }^{24,27}$ Additionally, the clinical application of essential oils has also been challenged by their high volatility, high sensitivity to environmental conditions (eg, high temperature, light and oxygen), low stability and high lipophilicity. ${ }^{24,25}$ Attempts made in trying to resolve these limitations are considered promising, especially through the use of nano-based drug delivery systems (NDDSs). ${ }^{28-31}$

This review first describes the tumour targeting mechanisms of NDDSs, and summarises the major classes of NDDSs by highlighting their advantages, disadvantages and current clinical status in $\mathrm{BC}$ treatment. Thereafter, the anti-BC mechanisms of selected natural products (including extracts, essential oils and natural bioactive compounds) and their nanoformulations that have demonstrated preclinical anti-BC activities are discussed.

\section{The Tumour Targeting Mechanisms of Nano-Based Drug Delivery Systems}

NDDSs represent a rapidly developing area of science, where nanoscale materials are utilised as carriers for delivering drugs to their sites of action. ${ }^{32}$ The use of NDDSs for drug delivery can enhance the bioavailability of poorly water-soluble drugs, enable the co-delivery of multiple drugs, provide targeted drug delivery, protect normal cells from drug toxicity and prolong drug action. ${ }^{32-34}$
Targeted drug delivery to tumours is of the utmost importance to enhance the efficacy of anti-cancer drugs while minimising their systemic toxicity, and it may be achieved by NDDSs via passive and active targeting mechanisms (Figure 2). ${ }^{35,36}$

\section{The Passive Tumour Targeting Mechanism}

Passive tumour targeting generally depends on a phenomenon called the enhanced permeation and retention (EPR) effect. ${ }^{33}$ Tumour angiogenesis is stimulated in response to the needs of tumours for nutrients, oxygen and waste excretion. ${ }^{37}$ However, the new tumour vasculature exhibits both structural and functional abnormalities. ${ }^{37}$ For instance, the newly formed blood vessels surrounding tumours are leaky (with pore sizes ranging from $100 \mathrm{~nm}$ to $2 \mu \mathrm{M}$ ), thus allowing for enhanced permeation of NDDSs. ${ }^{38}$ Moreover, tumours also lack normal lymphatic drainage system, leading to enhanced retention of these NDDSs. ${ }^{38}$ Overall, the EPR effect can improve the specificity of drug delivery to tumours over normal tissues by approximately $20-30 \% .{ }^{33}$ However, NDDSs must (1) have reasonable stability in the blood circulation and (2) be able to avoid clearance by the reticuloendothelial system (RES) and sequestration by the mononuclear phagocyte system (MPS) in order to reach the tumours and achieve the EPR effect. $^{39}$ These two challenges have specifically been addressed via the PEGylation of NDDSs, which can improve their hydrophilicity and decrease their immunogenicity. ${ }^{33}$ 

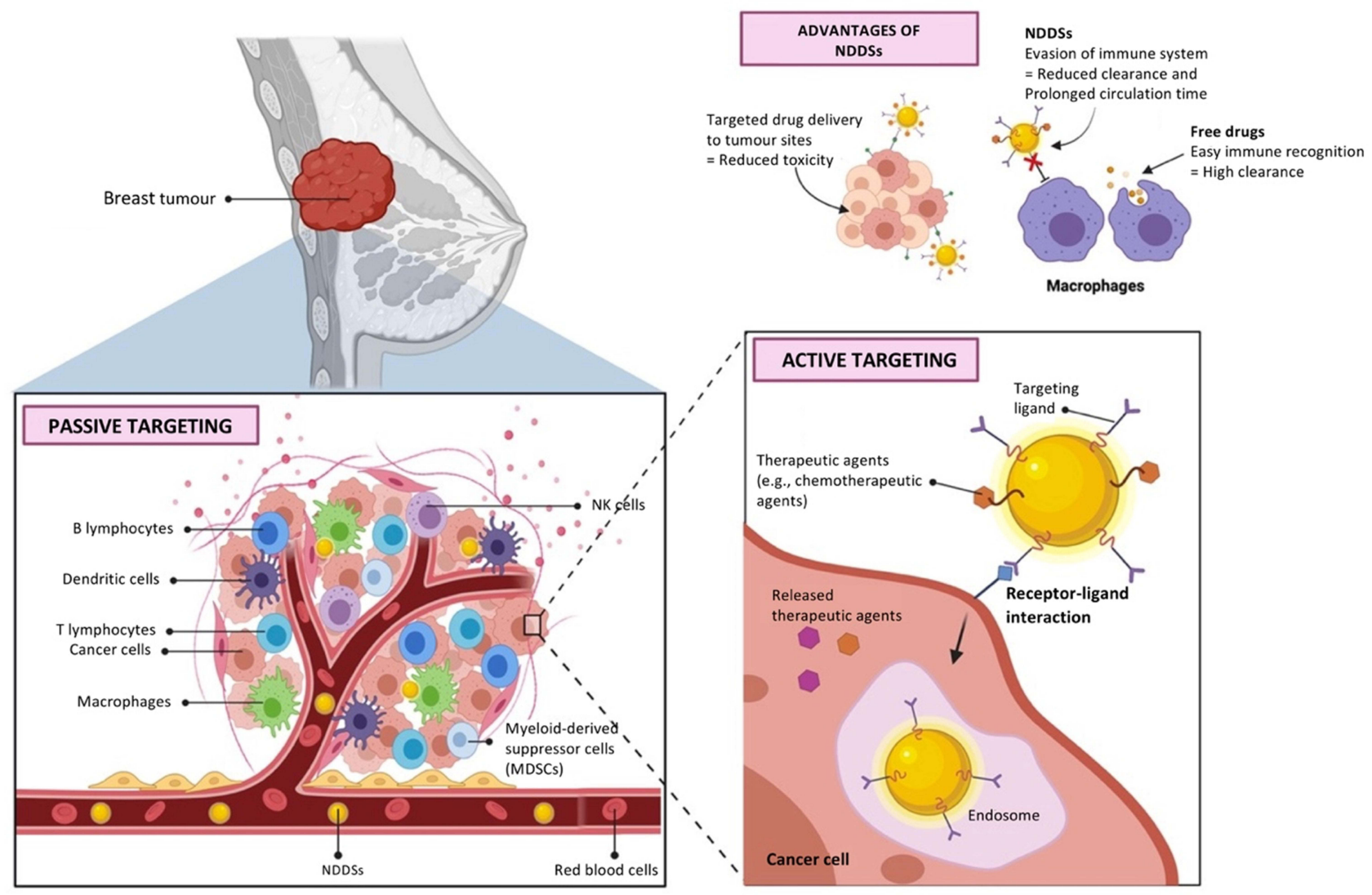

Figure 2 Passive and active targeting mechanisms of nano-based drug delivery systems to tumours.

Notes: Created with BioRender.com. Data from Byrne et $\mathrm{al}^{35}$ and Rosenblum et al. ${ }^{36}$

Abbreviation: NDDSs, nano-based drug delivery systems.

\section{The Active Tumour Targeting Mechanism}

Following the tumour accumulation of NDDSs through the EPR effect, drug efficiency can be further improved via active tumour targeting. ${ }^{33}$ Active tumour targeting is achieved by binding on the NDDS surface of any ligands that interact with receptors that are overexpressed on the surface of cancer cells. ${ }^{39}$ This action increases the affinity of NDDSs for cancer cells and may enhance their uptake by cancer cells via receptor-mediated endocytosis. ${ }^{33,40}$ Interestingly, NDDSs have also been actively targeted to tumour microenvironment (TME), ${ }^{40}$ tumour endothelial cells ${ }^{41}$ and organelles of tumour cells ${ }^{42}$ for cancer therapy.

\section{The Major Classes of Nano-Based Drug Delivery Systems Evaluated for Breast Cancer Therapy}

The use of NDDSs for cancer therapy is promising, as NDDSs have demonstrated potentials in enhancing the efficacy of anti-cancer drugs, reducing their toxicity to normal cells and overcoming drug resistance. ${ }^{43}$ NDDSs can generally be grouped into three different categories, namely organic, inorganic and hybrid (made of $\geq 2$ types of nanomaterials) NDDSs. ${ }^{33}$ Several major classes of NDDSs have been investigated for the delivery of anti-BC agents ${ }^{44}$ (Figure 3). Each of these NDDS classes is associated with certain advantages and disadvantages (Table 2), thus reflecting the importance of selecting the most appropriate delivery system for a particular drug.

\section{The Organic Nano-Based Drug Delivery Systems}

\section{The Carbon-Based Nanocarriers}

The capability of carbon atoms to undergo sp-, $\mathrm{sp}^{2}$ - and $\mathrm{sp}^{3}$-hybridisation explains the existence of multiple carbon allotropes. ${ }^{45}$ In addition to the three naturally occurring carbon allotropes (ie, amorphous carbon, diamond and graphite), several synthetic carbon allotropes (eg, carbon nanotubes, carbon nanocones, carbon nanohorns, fullerene, graphene and nanodiamond) have also been developed. ${ }^{45}$ In recent years, carbon-based nanocarriers have been extensively exploited for different biomedical 


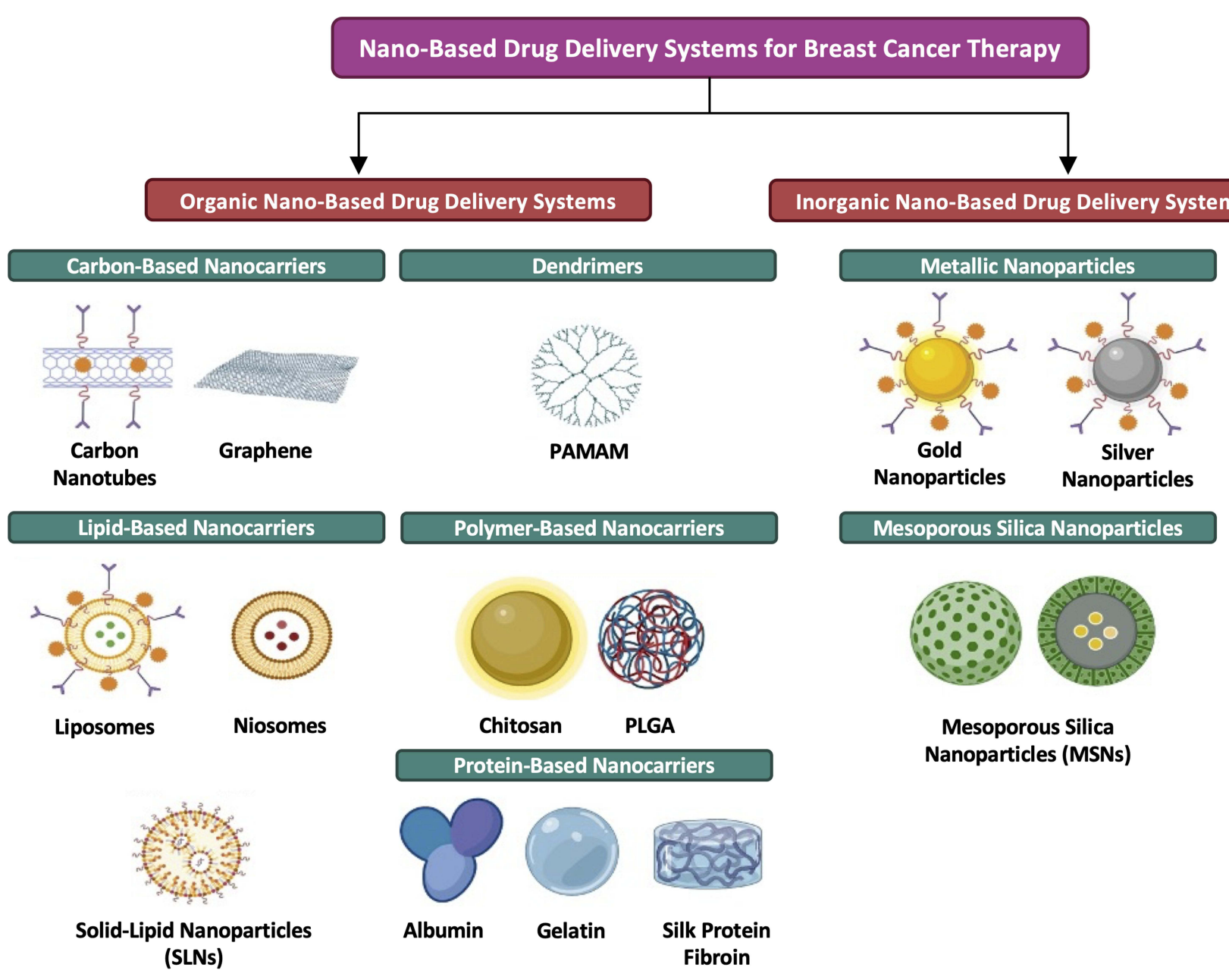

Figure 3 Major classes of nano-based drug delivery systems for breast cancer therapy. Note: Created with BioRender.com.

Abbreviations: PAMAM, poly(amidoamine); PLGA, poly(lactic-co-glycolic acid).

applications (eg, bio-sensing and drug delivery) owing to their unique profiles of chemical and physical properties (eg, electrical and thermal conductivity, mechanical strength, optical properties and structural diversity). ${ }^{46,47}$ Moreover, other aspects of carbon-based nanocarriers such as their large surface area, high chemical stability, preferential tumour accumulation and high cellular entry have also made them potentially promising as drug carriers in cancer treatment. ${ }^{48}$

An activated carbon nanoparticle-epirubicin suspension was developed and tested clinically as regional lymphatic chemotherapy in $\mathrm{BC}$ patients. ${ }^{49}$ It was reported that $\mathrm{BC}$ patients subjected to regional injection of activated carbon nanoparticle-epirubicin suspension had higher epirubicin concentration in the lymph nodes and lower plasma epirubicin concentration than those subjected to intravenous injection of free epirubicin, indicating that this nanoformulation can improve the therapeutic efficacy of epirubicin while minimising its systemic toxicities. This nanoformulation is also capable of releasing epirubicin slowly in the lymph nodes, which may prolong its chemotherapeutic action. Further development of carbon-based nanocarriers is, however, often hindered by controversies surrounding their inherent toxicities. ${ }^{48}$

\section{The Dendrimers}

Dendrimers are three-dimensional polymeric macromolecules that are characterised by their well-organised and highly branched structures. ${ }^{50}$ A typical dendrimer consists of a symmetric central core, together with an inner shell and an outer shell. ${ }^{51}$ The precise molecular weight, biocompatibility, monodispersity, high aqueous solubility, high biological barrier penetrability and polyvalency of dendrimers have contributed to their extensive biomedical 


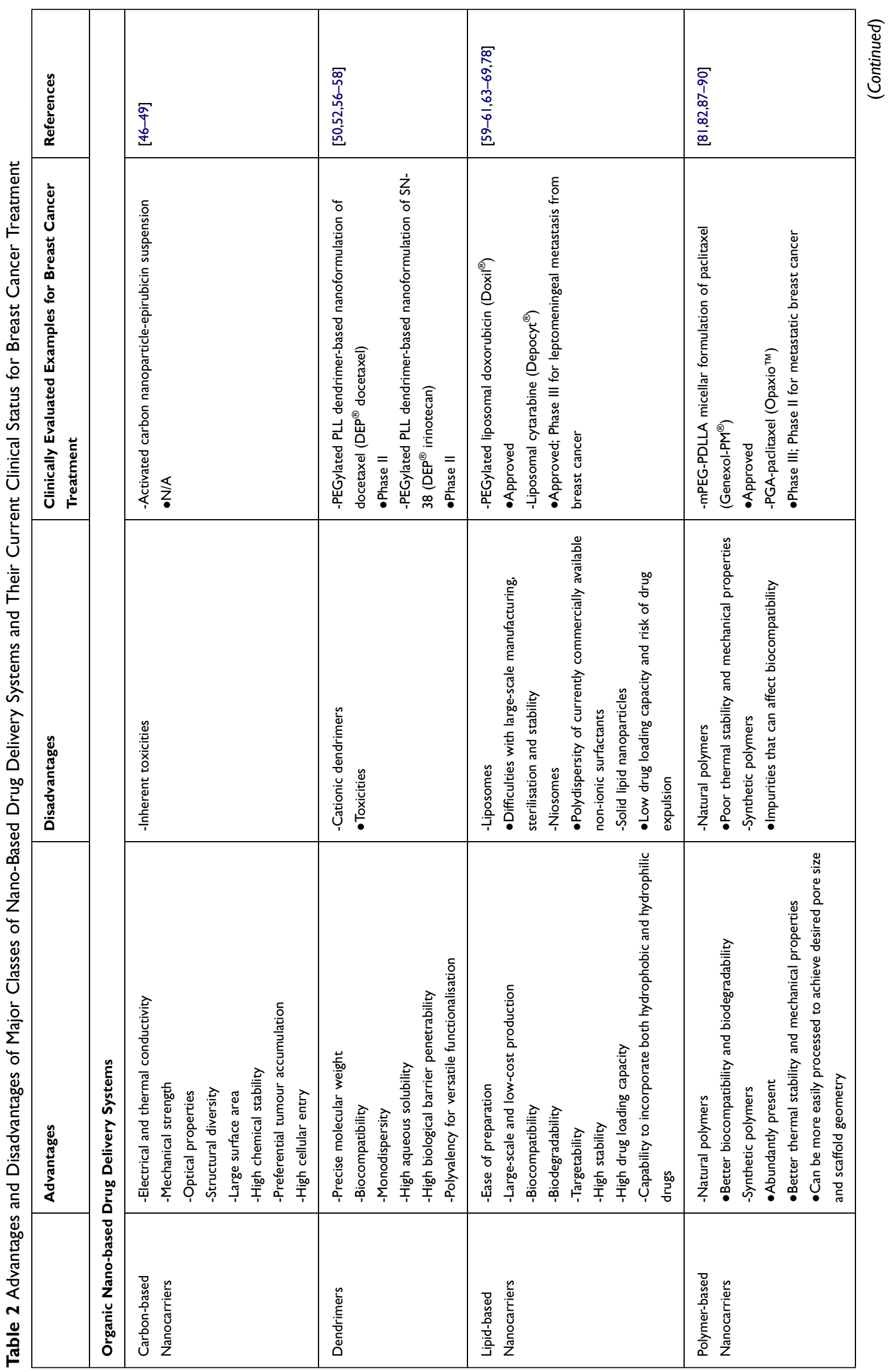




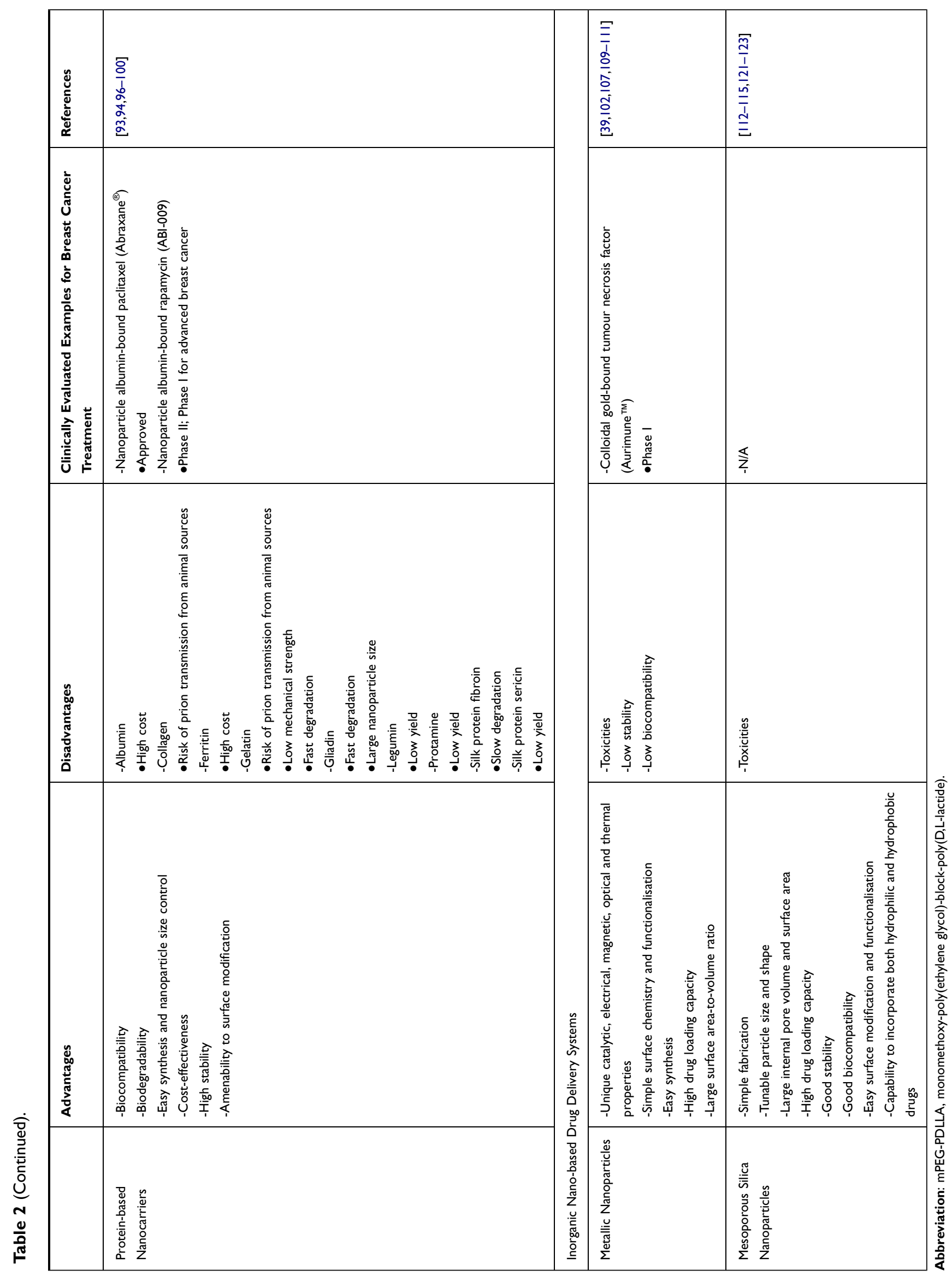


and therapeutic applications (eg, imaging, gene therapy and drug delivery). ${ }^{50,52}$ The exploitation of dendrimers for drug delivery dates back to the late $1990 \mathrm{~s} .{ }^{53}$ In fact, dendrimers have been considered to be multi-functional drug carriers, as they can enhance the solubility, dissolution, adsorption, bioavailability, stability and efficacy of drugs as well as enable controlled drug release and targeted drug delivery. ${ }^{52,53}$

Various types of dendrimers have been investigated as drug carriers in oncology, including dendrimer based on 2,2-bis(hydroxymethyl) propionic acid, melamine-based dendrimer, poly(amidoamine) (PAMAM) dendrimer, poly (glycerol-succinic acid) dendrimer, poly(propylene imine) (PPI) dendrimer, 5-aminolevulinic acid (ALA)-containing dendrimer and poly-L-lysine (PLL) dendrimer. ${ }^{54,55}$ However, while neutral and anionic dendrimers are usually non-toxic, cationic dendrimers often confer high toxicity. ${ }^{56}$ Cationic dendrimers tend to interact with negatively charged biological membranes, which can consequently lead to membrane integrity disruption, cytosolic protein leakage and eventually cell lysis. ${ }^{50}$ It has been reported that the surface modification of dendrimers (eg, PEGylation) can mask their charge(s) and thereby reduce their toxicities. $^{55}$

A PEGylated PLL dendrimer-based nanoformulation of docetaxel demonstrated superiority over conventional docetaxel in terms of efficacy, safety and pharmacokinetics in the Phase I trial, in which patients with advanced brain, breast, cervical, gastro-oesophageal, lung, pancreatic, prostate and renal cancers were enrolled. ${ }^{57}$ Based on the positive Phase I results, nanoformulated docetaxel has been advanced to Phase II. ${ }^{57}$ Similarly, a PEGylated PLL dendrimer-based nanoformulation of SN-38 has also progressed to Phase II following the observation of improved anti-cancer efficacy and safety as compared to conventional irinotecan in breast, colorectal and pancreatic cancer patients in the Phase I component of its Phase I/II trial. ${ }^{58}$

\section{The Lipid-Based Nanocarriers}

Lipid-based nanocarriers (eg, liposomes, niosomes and solid-lipid nanoparticles [SLNs]) have attracted considerable attention in drug delivery owing to their ease of preparation, large-scale and low-cost production, biocompatibility, biodegradability, targetability, high stability and high drug loading capacity. ${ }^{59,60}$ Additionally, they can also prolong drug action by enabling controlled drug release and extending drug half-life. ${ }^{60}$ Lipid-based nanocarriers are particularly considered to have revolutionised cancer treatment, as they have been reported to improve the efficacies of anti-cancer drugs as well as reduce their therapeutic doses, associated toxicities and drug resistance. $^{60}$

Liposomes are the first generation of lipid-based nanocarriers developed for drug delivery. ${ }^{61}$ They are spherical lipid vesicles consisting of an aqueous core that is surrounded by at least one phospholipid bilayer. ${ }^{62}$ Due to the amphipathic nature of phospholipids, liposomes are capable of loading both hydrophobic and hydrophilic drugs into the lipid bilayer and the aqueous internal compartments, respectively. ${ }^{59,61}$ In 1995, PEGylated liposomal doxorubicin was approved by the US Food and Drug Administration (FDA) for the treatment of AIDS-related Kaposi's sarcoma, making it the first FDA-approved nanomedicine. ${ }^{63}$ It is currently also indicated for the clinical treatment of recurrent ovarian cancer, metastatic BC and multiple myeloma. ${ }^{64}$ In all settings, PEGylated liposomal doxorubicin has shown reduced cardiotoxicity in comparison to free doxorubicin. ${ }^{63}$ Liposomal cytarabine obtained FDA approval for the intrathecal treatment of lymphomatous meningitis in $1999 .{ }^{65}$ Since then, a number of clinical trials have been underway to establish the effectiveness of liposomal cytarabine in other cancer types. $^{66}$ It was found in a Phase III trial that systemic therapy plus intrathecal liposomal cytarabine resulted in better median progression-free survival than systemic therapy alone (3.8 vs 2.2 months) in BC patients with newly diagnosed leptomeningeal metastasis. ${ }^{67}$ Nonetheless, the development of liposomal nanoformulation is limited by difficulties with large-scale manufacturing, sterilisation and stability. ${ }^{68}$

Niosomes are spherical vesicles with closed bilayer structures that arise from the self-clustering of cholesterol and non-ionic surfactants in aqueous media. ${ }^{59}$ They have similar structures and physical-chemical properties as liposomes, and can also load both hydrophobic and hydrophilic drugs. ${ }^{68,69}$ In contrast to liposomes, however, niosomes require simpler fabrication methods, lower production costs and possess greater stability. ${ }^{68}$ Therefore, niosomes have been proposed as an alternative to liposomal delivery of anti-cancer drugs. ${ }^{59}$ Niosomal nanoformulations of cisplatin, $^{70}$ doxorubicin $^{71}$ and tamoxifen citrate $^{72}$ have been reported to possess higher anti-cancer efficacy than their free drugs in preclinical BC models, but none of these has been advanced to clinical trials to date. One disadvantage of niosomes is that their currently 
commercially available non-ionic surfactants (ie, Spans and Tweens) are all polydisperse. ${ }^{69}$

SLNs, a relatively new colloidal drug delivery system, are made of lipid matrices that remain in a solid state at physiological temperatures. ${ }^{60}$ Similar to liposomes and niosomes, SLNs are also capable of incorporating both hydrophobic and hydrophilic drugs. ${ }^{60}$ However, they are superior to liposomes in terms of reproducibility, feasibility of large-scale production, stability and entrapment efficiency for hydrophobic drugs. ${ }^{73}$ Although no SLN-based nanoformulation of anti-cancer drugs has been clinically studied for BC treatment to date, there have been preclinical reports of the anti-BC activities of doxorubicin- ${ }^{74}$ methotrexate- ${ }^{75}$ paclitaxel- ${ }^{76}$ and tamoxifen- ${ }^{77}$ loaded SLNs. However, SLNs are associated with several drawbacks, including low drug loading capacity and risk of drug expulsion due to crystallisation during storage. ${ }^{78}$

\section{The Polymer-Based Nanocarriers}

In general, polymer-based nanocarriers are able to protect drugs from rapid metabolism and clearance by RES, liver and kidney as well as offer targeted delivery and sustained release of drugs. ${ }^{79}$ They can be prepared from either natural or synthetic polymers. ${ }^{80}$ As opposed to natural polymers, synthetic polymers are abundantly present, possess better thermal stability and mechanical properties and can be more easily processed to achieve desired pore size and scaffold geometry. ${ }^{81}$ However, synthetic polymers often come with impurities that can affect their biocompatibility, while natural polymers generally offer better biocompatibility and biodegradability. ${ }^{82}$ In recent years, semisynthetic polymers, which are derived from the modification of natural polymers via blending, crosslinking or grafting with synthetic polymers, have been introduced. ${ }^{82}$ They exhibit combined advantageous properties of both natural and synthetic polymers and thus are a highly promising type of nanomaterial for drug delivery. ${ }^{81}$

Polysaccharides represent a class of natural polymer that has been extensively exploited for drug delivery. ${ }^{83}$ They can be obtained naturally from algal (eg, alginate), animal (eg, chitosan, chondroitin and hyaluronic acid), plant (eg, pectin, cellulose and gum arabic) and microbial (eg, dextran, xanthan gum and hyaluronic acid) origins, ${ }^{84,85}$ among which alginate, chitosan, dextran and hyaluronic acid have been most frequently utilised for delivering anti-cancer drugs. ${ }^{83}$ Various synthetic polymers have also been exploited for the preparation of NDDSs, including hydrophobic polymers such as poly(lactic-co-glycolic acid) (PLGA), poly (lactic acid) (PLA) and polycaprolactone (PCL) as well as hydrophilic polymers such as poly(ethylene glycol) (PEG), poly(glutamic acid) (PGA), poly(ethyleneimine) (PEI), poly (acrylamide) (PAM) and poly(vinyl alcohol) (PVA). ${ }^{84,86}$

Polymer-based nanoformulations of various chemotherapeutic agents have also been clinically tested for BC treatment. In a Phase III trial, a monomethoxy-poly(ethylene glycol)-block-poly(D,L-lactide) (mPEG-PDLLA) micellar formulation of paclitaxel was found to offer superior clinical efficacy (ie, objective response rate of $39.1 \%$ vs $24.3 \%$ ) and manageable toxicities in comparison to conventional paclitaxel in patients with recurrent or metastatic HER2-negative $\mathrm{BC}{ }^{87}$ This micellar formulation of paclitaxel is now on the South Korean market for treating metastatic BC, non-small cell lung cancer (NSCLC) and ovarian cancer. ${ }^{88}$ Another nanoformulation, PGA-paclitaxel, has also been evaluated in Phase II trials for the treatment of BC, NSCLC and ovarian cancer. ${ }^{89}$ Specifically, a Phase II trial reported that the combination of PGA-paclitaxel plus capecitabine showed significant efficacy and reasonable tolerability in metastatic BC patients. ${ }^{90}$ Notably, PGA-paclitaxel have been advanced to Phase III trials for the treatment of NSCLC and advanced ovarian cancer. $^{89}$

\section{The Protein-Based Nanocarriers}

Protein-based nanocarriers consist of multiple protein subunits that can undergo spontaneous and precise self-association to form nanocarriers with internal hollow cavities. ${ }^{91}$ Over the past few years, there has been a rapid expansion in the practical applications (eg, biocatalysis, diagnostic imaging, drug delivery and vaccine development) of protein-based nanocarriers owing to their unique properties. ${ }^{92}$ In addition to being biocompatible and biodegradable, protein-based nanocarriers also offer other advantages such as ease of synthesis and size control, cost-effectiveness, high stability, amenability to surface modification for targeted drug delivery and ability to provide controlled drug release. ${ }^{93,94}$ However, nanocarriers derived from different proteins have been associated with certain disadvantages such as high cost (eg, albumin and ferritin), risk of prion transmission from animal sources (eg, collagen and gelatin), low mechanical strength (eg, gelatin), slow degradation (eg, silk protein fibroin), fast degradation (eg, gelatin and gliadin), large nanoparticle size (eg, gliadin) and low yield (eg, legumin, protamine and silk protein sericin). ${ }^{93,94}$

The most extensive use of protein-based nanocarriers as NDDSs has been seen in oncology. There has been a 
heavy focus particularly on albumin nanocarriers, as albumin has been reported to preferentially accumulate in solid tumours. ${ }^{95}$ For example, nanoparticle albumin-bound paclitaxel that demonstrated greater anti-cancer efficacy and lower toxicity than conventional paclitaxel in both preclinical and clinical studies successfully obtained FDA approval for the treatment of metastatic $\mathrm{BC}$ in $2005{ }^{96,97}$ In a Phase I trial, nanoparticle albumin-bound rapamycin also showed preliminary evidence of response and stable disease as well as acceptable tolerability in patients with advanced non-hematologic cancers, including BC. ${ }^{98}$ It is currently being tested in Phase II trials, either alone or in combination with other therapies, for the treatment of various cancers such as high-grade glioma, newly diagnosed glioblastoma ${ }^{99}$ and advanced malignant perivascular epithelioid cell tumour. ${ }^{100}$

\section{The Inorganic Nano-Based Drug Delivery Systems}

The Metallic Nanoparticles

Metallic nanoparticles are colloidal particles with diameters ranging from 10 to $1000 \mathrm{~nm} .{ }^{101}$ They are known for their unique catalytic, electrical, magnetic, optical and thermal properties, simple surface chemistry and functionalisation as well as ease of synthesis. ${ }^{102}$ These features have led to the extensive investigation of metallic nanoparticles in a wide range of biomedical applications (eg, diagnostic testing, imaging, radiotherapy enhancement, thermal ablation as well as gene and drug delivery), rendering them multi-purpose. ${ }^{102}$

Metallic nanoparticles are associated with both intrinsic and extrinsic anti-cancer effects. ${ }^{102}$ For instance, several metallic nanoparticles (eg, silver, gold, cerium oxide, copper oxide, iron oxide, titanium oxide, titanium dioxide and zinc oxide) have been reported to mediate intrinsic anti-cancer activities via different mechanisms. ${ }^{103,104}$ The extrinsic anti-cancer activities of metallic nanoparticles are seen in targeted hyperthermic therapy. ${ }^{105}$ For example, a thermal therapy product based on iron oxide nanoparticles has been approved by the European Medicines Agency (EMA) to treat glioblastoma. ${ }^{106}$ Following the direct injection of aqueous iron oxide nanoparticle dispersion into the tumour, an alternating magnetic field is applied to generate heat for killing the cancer cells. ${ }^{106}$

Besides being useful as anti-cancer agents, metallic nanoparticles can also be utilised as NDDSs for anti-cancer drugs. They have high drug loading capacity and possess a large surface area-to-volume ratio that facilitates chemical modification. ${ }^{107}$ Moreover, superparamagnetic metallic nanoparticles (eg, iron oxide) can also enable site-specific delivery of drugs via the application of an external magnetic field. ${ }^{108} \mathrm{~A}$ metallic nanoformulation, colloidal gold-bound tumour necrosis factor, has completed Phase I trials in patients with different cancers, including BC. ${ }^{109}$ It could be administered at doses that exceeded the maximum tolerated dose of native tumour necrosis factor while showing reasonable tolerability and tumour targetability. ${ }^{110}$ However, some metallic nanoparticles have been associated with toxicities even though the metals used are relatively inert (eg, gold, silver and copper), as well as with low stability and biocompatibility. ${ }^{39,111}$

\section{The Mesoporous Silica Nanoparticles}

Mesoporous silica nanoparticles (MSNs) are silica materials with a highly ordered porosity of 2 to $50 \mathrm{~nm}$ in diameter. ${ }^{12}$ They have emerged as an ideal NDDS owing to their unique properties, including simple fabrication, tunable particle size and shape, large internal pore volume and surface area giving rise to high drug loading capacity, good stability, good biocompatibility, easy surface modification and functionalisation as well as capability to incorporate both hydrophilic and hydrophobic drugs. ${ }^{112-115}$

The first introduction of MSNs as NDDSs dates back to 2001 when Vallet-Regí et al ${ }^{116}$ successfully encapsulated an anti-inflammatory drug (ie, ibuprofen) into MSNs. Considerable research efforts have since been devoted to the development of MSNs for treating various diseases, particularly cancer. ${ }^{113}$ MSN-based nanoformulations of various chemotherapeutic agents (eg, doxorubicin ${ }^{117}$ and epirubicin ${ }^{118}$ ) and nucleic acids (eg, siPlk1 plus miR$200 \mathrm{c}^{119}$ and HER2-targeted siRNA ${ }^{120}$ ) have demonstrated anti-BC effects preclinically. However, the clinical translation of MSNs may be limited by its reported toxicities (eg, cardiotoxicity, pulmonary toxicity, renal toxicity and genotoxicity). ${ }^{121-123}$

\section{The Anti-Breast Cancer Mechanisms of Medicinal Plant Extracts/Essential Oils and Anti-Breast Cancer Activities of Their Nanoformulations in Preclinical Models}

Extracts/essential oils of certain medicinal plants contain a cocktail of bioactive compounds that exert anti-BC activities via different mechanisms of action (Table 3). These bioactive compounds may exhibit synergistic effects, thereby allowing the extracts and essential oils to exhibit 


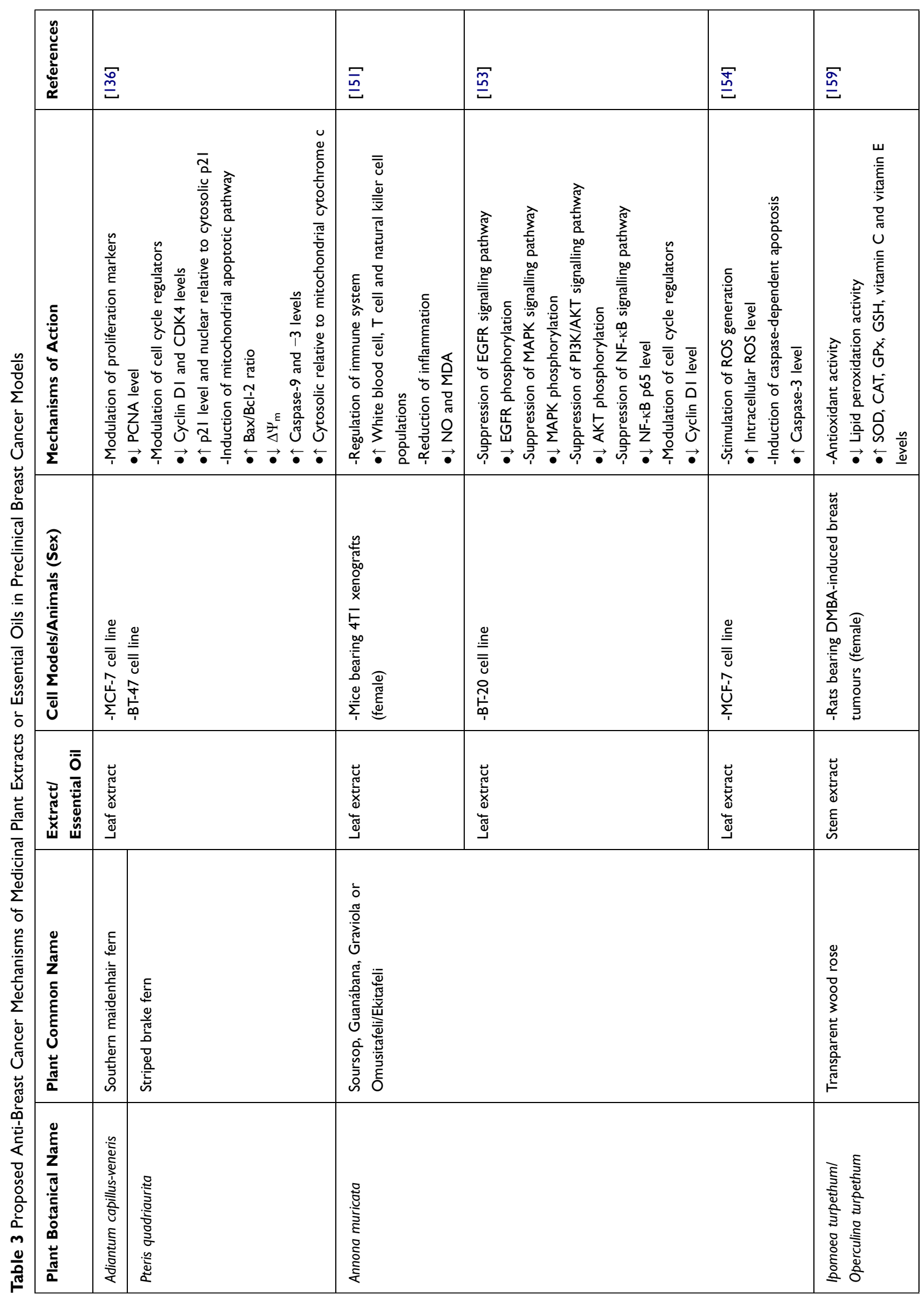




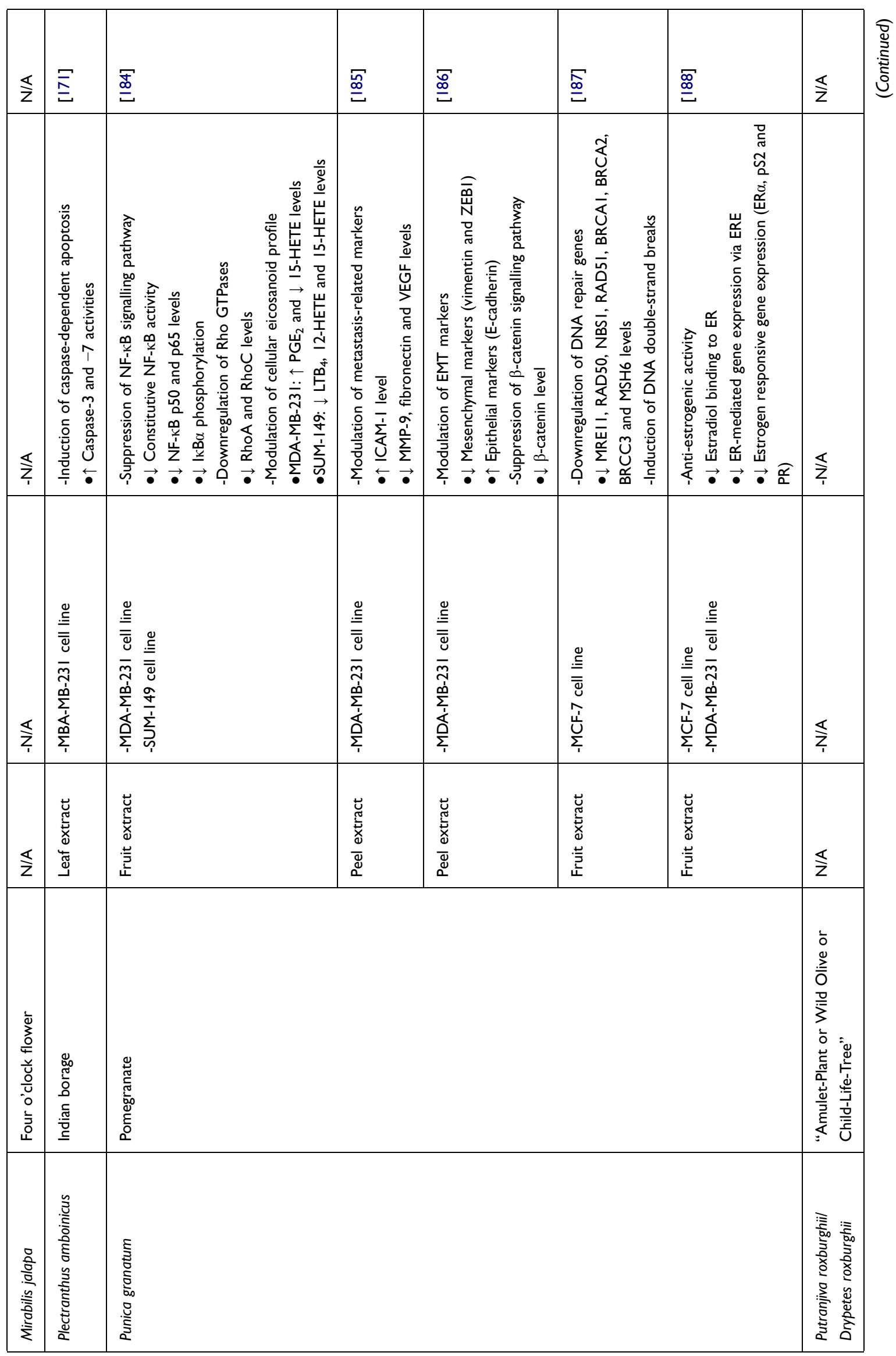




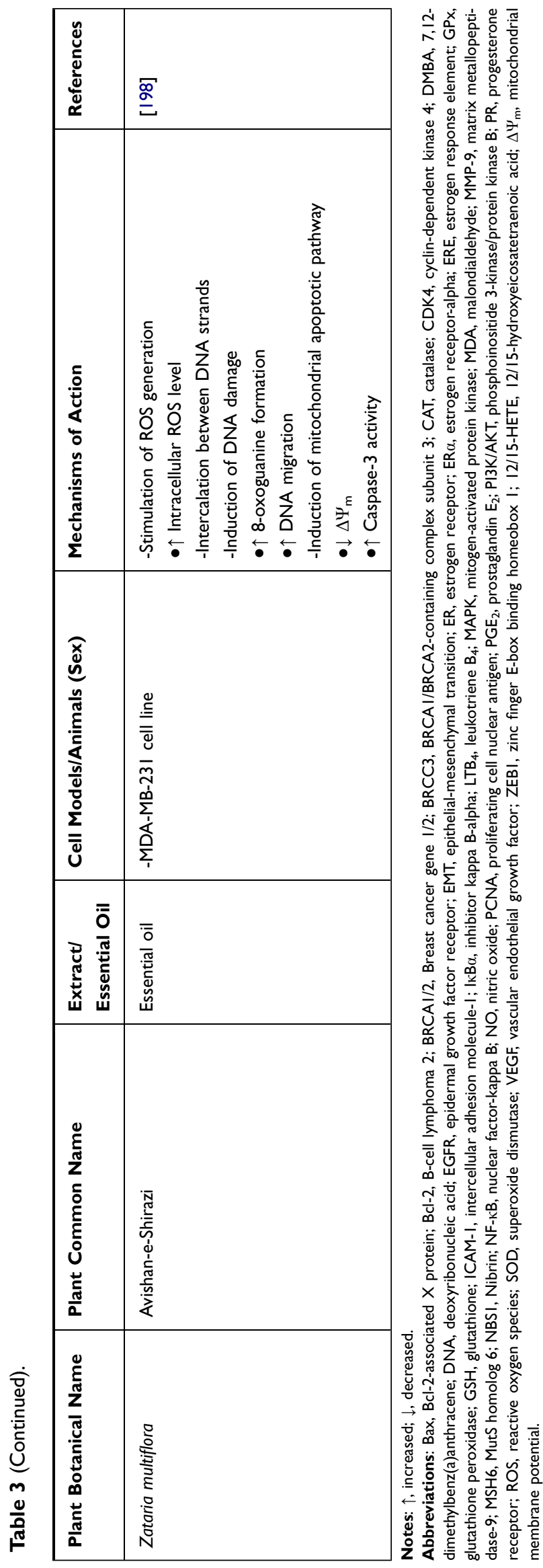

higher anti-cancer activities than a single bioactive compound. ${ }^{124}$ However, the clinical use of extracts and essential oils in cancer treatment is often limited by their poor bioavailability. ${ }^{24,27}$ In line with this, multiple studies have developed nanoformulations for medicinal plant extracts/essential oils that have demonstrated anti-BC potentials preclinically but could not be translated clinically due to bioavailability issues (Table 4).

\section{The Adiantum capillus-veneris and Pteris quadriaurita Extracts}

Adiantum capillus-veneris, or southern maidenhair fern, is a type of herb generally cultivated in temperate and tropical regions. ${ }^{125}$ It is widely distributed in America, Europe, Atlantic coast as far as Ireland, southern Alpine valley regions, Australia and Iran. ${ }^{125}$ Traditionally, A. capillus-veneris is utilised either as a single herbal medicine or in multi-herbal formulations to treat human diseases such as bronchial disorders, cold, cough, fever, hepatitis, jaundice, skin disorders and tumours. ${ }^{125,126}$ Its therapeutic potential is further reflected by a range of reported pharmacological activities, including anti-diabetic, ${ }^{127}$ anti-inflammatory, ${ }^{128}$ antimicrobial, ${ }^{129}$ antinociceptive, ${ }^{130}$ hypocholesterolemic, ${ }^{131}$ wound healing, ${ }^{132}$ antioxidant and anti-cancer ${ }^{133}$ activities.

Pteris, one of the largest fern genera, consists of approximately $200-250$ species. ${ }^{134}$ Pteris spp. are widely distributed on all continents except Antarctica. They have been used by humans as ornamental plants, arsenic hyperaccumulators, food, spices and medicines. ${ }^{134,135}$ Importantly, Pteris is known to be rich in ent-kaurane diterpenoids, a compound class whose members often possess good anti-cancer activity. ${ }^{135}$ For example, Pteris quadriaurita (striped brake fern) has been reported to exhibit anti-cancer activity ${ }^{136}$ in addition to anti-bacterial, anti-fungal, anti-haemolytic and antioxidant activities. ${ }^{137}$

The methanolic leaf extracts of both A. capillus-veneris and $P$. quadriaurita have demonstrated anti-cancer activities against $\mathrm{BC}$ cell lines. ${ }^{136}$ In the same study, the researchers synthesised gold nanoparticles (AuNPs) from these extracts and evaluated the effects of the resulting AuNPs on MCF-7 and BT-47 BC cell lines. Only $P$. quadriaurita AuNPs were found to possess greater cytotoxicity against MCF-7 cells than its free extract $\left(\mathrm{IC}_{50}\right.$ values of $9 \mu \mathrm{g} / \mathrm{mL}$ vs $380 \mu \mathrm{g} / \mathrm{mL}$ ). Nonetheless, subsequent gene and protein expression analyses revealed that MCF-7 and BT-47 cells treated with A. capillus-veneris and $P$. quadriaurita AuNPs had a more significant 


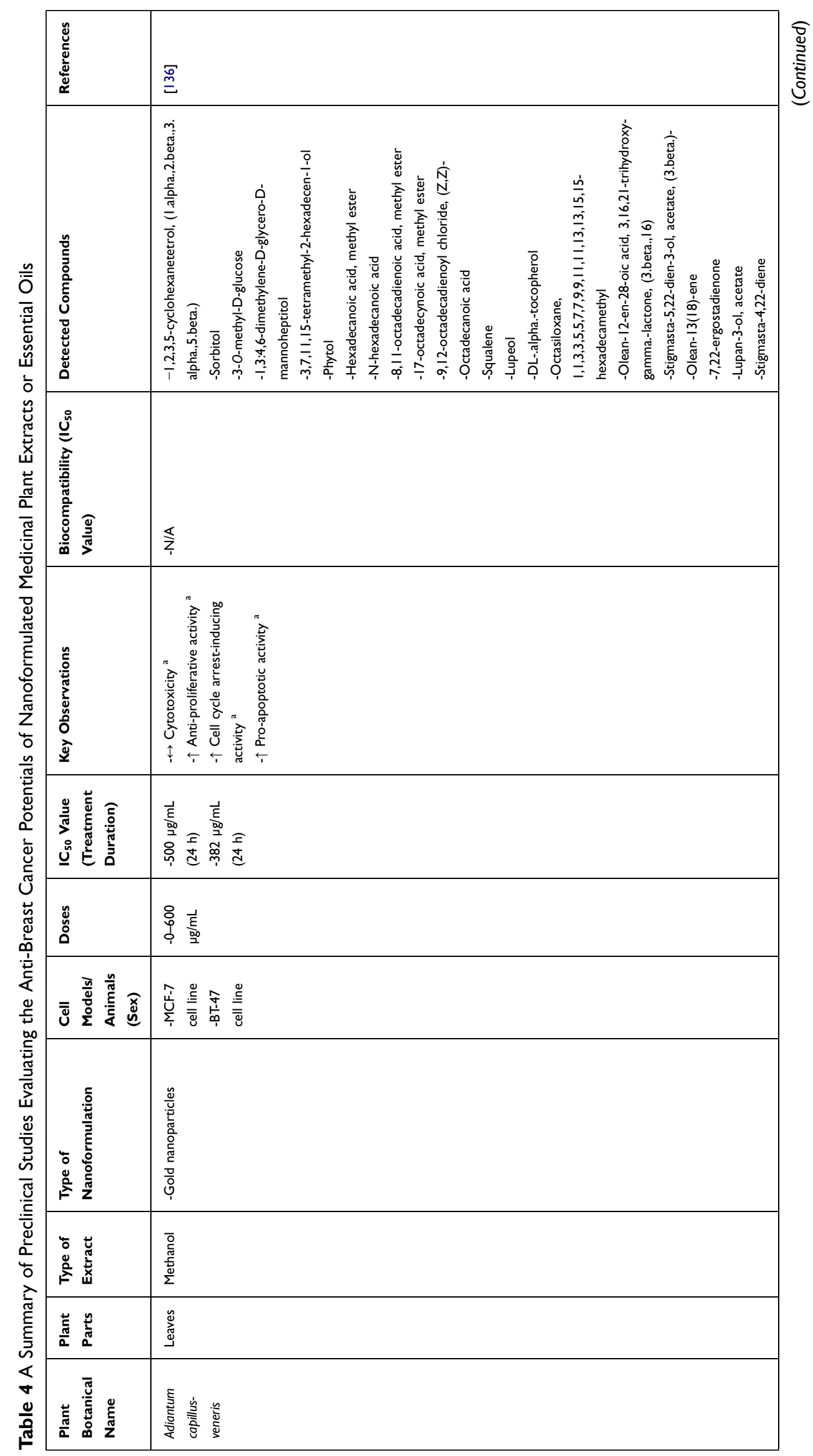




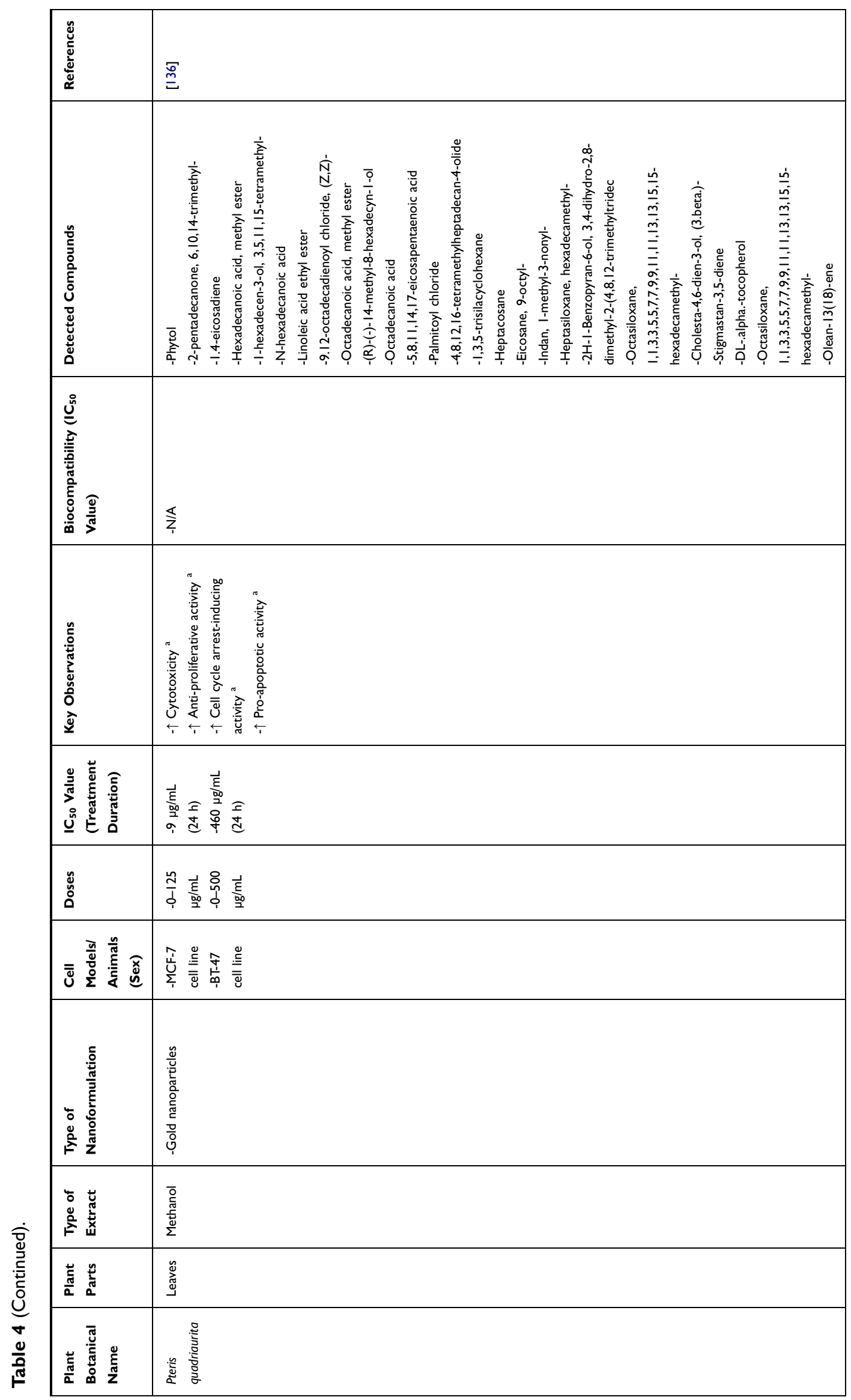




\begin{tabular}{|c|c|c|c|c|c|c|}
\hline 氙 & 官 & $\stackrel{\bar{\sigma}}{\underline{E}}$ & 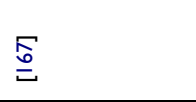 & $\stackrel{\sqrt[\Omega]{5}}{\underline{5}}$ & $\stackrel{\sqrt[\Phi]{\infty}}{\underline{\infty}}$ & 离 \\
\hline 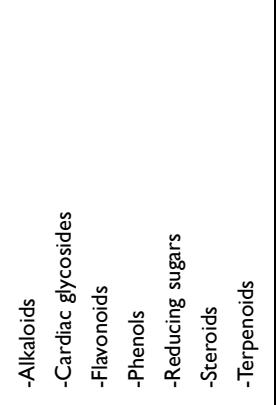 & $\stackrel{s}{z}$ & 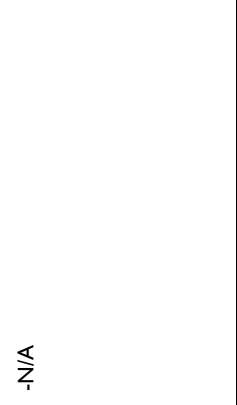 & 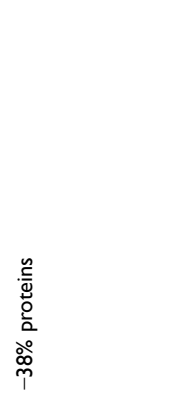 & $\widehat{z}_{i}$ & 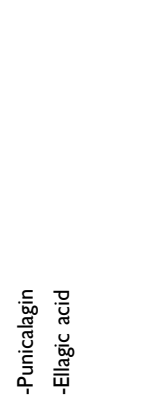 & $\mathbb{s}_{1}$ \\
\hline$\sum_{i}^{\pi}$ & 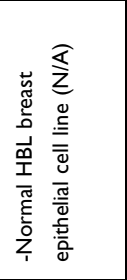 & 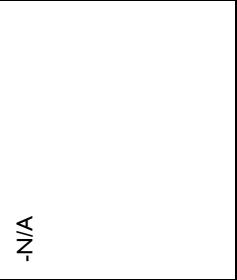 & 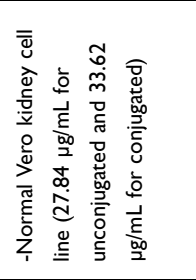 & $\$$ & $\aleph_{i}^{\nwarrow}$ & 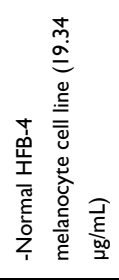 \\
\hline 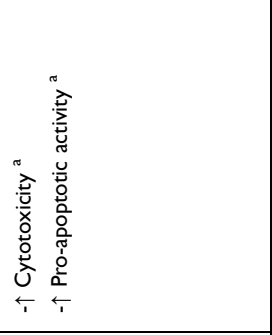 & 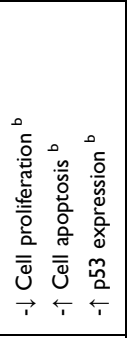 & 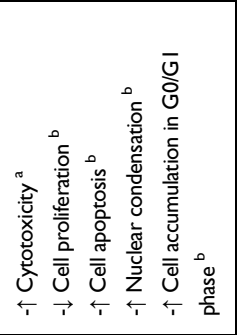 & 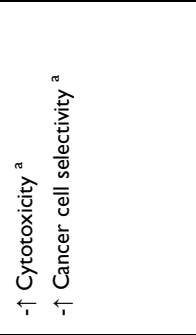 & 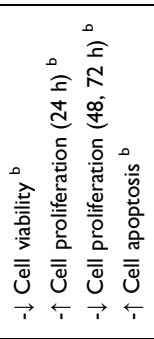 & 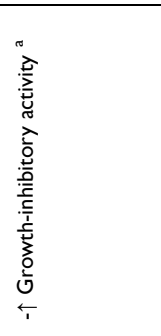 & 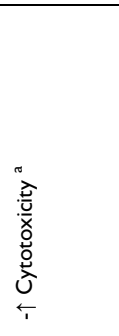 \\
\hline 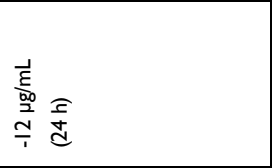 & 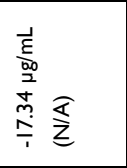 & 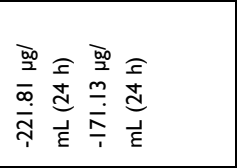 & 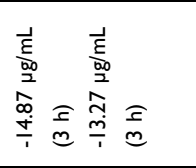 & 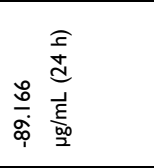 & 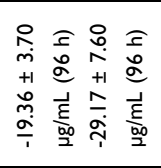 & 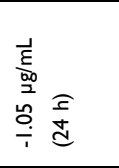 \\
\hline 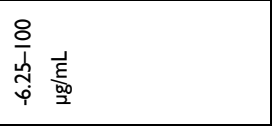 & 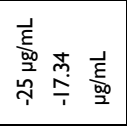 & $\begin{array}{l}8 \\
0 \\
0 \\
\frac{0}{1} \\
\end{array}$ & 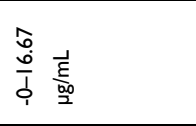 & 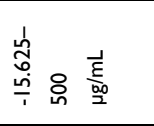 & 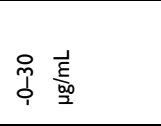 & 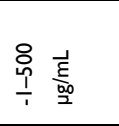 \\
\hline 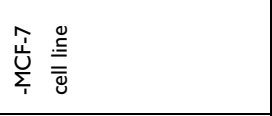 & 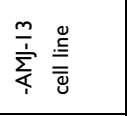 & 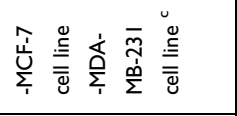 & 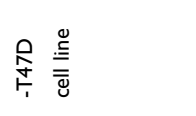 & 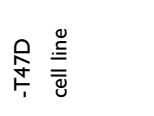 & 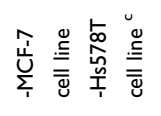 & 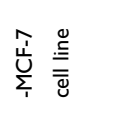 \\
\hline 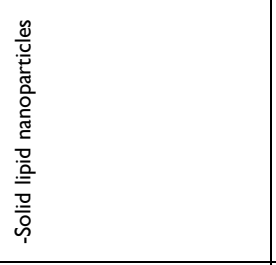 & 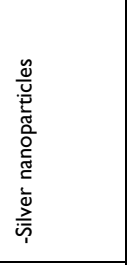 & 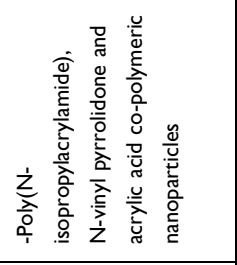 & 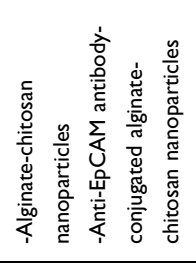 & 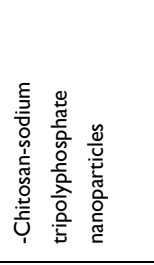 & 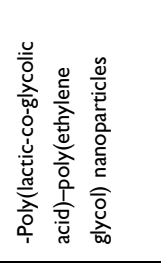 & 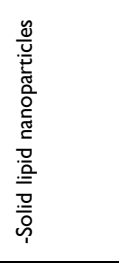 \\
\hline $\begin{array}{l}\text { 高 } \\
\text { 捳 } \\
\end{array}$ & 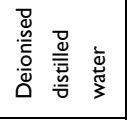 & $\begin{array}{l}\bar{o} \\
\text { o. } \\
\text { 業 } \\
\end{array}$ & $\frac{a}{\bar{\alpha}}$ & 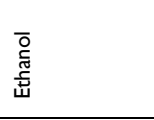 & \multicolumn{2}{|l|}{$\widehat{\Sigma}$} \\
\hline$\frac{\underline{n}}{2}$ & $\begin{array}{l}\frac{n}{\mathbb{N}} \\
\frac{\mathbb{D}}{2}\end{array}$ & $\begin{array}{l}\stackrel{0}{0} \\
\stackrel{\circ}{\alpha}\end{array}$ & స్త్ & స్లّ & \multicolumn{2}{|l|}{ 号 } \\
\hline 总 & & 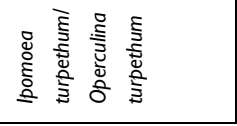 & $\begin{array}{l}\frac{0}{\bar{z}} \\
\text { 产 } \\
\text { 高 } \\
\end{array}$ & 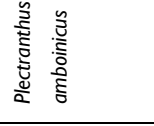 & \multicolumn{2}{|l|}{ 总 } \\
\hline
\end{tabular}




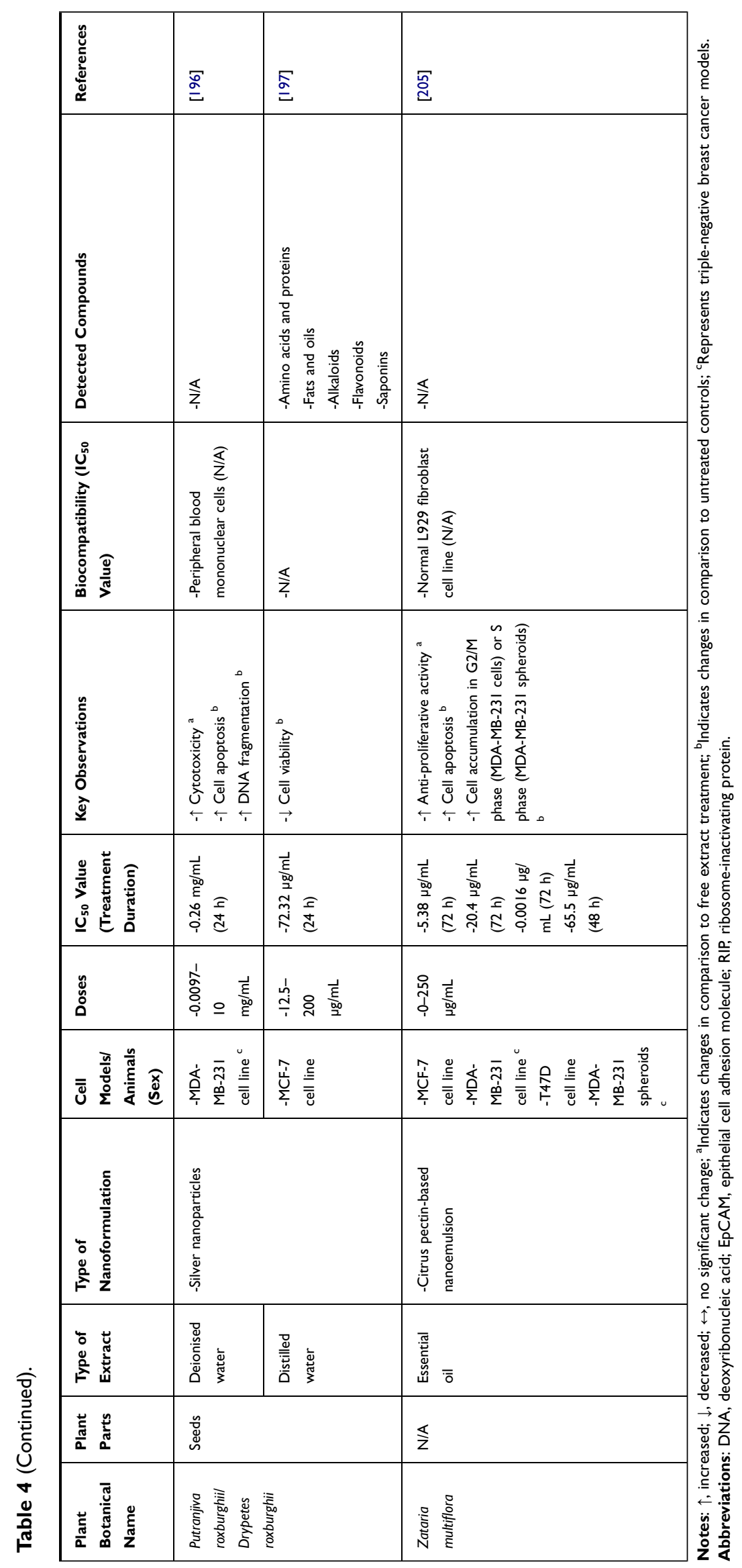


reduction in the protein level of proliferating cell nuclear antigen (PCNA; ie, a proliferation marker) than those treated with free extracts. A more significant reduction in the mRNA and protein levels of cyclin D1 and the protein level of cyclin-dependent kinase (CDK)4, as well as a more significant increase in the mRNA level of p21 (ie, a CDK inhibitor) and the protein level of nuclear p21 relative to cytosolic p21 were also observed. Moreover, both $A$. capillus-veneris and $P$. quadriaurita extracts and their AuNPs also induced apoptosis in MCF-7 and BT-47 cells, as evidenced by a significant increase in the number of TUNEL- and Annexin V-positive cells. Apoptosis was further confirmed to be mediated by the mitochondrial apoptotic pathway, as indicated by a drop in mitochondrial membrane potential $\left(\Delta \Psi_{\mathrm{m}}\right)$; a significant increase in the mRNA and protein levels of Bcl-2-associated X protein (Bax; ie, a pro-apoptotic protein) and the protein levels of caspase-9 (ie, an initiator caspase of the mitochondrial apoptotic pathway), caspase-3 (ie, an effector caspase) and cytosolic cytochrome c relative to mitochondrial cytochrome c; as well as a significant decrease in the mRNA and protein levels of B-cell lymphoma 2 (Bcl-2; ie, an anti-apoptotic protein). Importantly, AuNPs induced greater changes in the expression of the abovementioned apoptotic markers than their free extracts. Taken together, these findings suggest that the formulation of $A$. capillusveneris and $P$. quadriaurita extracts into AuNPs can improve their anti-proliferative, cell cycle arrest-inducing and pro-apoptotic activities against $\mathrm{BC}$ cells.

\section{The Annona muricata Extracts}

Annona muricata is a fruit tree widely cultivated in the tropical regions of Central and South America, Western, Central and Eastern Africa as well as Southeast Asia. ${ }^{138}$ It is known by a range of common names at different places, including Soursop (English), Guanábana (Latin American Spanish), Graviola (Portuguese) and Omusitafeli/Ekitafeli (Uganda). ${ }^{138}$ Traditionally, different parts of $A$. muricata such as fruits, leaves, seeds, flowers, bark and roots have been used to treat cancer, diabetes, malaria, parasitic infections and stomach ache, etc. ${ }^{138,139}$ More recent studies have discovered various pharmacological activities of $A$. muricata extracts, including anti-arthritic, ${ }^{140}$ anti-convulsant, ${ }^{141}$ antidiabetic, ${ }^{142}$ anti-hypertensive, ${ }^{143}$ antioxidant, ${ }^{144}$ antiparasitic, ${ }^{145}$ hypolipidemic, ${ }^{146}$ wound healing, ${ }^{147}$ gastroprotective, ${ }^{148}$ hepatoprotective, ${ }^{149}$ anti-inflammatory and analgesic ${ }^{150}$ activities. In particular, extracts prepared from A. muricata leaves, fruits and seeds have demonstrated both in vitro and in vivo anti-BC activities. ${ }^{151-154}$ These anti$\mathrm{BC}$ activities have been linked to the regulation of immune system, the reduction of inflammation, the suppression of various signalling pathways (eg, epidermal growth factor receptor [EGFR], mitogen-activated protein kinase [MAPK], phosphoinositide 3-kinase/protein kinase B $[\mathrm{PI} 3 \mathrm{~K} / \mathrm{AKT}]$ and nuclear factor-kappa B [NF- $\mathrm{BB}]$ ), the modulation of cell cycle regulators, as well as the stimulation of ROS generation and consequent induction of caspase-dependent apoptosis. ${ }^{151,153,154}$

Sabapati et al ${ }^{155}$ loaded $A$. muricata ethanolic fruit extract into SLNs and found that extract-loaded SLNs caused a greater dose-dependent reduction in MCF-7 cell viability than the free extract $\left(\mathrm{IC}_{50}\right.$ values of $12 \mu \mathrm{g} / \mathrm{mL}$ vs $30 \mu \mathrm{g} / \mathrm{mL}$ ). Flow cytometric analysis of Annexin V-FITCstained cells further showed that extract-loaded SLNs could induce a significantly higher percentage of apoptotic MCF-7 cell death than the free extract ( $86.0 \%$ vs $71.34 \%$ ). Interestingly, void SLNs did not elicit significant cytotoxicity against MCF-7 cells. Collectively, these findings indicate that SLNs are biocompatible NDDSs capable of enhancing the cytotoxicity and pro-apoptotic activity of A. muricata extract against $\mathrm{BC}$ cells.

In another study, Jabir et $\mathrm{al}^{156}$ reported the green synthesis of silver nanoparticles using silver nitrate solution and $A$. muricata aqueous peel extract. The resulting silver nanoparticles (AMSNPs) elicited a significant, timedependent anti-proliferative effect on AMJ-13 BC cell line $\left(\mathrm{IC}_{50}=17.34 \mu \mathrm{g} / \mathrm{mL}\right)$ but had a less significant effect on normal HBL breast epithelial cell line. This anti-proliferative activity of AMSNPs was linked to the induction of apoptosis via p53 signalling, as evidenced by the observations of disrupted membrane integrity and lysosomal vacuoles, increased percentage of sub-G1 phase corresponding to apoptotic cells, $\Delta \Psi_{\mathrm{m}}$ loss and upregulated p53 expression in treated AMJ-13 cells. However, the study did not compare the anti-BC effect of AMSNPs with that of free $A$. muricata aqueous peel extract.

\section{The Ipomoea turpethum Extracts}

Ipomoea turpethum (or Operculina turpethum), commonly known as "transparent wood rose", can be found in many countries such as Africa, America, Bangladesh, China, India, Madagascar, Mauritania, Pakistan, Philippines and Sri Lanka. ${ }^{157,158}$ It is one of the medicinal plants that have been employed in the Ayurvedic medicine for treating bronchitis, cancer, cervical lymphadenitis, chronic gout, constipation, dysmenorrhea, fever, fistulas, hemorrhoids, herpes, 
induced lacrimation, inflammation, jaundice, neurological disorders, obesity, skin disorders and ulcers. ${ }^{157,158}$ Additionally, I. turpethum extracts (ie, from stems, roots, aerial and whole part) have also demonstrated anti-cancer potentials in preclinical BC models. ${ }^{159,160}$ One study further showed that the anti-BC activities of I. turpethum stem extract are mediated, at least partly, via its antioxidant activity. ${ }^{159}$

Similarly, Mughees et $\mathrm{al}^{161}$ found that I. turpethum ethanolic extracts prepared from different plant parts (ie, flowers, leaves, roots, aerial and whole part) demonstrated significant cytotoxicities against both MCF-7 and MDA-MB-231 BC cell lines. The root extract that exhibited the greatest cytotoxicity ( $\mathrm{IC}_{50}$ values of $452.35 \mu \mathrm{g} / \mathrm{mL}$ for MCF-7 cells and $310 \mu \mathrm{g} / \mathrm{mL}$ for MDA-MB-231 cells) was subsequently loaded into poly (N-isopropylacrylamide) (NIPAAM; for temperature sensitivity), N-vinyl pyrrolidone (VP; for temperature sensitivity) and acrylic acid (AA; for $\mathrm{pH}$ sensitivity) co-polymeric nanoparticles. The TME is generally more acidic and has a higher temperature than normal tissues owing to the excessive lactic acid produced from enhanced glycolysis and the secretion of pyrogenic substances by tumour cells. ${ }^{162}$ Intriguingly, the NIPAAM-VP-AA double-triggered nanoparticle system takes advantage of these TME characteristics for targeted delivery of loaded root extract to the tumour sites. ${ }^{161}$ Expectedly, it was observed that this nanoformulation exerted greater cytotoxicity than the free root extract (ie, $\mathrm{IC}_{50}$ values of $221.81 \mu \mathrm{g} / \mathrm{mL}$ for MCF-7 cells and $171.13 \mu \mathrm{g} / \mathrm{mL}$ for MDAMB-231 cells). Moreover, $\mathrm{IC}_{50}$ concentrations of this nanoformulation also markedly reduced MCF-7 (from $99.2 \%$ to $57.7 \%$ ) and MDA-MB-231 (from $99.3 \%$ to $55.4 \%$ ) cell proliferation; as well as significantly increased the percentage of early and late apoptotic MCF-7 (from 2.2\% to $3.4 \%$ and from $4.1 \%$ to $9.2 \%$ respectively) and MDA-MB-231 (from $6.3 \%$ to $14.7 \%$ and from $4.5 \%$ to $7.3 \%$ respectively) cells, the condensation of nuclear chromatin and the accumulation of MCF7 (from $50.7 \%$ to $63.4 \%$ ) and MDA-MB-231 (from 57.9\% to $81.3 \%$ ) cell populations in G0/G1 phase. These observations collectively indicate that the NIPAAM-VP-AA co-polymeric nanoparticle-based nanoformulation can enhance the cytotoxicity of I. turpethum extract as well as exert anti-proliferative, pro-apoptotic and cell cycle arrest-inducing activities against $\mathrm{BC}$ cells.

\section{The Mirabilis jalapa Extracts}

Mirabilis jalapa (four o'clock flower), a medicinal plant that can be found in Brazil, India and Mexico, has been used traditionally in the treatment of abscess, boils, bruises, diarrhoea, inflammation, pain, piles, ulcers, urticaria and wounds. ${ }^{163}$ It has been reported to contain ribosome-inactivating proteins (RIPs) ${ }^{163}$ RIPs are a family of proteins with $\mathrm{N}$-glycosidase activity that catalyses the removal of a single adenine from ribosomal ribonucleic acid, thereby leading to protein synthesis inhibition. ${ }^{164}$ They play a key role in defending plants against attacks from pathogens and insects. ${ }^{165}$ Interestingly, RIPs isolated from M. jalapa leaves have demonstrated cytotoxicity against T47D BC cell line. ${ }^{166}$ However, more needs to be done to fully elucidate the anti$\mathrm{BC}$ mechanism(s) of RIPs.

As proteins are subjected to rapid enzymatic degradation following oral administration and have poor membrane permeability, Wicaksono et al ${ }^{167}$ formulated a RIP extract of $M$. jalapa leaves (RIP-MJ) into anti-EpCAM antibody-conjugated alginate-chitosan nanoparticles. Epithelial cell adhesion molecule (EpCAM) is a transmembrane glycoprotein that is lowly expressed in normal breast tissues but becomes overexpressed in breast carcinomas. ${ }^{168}$ As such, conjugation of nanoparticles with anti-EpCAM antibody enables active breast tumour targeting. For instance, anti-EpCAM antibodyconjugated and unconjugated RIP-MJ nanoparticles elicited greater cytotoxicity against T47D cells than free RIP-MJ ( $\mathrm{IC}_{50}$ values of $13.27 \mu \mathrm{g} / \mathrm{mL}$ and $14.87 \mu \mathrm{g} / \mathrm{mL}$ vs 1842.03 $\mu \mathrm{g} / \mathrm{mL}) .{ }^{167}$ Interestingly, while free RIP-MJ had a lower $\mathrm{IC}_{50}$ value in normal Vero kidney cells than in T47D cells $(1387.87 \mu \mathrm{g} / \mathrm{mL}$ vs $1842.03 \mu \mathrm{g} / \mathrm{mL}$ ), the opposite was observed for anti-EpCAM antibody-conjugated $\left(\mathrm{IC}_{50}\right.$ values of $33.62 \mu \mathrm{g} / \mathrm{mL}$ vs $13.27 \mu \mathrm{g} / \mathrm{mL}$ ) and unconjugated $\left(\mathrm{IC}_{50}\right.$ values of $27.84 \mu \mathrm{g} / \mathrm{mL}$ vs $14.87 \mu \mathrm{g} / \mathrm{mL}$ ) RIP-MJ nanoparticles. These findings collectively suggest that the use of NDDS and targeting ligand can improve both the cytotoxicity and the selectivity of RIP-MJ against BC cells.

\section{The Plectranthus amboinicus Extracts}

Plectranthus amboinicus, commonly known as Indian borage, is an Asian native plant that can also be found in the Americas. ${ }^{169}$ It has been used in Brazil to treat various medical conditions such as inflammation and cancer. ${ }^{170} \mathrm{In}$ particular, its leaves have been reported to contain compounds with anti-cancer activities (eg, cinaminics, essential oils, flavonoids and terpene derivatives). ${ }^{169}$ Unsurprisingly, preclinical studies focussing on P. amboinicus leaf extract revealed its anti-BC activities. ${ }^{169-174}$ In one of these studies, the pro-apoptotic activity of P. amboinicus leaf extract was linked to the activation of caspase-3 and caspase- $7 .^{171}$ 
Hasibuan and Sumaiyah ${ }^{175}$ loaded $P$. amboinicus ethanolic leaf extract into chitosan-sodium tripolyphosphate nanoparticles (PAEEN) and reported that $24 \mathrm{~h}$ of PAEEN treatment could cause a dose-dependent reduction in T47D cell viability $\left(\mathrm{IC}_{50}=89.166 \mu \mathrm{g} / \mathrm{mL}\right)$. Interestingly, although T47D cell proliferation increased following $24 \mathrm{~h}$ of PAEEN treatment, a dose-dependent reduction in T47D cell proliferation was seen following $48 \mathrm{~h}$ and $72 \mathrm{~h}$ of PAEEN treatment. Subsequent flow cytometric analysis revealed that PAEEN could also induce apoptosis in T47D cells. However, the study did not compare these observed cytotoxic, anti-proliferative and pro-apoptotic activities of PAEEN with those of free $P$. amboinicus ethanolic leaf extract.

\section{The Punica granatum Extracts}

Punica granatum (pomegranate), a deciduous shrub native to Asian countries such as Iran and India, is also widely cultivated in Mediterranean countries, such as Egypt, Morocco, Spain, Tunisia and Turkey. ${ }^{176,177}$ The therapeutic potentials of various $P$. granatum parts (ie, bark, flowers, fruits, leaves, roots and seeds) have been recognised early and exploited in different traditional medicine systems (eg, Ayurveda, Chinese, Islamic and Persian) for treating diarrhoea, dysentery, heart choking, intense cough, jaundice, nasal bleeding, periodontitis, sore throat, spleen diseases, ulcers, etc. ${ }^{178}$ These medicinal benefits of P. granatum are attributed to its pharmacological activities such as antimicrobial, ${ }^{179}$ antioxidant, ${ }^{180}$ wound healing, ${ }^{181}$ cardioprotective, ${ }^{182}$ anti-inflammatory and antinociceptive $^{183}$ activities. There has also been extensive preclinical evaluation of the potential utilisation of $P$. granatum fruit and peel extracts in BC treatment. ${ }^{184-188}$ Evidences from these studies suggested that the anti-BC activities of $P$. granatum extracts are mediated via the suppression of NF- $\kappa \mathrm{B}$ and $\beta$-catenin signalling pathways; the downregulation of Rho GTPases; the modulation of cellular eicosanoid profile, metastasis-related and epithelial-mesenchymal transition (EMT) markers; the downregulation of DNA repair genes and consequent induction of DNA double-strand breaks; and its anti-estrogenic activity.

Shirode et al ${ }^{189}$ encapsulated $P$. granatum fruit extract into poly(lactic-co-glycolic acid)-poly(ethylene glycol) (PLGA-PEG) nanoparticles and reported that $P$. granatum extract-loaded nanoparticles induced a more significant reduction in MCF-7 and Hs578T BC cell growth than the free extract $\left(\mathrm{IC}_{50}\right.$ values of $19.36 \pm 3.70 \mu \mathrm{g} / \mathrm{mL}$ vs $44.34 \pm$ $7.81 \mu \mathrm{g} / \mathrm{mL}$ in MCF-7 cells and $29.17 \pm 7.60 \mu \mathrm{g} / \mathrm{mL}$ vs
$61.93 \pm 16.11 \mu \mathrm{g} / \mathrm{mL}$ in Hs578T cells). Interestingly, void PLGA-PEG nanoparticles had no significant effect on MCF-7 and Hs578T cell growth. These observations collectively indicate that the PLGA-PEG nanoparticle system is biocompatible and capable of enhancing the growthinhibitory activity of $P$. granatum extract against BC cells.

Besides, Badawi et $\mathrm{al}^{190}$ loaded $P$. granatum fruit extract into SLNs and found that this nanoformulation significantly reduced MCF-7 cell viability to a greater extent than the free extract, with a 47 -fold reduction in $\mathrm{IC}_{50}$ value $(1.05 \mu \mathrm{g} / \mathrm{mL}$ vs $49.2 \mu \mathrm{g} / \mathrm{mL})$. Similarly, void SLNs were observed to exhibit cytotoxicity against MCF7 cells. The observed enhancement in cytotoxicity may thus, at least partly, be explained by the synergistic effect between $P$. granatum extract and SLNs. Importantly, $P$. granatum extract-loaded SLNs had a higher $\mathrm{IC}_{50}$ value in normal HFB-4 melanocytes than in MCF-7 cells (19.34 $\mu \mathrm{g} / \mathrm{mL}$ vs $1.05 \mu \mathrm{g} / \mathrm{mL}$ ), suggesting that this nanoformulation is BC cell-selective. Collectively, these observations suggest that SLNs can enhance the cytotoxicity of $P$. granatum extract against $\mathrm{BC}$ cells, possibly via synergism and improvement of $\mathrm{BC}$ cell selectivity.

\section{The Putranjiva roxburghii Extracts}

Putranjiva roxburghii (or Drypetes roxburghii), an evergreen tree native to India, is locally referred to as "Amulet-Plant or Wild Olive or Child-Life-Tree". ${ }^{191}$ It is also widely distributed in Bangladesh, Myanmar, Nepal, Sri Lanka, Thailand, Papua New Guinea, Taiwan, the United States, Trinidad and Tobago. ${ }^{191,192}$ Traditionally, it has been used in Ayurveda for treating conditions such as azoospermia, burning sensation, hot swellings, eye disorders, smallpox as well as mouth and stomach ulcers. ${ }^{192}$ More recent studies have revealed the anti-BC, anti-epileptic, antioxidant, anti-inflammatory, antimicrobial, antinociceptive and anti-pyretic potentials of $P$. roxburghii leaf and seed extracts. ${ }^{193-195}$ However, further mechanistic studies are required to explain how $P$. roxburghii extracts exert these pharmacological activities.

Balkrishna et $\mathrm{al}^{196}$ carried out the green synthesis of silver nanoparticles using silver nitrate solution and $P$. roxburghii aqueous seed extract. The study revealed that $P$. roxburghii silver nanoparticles (PJSNPs) could exert more potent cytotoxic effect on MDA-MB-231 cells than the free extract $\left(\mathrm{IC}_{50}\right.$ values of $0.26 \mathrm{mg} / \mathrm{mL}$ vs $\left.7.7 \mathrm{mg} / \mathrm{mL}\right)$. This promising finding may be attributed to the small size $(\sim 8 \pm 2$ $\mathrm{nm})$ and negative zeta potential $(-26.71 \mathrm{mV})$ of PJSNPs, which can enhance both their bioavailability and cellular 
uptake. Furthermore, $\mathrm{IC}_{50}$ concentration of PJSNPs also increased the percentage of apoptotic cells $(69 \%)$ and induced DNA fragmentation in MDA-MB-231 cells. Notably, PJSNP treatment did not show marked cytotoxicity against peripheral blood mononuclear cells (PBMCs). Taken together, this nanoformulation can enhance the cytotoxicity of P. roxburghii extract and exert pro-apoptotic activity against $\mathrm{BC}$ cells while sparing toxicities against PBMCs. Another study by Nayaka et al ${ }^{197}$ similarly reported the cytotoxicity of PJSNPs against MCF-7 cells $\left(\mathrm{IC}_{50}=72.32 \mu \mathrm{g} / \mathrm{mL}\right)$.

\section{The Zataria multiflora Essential Oils}

Zataria multiflora, or Avishan-e-Shirazi, is a thyme-like plant that can be found extensively in Iran, Afghanistan and Pakistan. ${ }^{198}$ It is not only a popular condimental plant but also a traditional medicinal plant that has been employed as anaesthetic, analgesic, anthelmintic, anti-diarrheal, antiseptic, anti-spasmodic, carminative, diaphoretic, diuretic, stimulant and vermifuge agents. ${ }^{199}$ More recent studies have evaluated the pharmacological activities of $Z$. multiflora essential oil (ZEO), the constituents of which are dominated by oxygenated monoterpenes, monoterpene hydrocarbons and sesquiterpene hydrocarbons. ${ }^{200}$ Besides antimicrobial, ${ }^{201}$ antioxidant, ${ }^{202}$ anti-cholinesterase and anti-inflammatory $^{203}$ activities, ZEO has also been reported to mediate potent anti-BC activities via the stimulation of ROS generation, the intercalation of DNA strands, the induction of DNA damage and the eventual induction of mitochondrial apoptotic pathway. ${ }^{198,204}$

Salehi et $\mathrm{al}^{205}$ attempted to overcome the limitations hindering the clinical development of essential oils via the development of a citrus pectin-based nanoemulsion for ZEO (CP-ZEO NE). Both ZEO and CP-ZEO NE treatments dose-dependently decreased MCF-7, MDA-MB-231 and T47D cell proliferation but had no significant effect on the proliferation of normal L929 fibroblast cells. However, a reduced sensitivity to ZEO was observed in MDA-MB231 and T47D cells $24 \mathrm{~h}$ following treatment, possibly due to the high volatility and low stability of ZEO. Interestingly, CP-ZEO NE preparation may have improved ZEO stability, as CP-ZEO NE-treated MCF-7, MDA-MB231 and T47D cells demonstrated the highest sensitivity to CP-ZEO NE at $72 \mathrm{~h}$. This finding is consistent with the lower $\mathrm{IC}_{50}$ values of CP-ZEO NE over ZEO at $72 \mathrm{~h}$ in MCF-7 (5.38 $\mu \mathrm{g} / \mathrm{mL}$ vs $33.1 \mu \mathrm{g} / \mathrm{mL})$, MDA-MB-231 (20.4 $\mu \mathrm{g} / \mathrm{mL}$ vs $30.54 \mu \mathrm{g} / \mathrm{mL})$ and T47D $(0.0016 \mu \mathrm{g} / \mathrm{mL}$ vs $37.03 \mu \mathrm{g} / \mathrm{mL}$ ) cells. Similarly, CP-ZEO NE also demonstrated greater anti-proliferative activity against MDA-MB-231 spheroids than ZEO, as reflected by a lower $\mathrm{IC}_{50}$ value after $48 \mathrm{~h}$ of treatment $(65.5 \mu \mathrm{g} / \mathrm{mL}$ vs $118.4 \mu \mathrm{g} / \mathrm{mL}$ ). Moreover, CP-ZEO NE also showed proapoptotic activity against MCF-7, MDA-MB-231 and T47D cells, as evidenced by apoptosis-related morphological changes (eg, small, rounded, wrinkled and irregular cell shape, low-density and membrane blebbing); increased orange-red fluorescence, nuclear fragmentation and chromatin condensation in dual acridine orange/ethidium bromide (AO/EB) staining test; a DNA ladder pattern on agarose gel electrophoresis; increased number of TUNEL-positive cells; "Hedgehog tails" in comet assay; increased apoptotic cell population in Annexin V-FITC/PI staining; and increased percentage of sub-G1 phase corresponding to apoptotic cells. Pro-apoptotic activity of CPZEO NE was similarly observed in MDA-MB-231 spheroids. Additionally, CP-ZEO NE treatment also induced a G2/M phase arrest in MDA-MB-231 cells but a $\mathrm{S}$ phase arrest in MDA-MB-231 spheroids. Taken together, CPZEO NE is a biocompatible nanoformulation that is capable of enhancing the stability and anti-proliferative activity of ZEO as well as exerting pro-apoptotic and cell cycle arrest-inducing activities against $\mathrm{BC}$ cells and spheroids.

\section{The Anti-Breast Cancer Mechanisms of Natural Bioactive Compounds and Anti-Breast Cancer Activities of Their Nanoformulations in Preclinical Models}

A number of bioactive compounds isolated from natural sources have been proven to be effective in the treatment of human diseases, including cancer. ${ }^{206}$ Table 5 summarises the proposed anti-BC mechanisms of selected natural bioactive compounds. However, the clinical utilisation of natural bioactive compounds is often challenged by their low stability, poor aqueous solubility and low bioavailability. ${ }^{207}$ One approach to overcoming these challenges includes the exploitation of NDDSs (Table 6).

\section{Balanocarpol}

Balanocarpol, a resveratrol dimer, can be isolated from many Hopea spp., particularly Hopea dryobalanoides and Hopea mengarawan found in the Malaysian rain forest. $^{208-210}$ Its anti-BC potential has been preclinically 


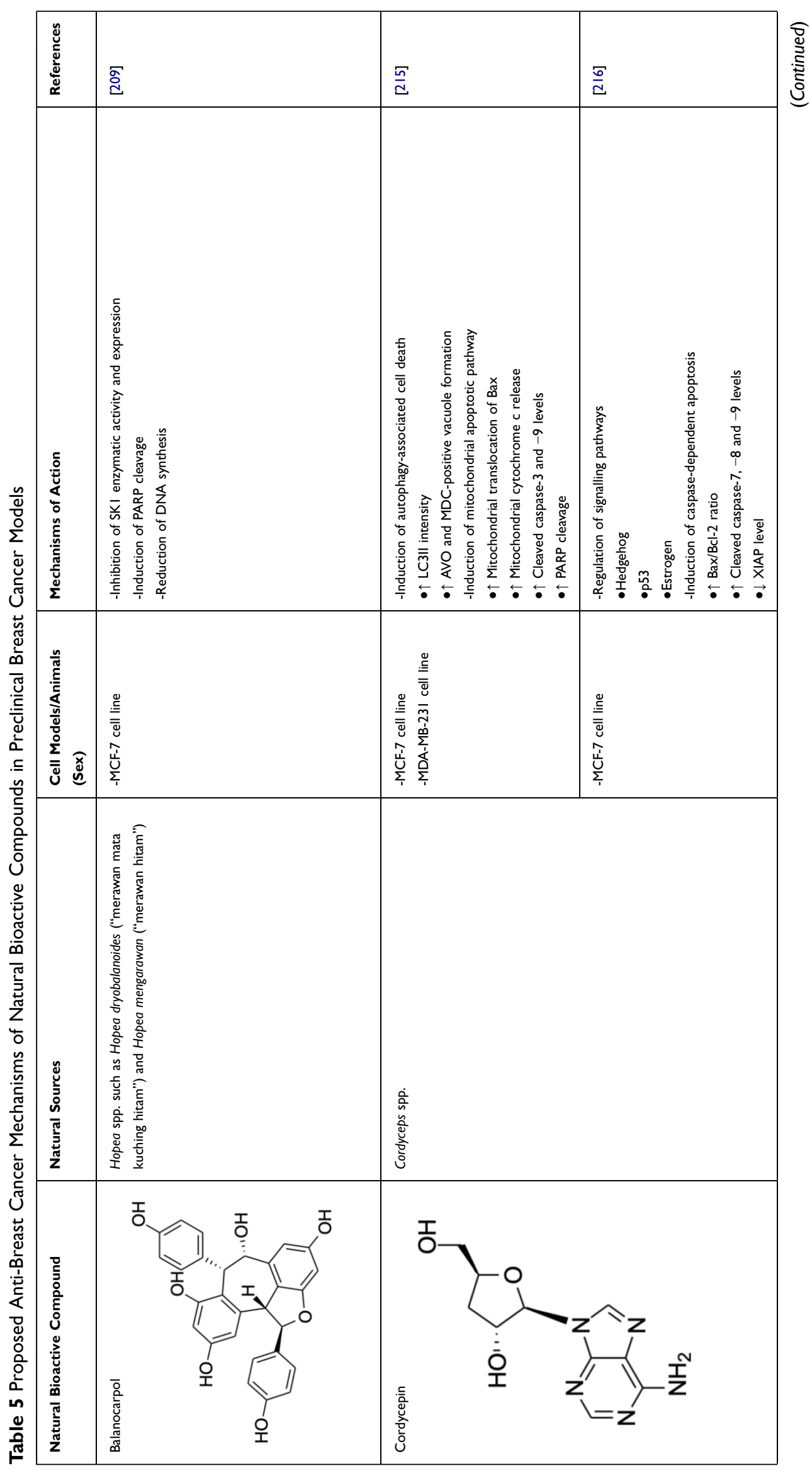




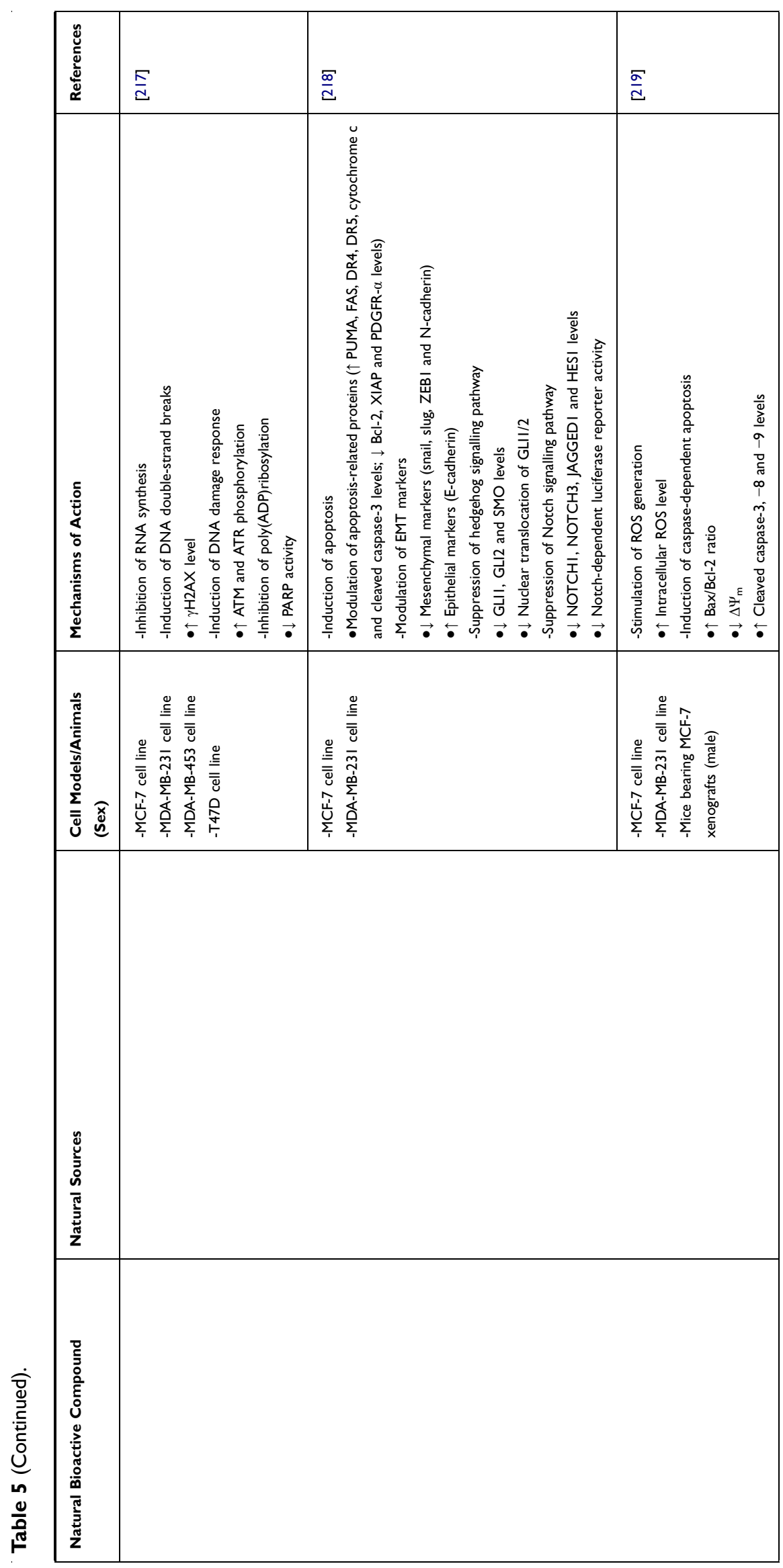




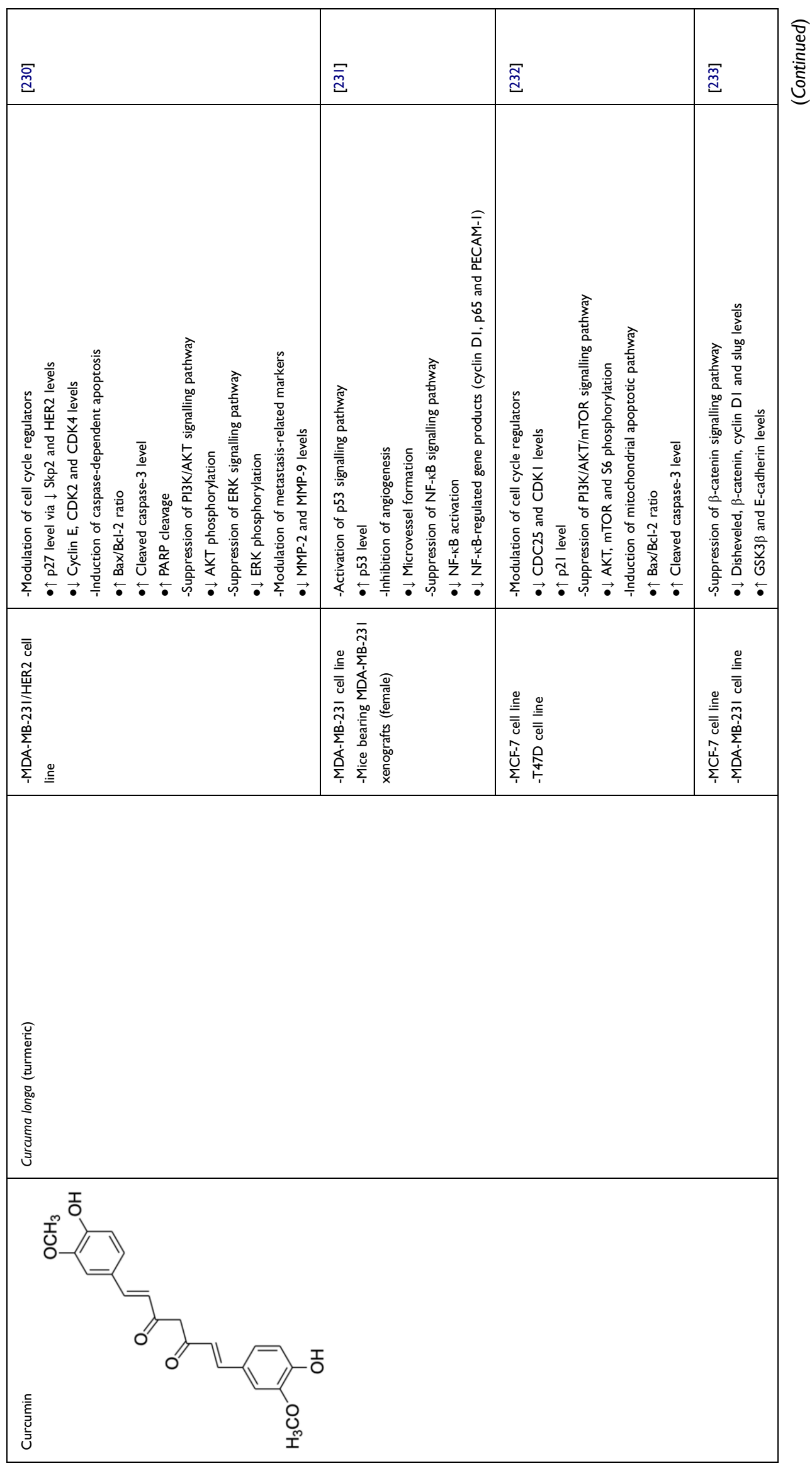




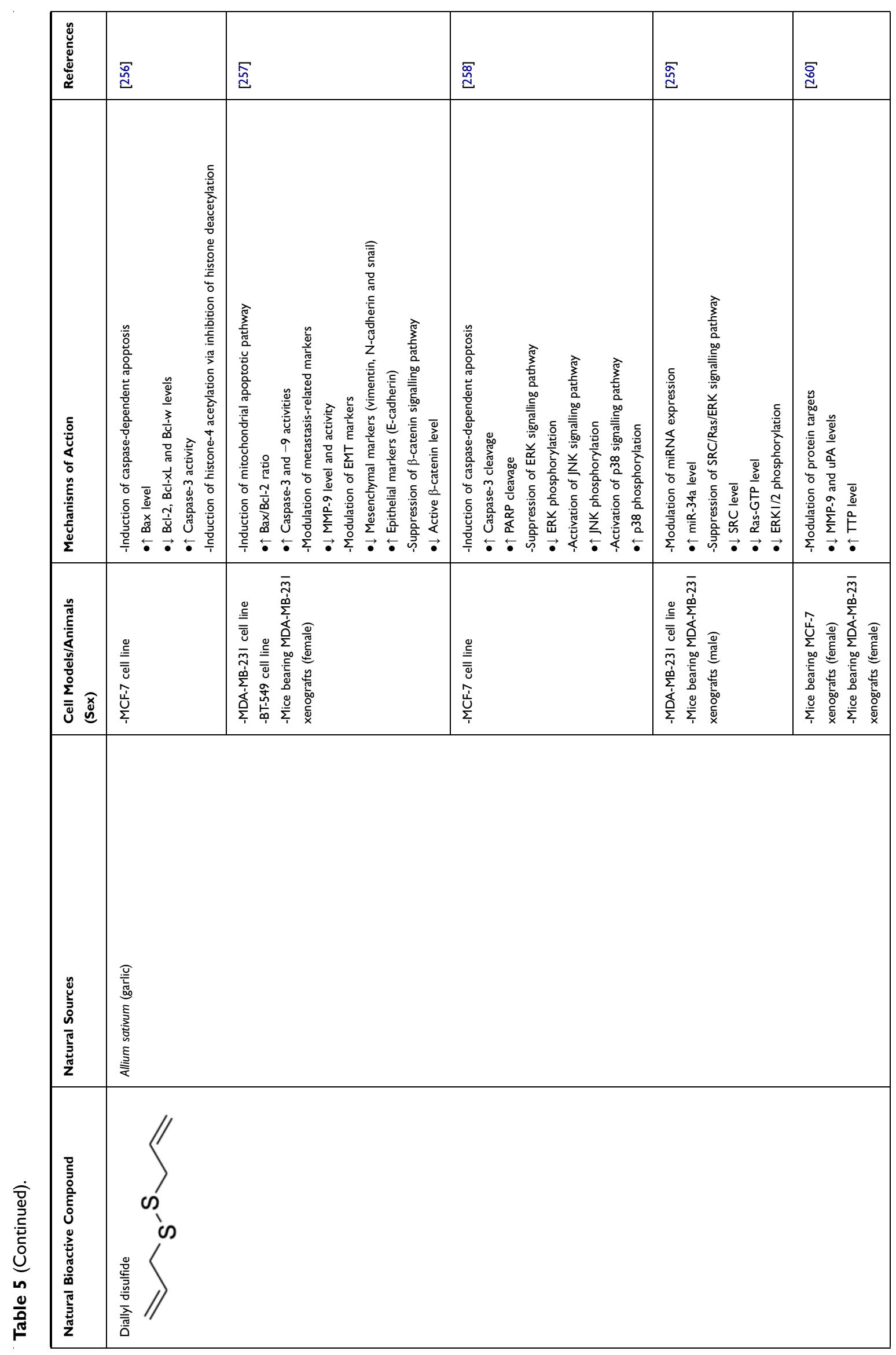



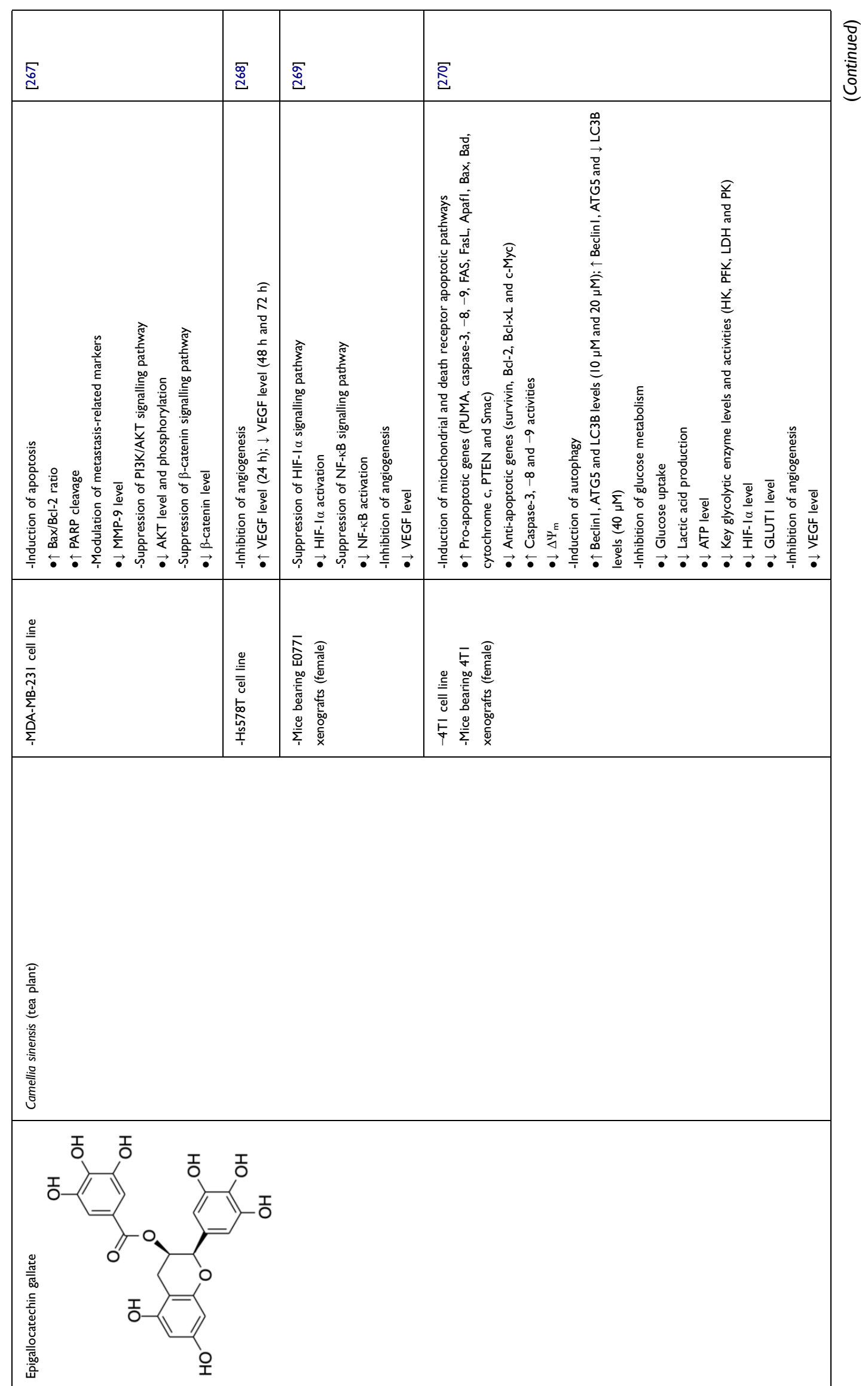


\begin{tabular}{|c|c|c|c|c|c|c|c|}
\hline 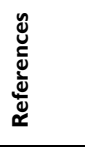 & $\overline{\bar{d}}$ & $\sqrt{\mathbb{Z}}$ & $\underset{\mathrm{d}}{\mathrm{E}}$ & \begin{tabular}{|l}
$\bar{D}$ \\
$\stackrel{\Xi}{\Xi}$
\end{tabular} & $\begin{array}{l}\bar{a} \\
\stackrel{్}{2}\end{array}$ & $\stackrel{\bar{d}}{\bar{\Xi}}$ & $\underset{\overline{\mathbf{d}}}{\overline{\mathrm{D}}}$ \\
\hline 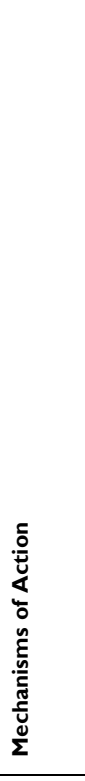 & 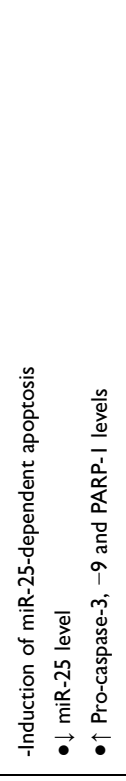 & 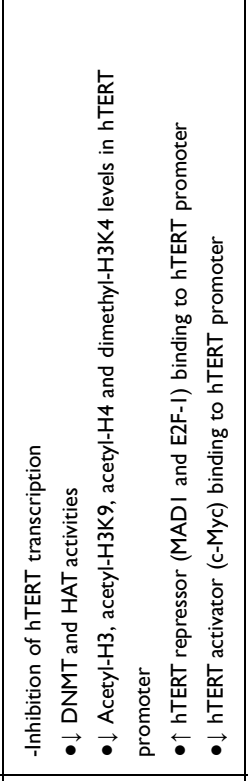 & 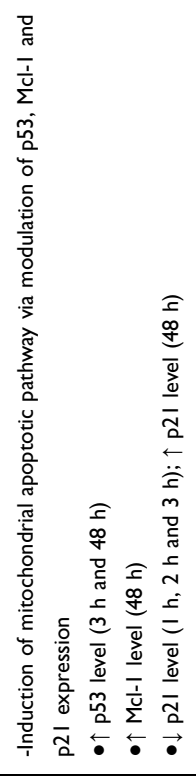 & 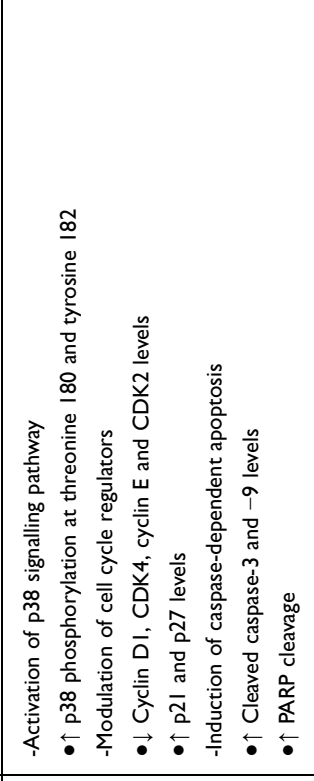 & 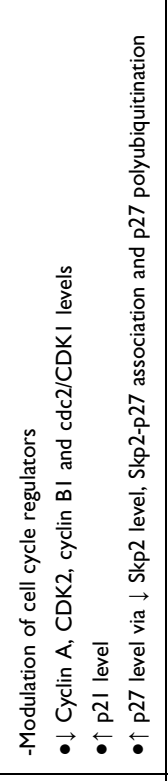 & 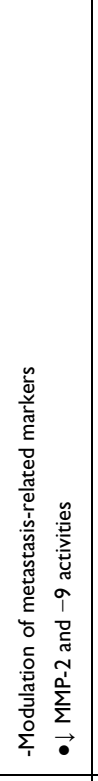 & 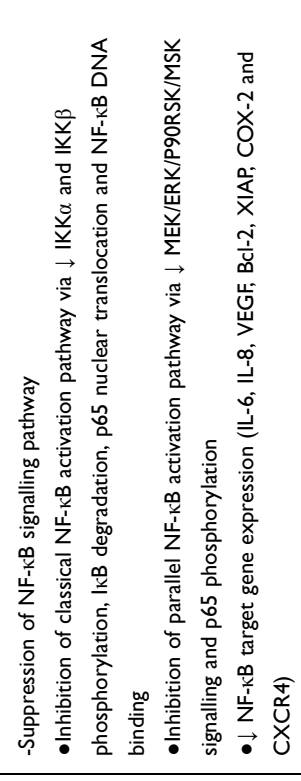 \\
\hline 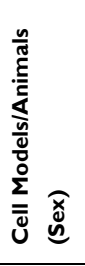 & 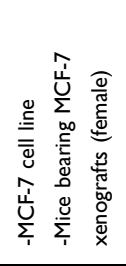 & 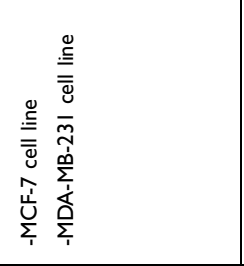 & 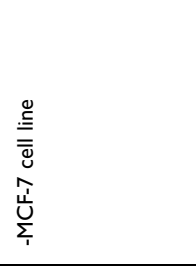 & 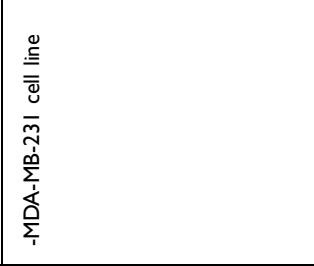 & 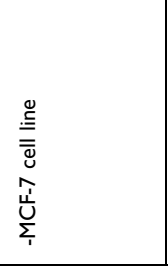 & 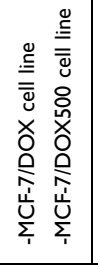 & 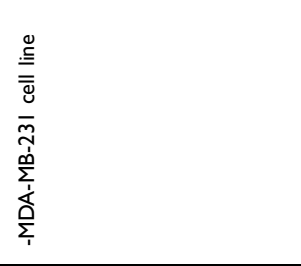 \\
\hline 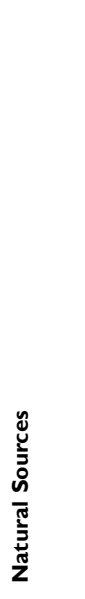 & & & 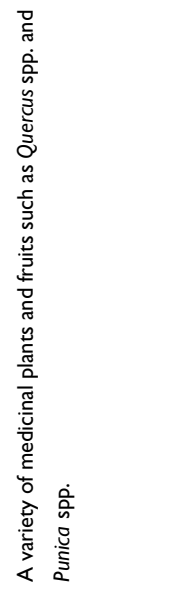 & & & & \\
\hline 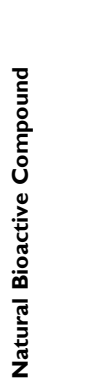 & & & (1) & 오 & & & \\
\hline
\end{tabular}




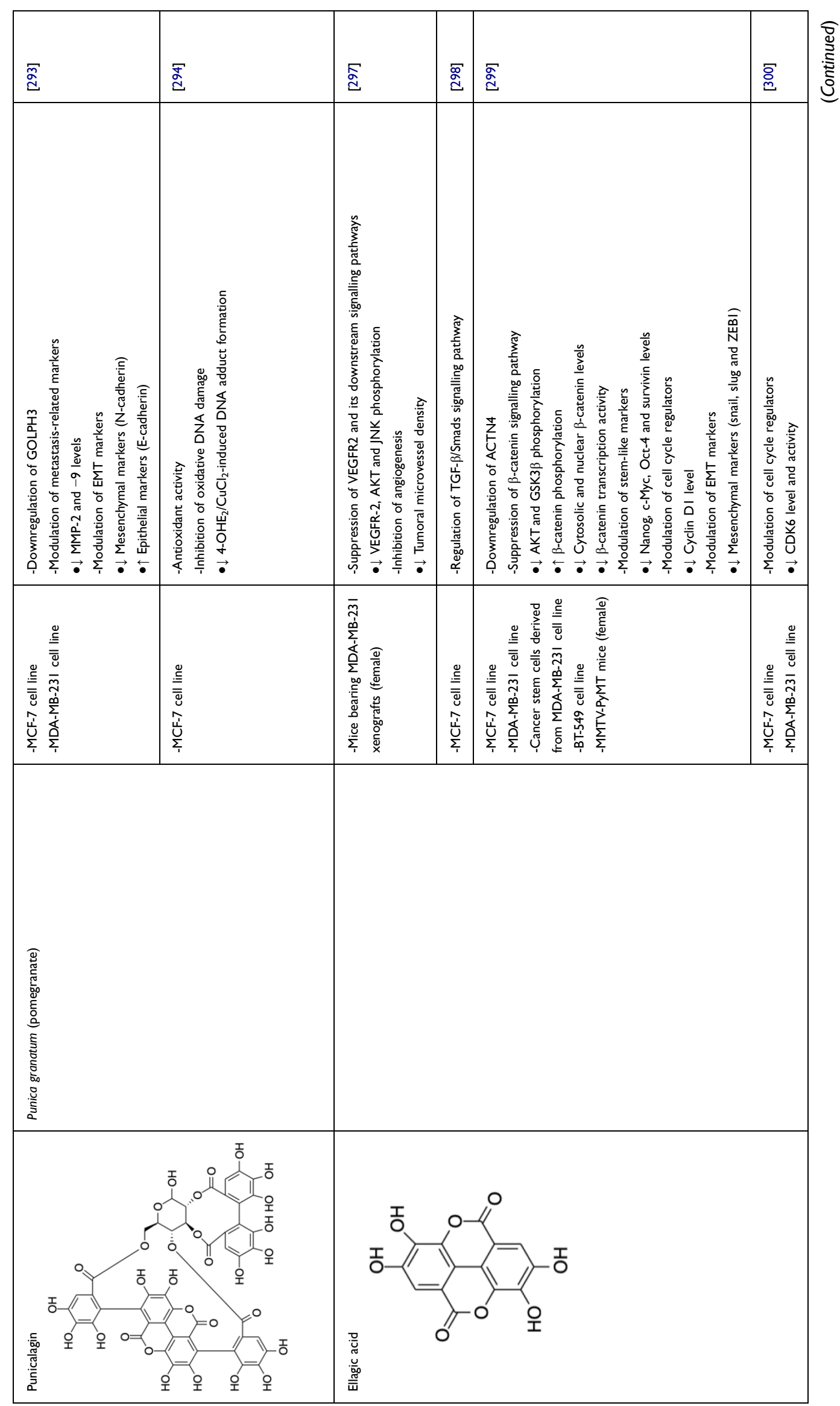




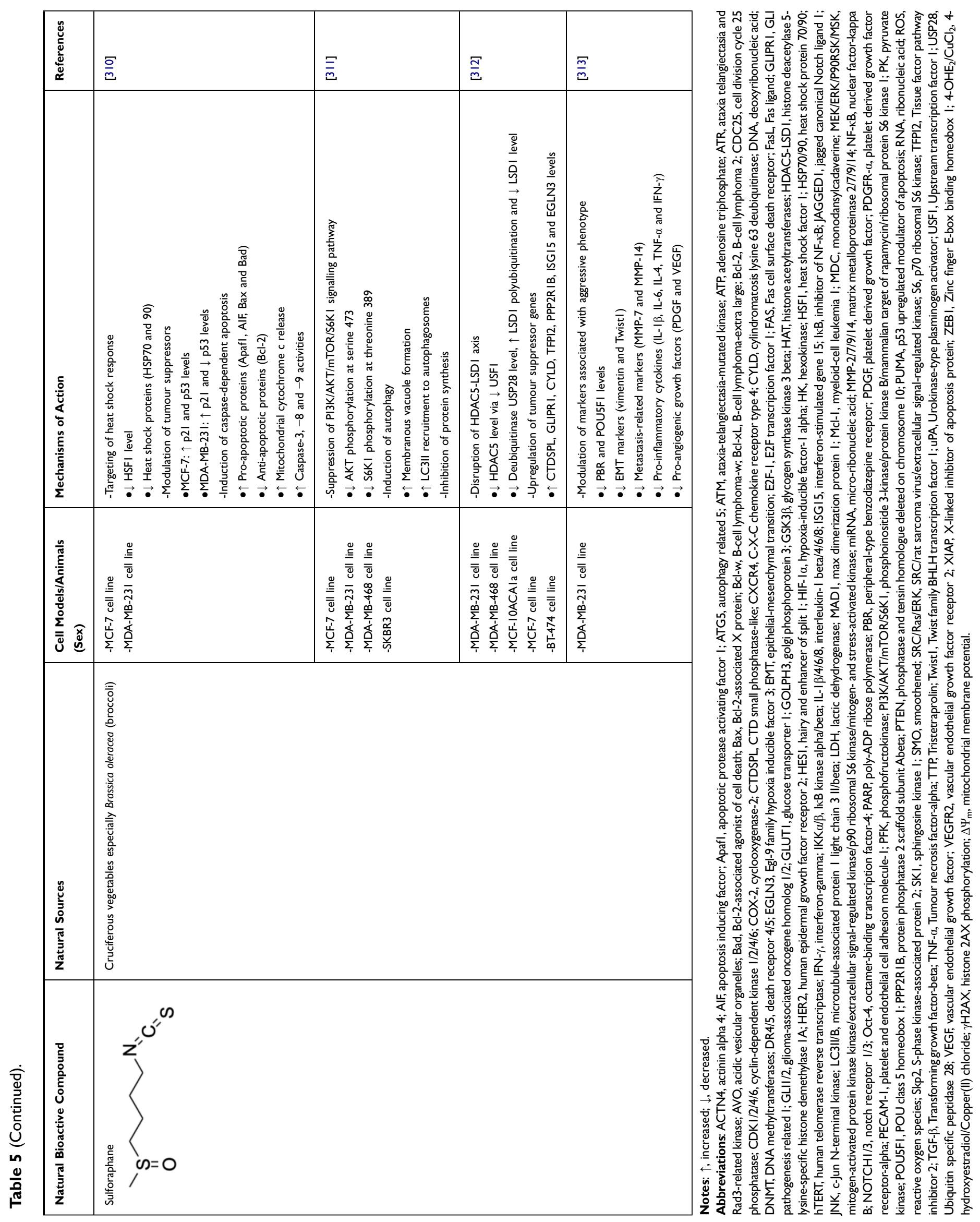




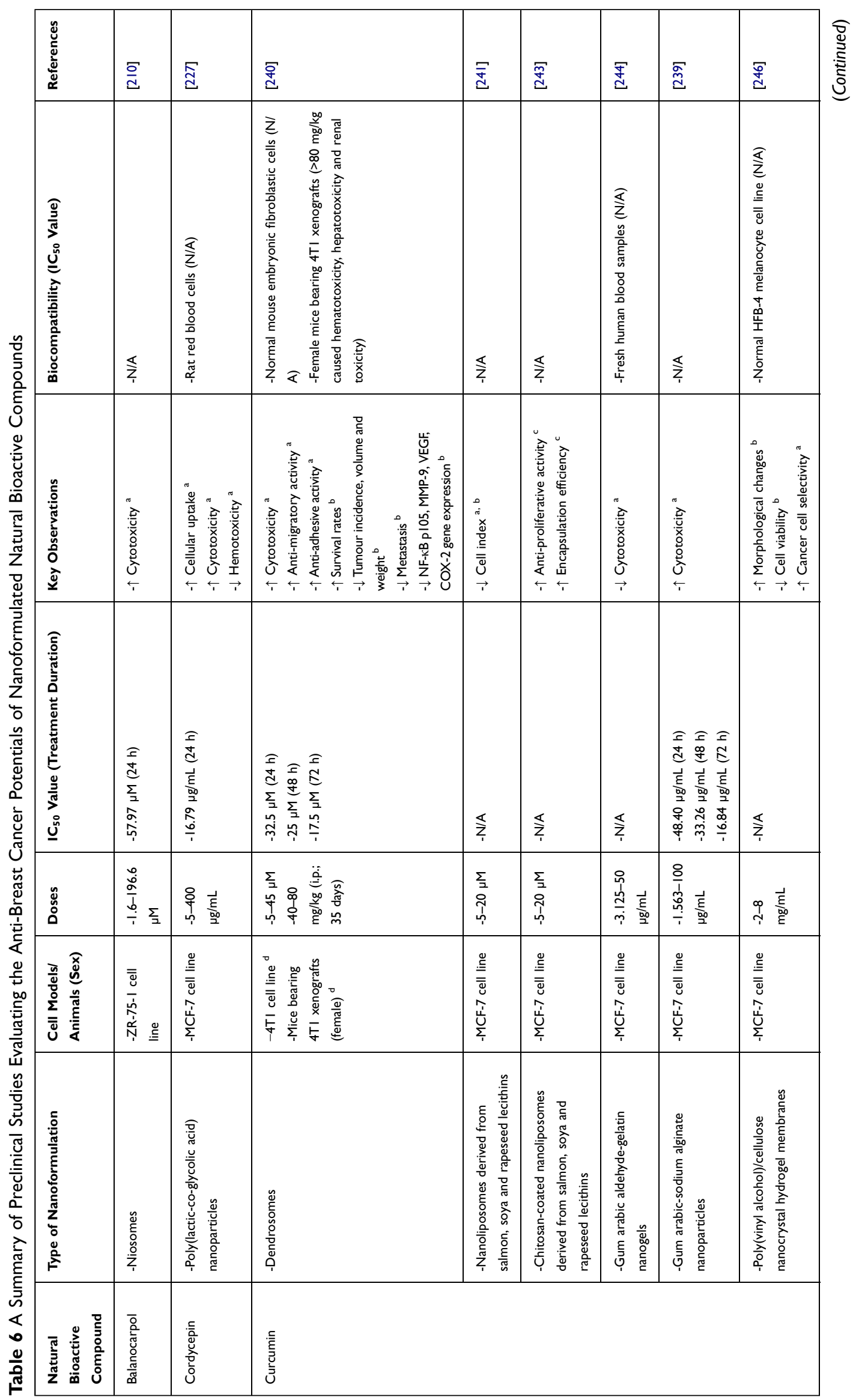




\begin{tabular}{|c|c|c|c|c|c|}
\hline 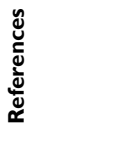 & 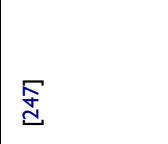 & $\stackrel{\text { D্ }}{\stackrel{d}{d}}$ & 总 & 戹 & $\underset{\mathfrak{d}}{\widetilde{d}}$ \\
\hline 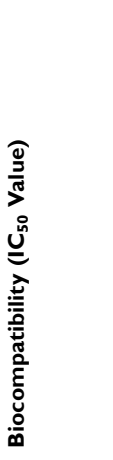 & 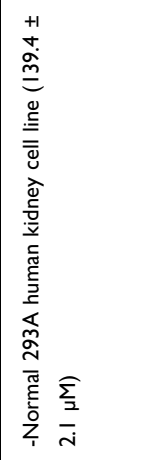 & $\underset{z}{\mathbb{z}}$ & $\aleph_{i}$ & 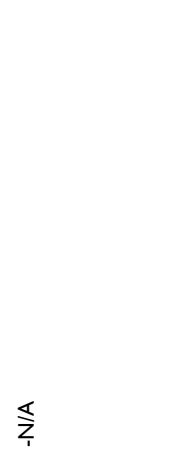 & $\underset{z}{\overleftarrow{z}}$ \\
\hline 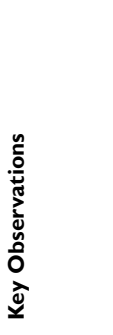 & 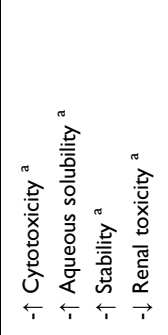 & 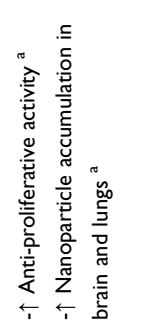 & 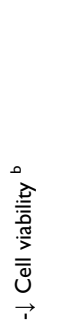 & 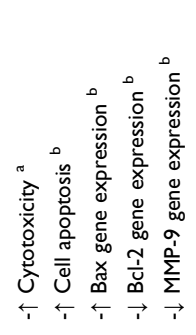 & 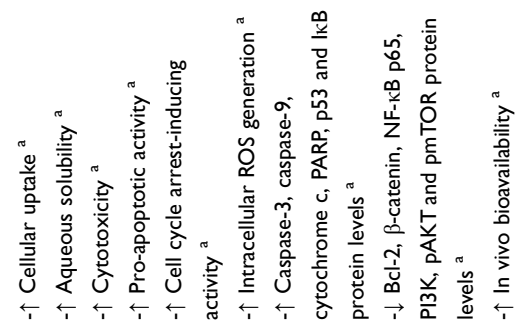 \\
\hline 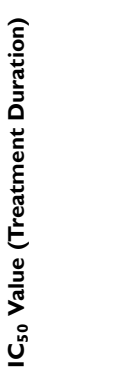 & 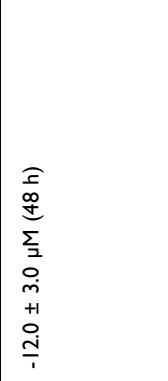 & $\underset{z}{\mathbb{z}}$ & 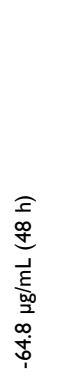 & 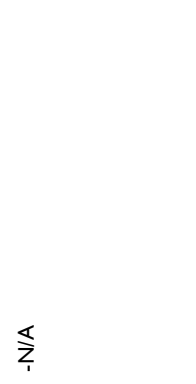 & $\underset{z}{\underline{z}}$ \\
\hline Џัڤ & $\begin{array}{l}\sum \\
\overline{2} \\
0 \\
\underline{\varphi} \\
\underline{T}\end{array}$ & 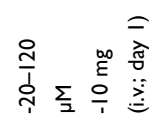 & 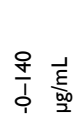 & $\begin{array}{l}\sum_{2} \\
\frac{n}{1} \\
1\end{array}$ & 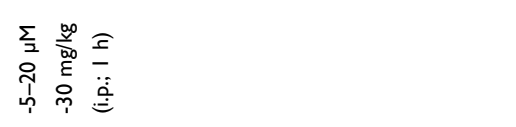 \\
\hline 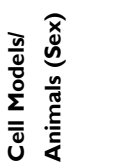 & 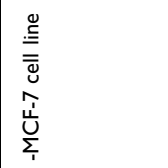 & 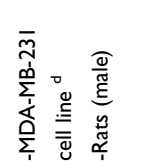 & 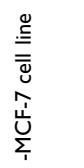 & 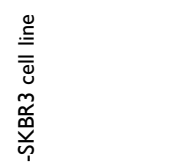 & 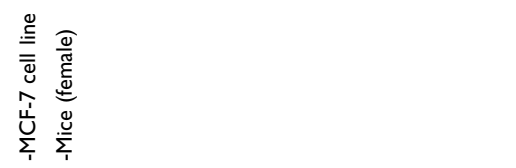 \\
\hline 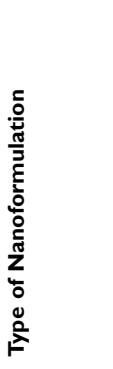 & 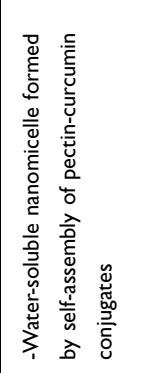 & 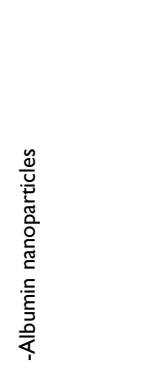 & 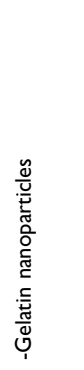 & 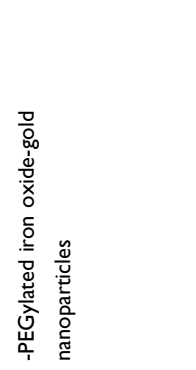 & 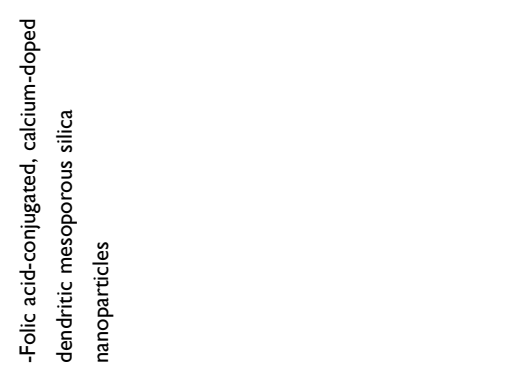 \\
\hline 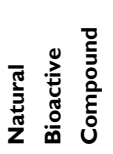 & & & & & \\
\hline
\end{tabular}




\begin{tabular}{|c|c|c|c|c|c|c|c|c|}
\hline $\overrightarrow{\widetilde{d}}$ & 을 & $\stackrel{\bar{N}}{\bar{U}}$ & $\stackrel{\bar{D}}{d}$ & 鸪 & \multicolumn{2}{|l|}{$\stackrel{\bar{\alpha}}{=}$} & 品 & 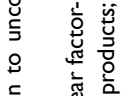 \\
\hline 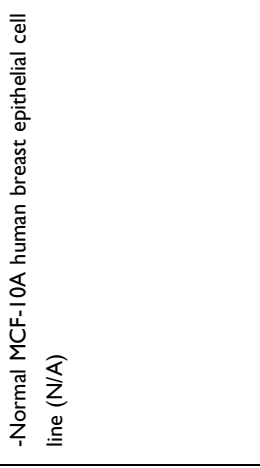 & $\sum_{i}^{\pi}$ & $\frac{\pi}{2}$ & $\frac{\pi}{2}$ & 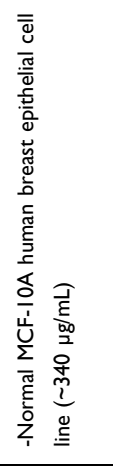 & \multicolumn{2}{|l|}{$\sum_{i}^{\frac{1}{2}}$} & $\sum_{i}^{\pi}$ & 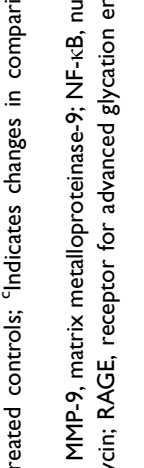 \\
\hline 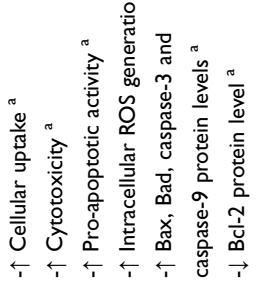 & 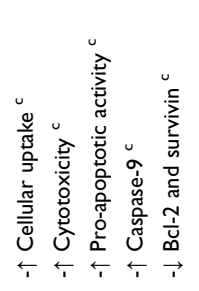 & 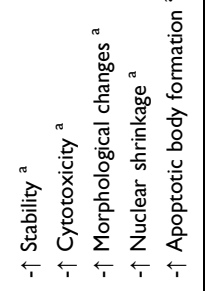 & 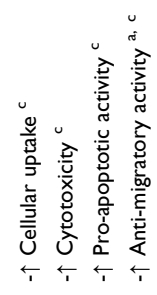 & 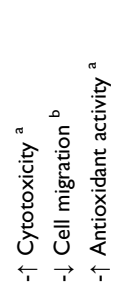 & \multicolumn{2}{|l|}{ 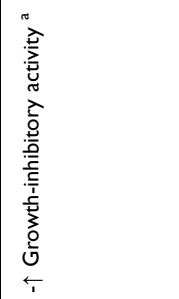 } & 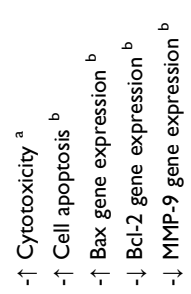 & 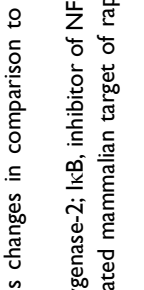 \\
\hline$\sum_{i}^{\frac{1}{2}}$ & $\frac{\pi}{2}$ & 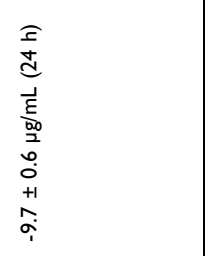 & 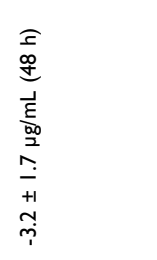 & 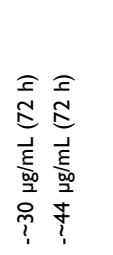 & 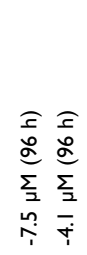 & 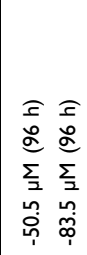 & $\frac{\pi}{z}$ & 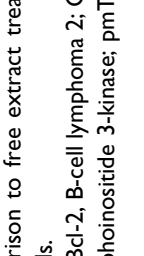 \\
\hline 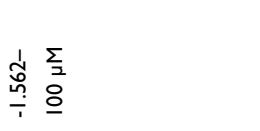 & 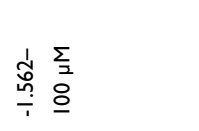 & 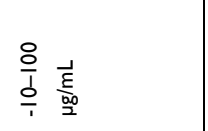 & 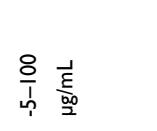 & 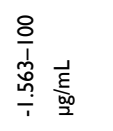 & \multicolumn{2}{|l|}{ 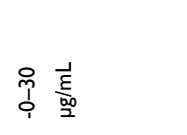 } & $\begin{array}{l}\frac{5}{2} \\
\frac{n}{1} \\
\frac{1}{9}\end{array}$ & 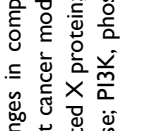 \\
\hline 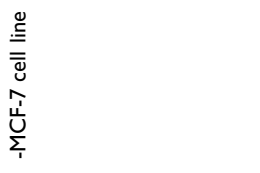 & 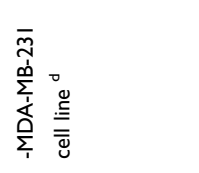 & 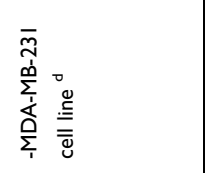 & 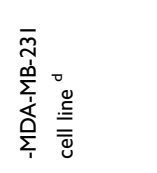 & 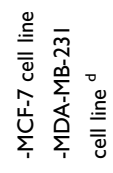 & \multicolumn{2}{|c|}{ 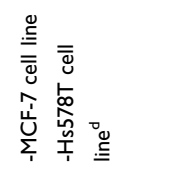 } & 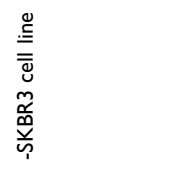 & 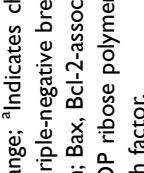 \\
\hline 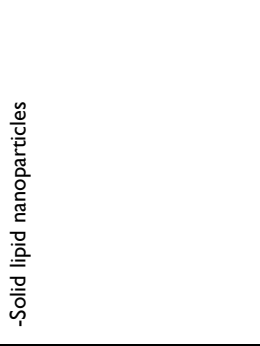 & 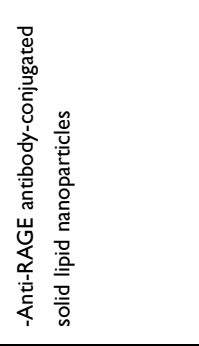 & 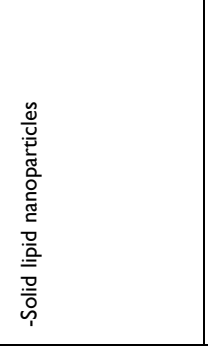 & 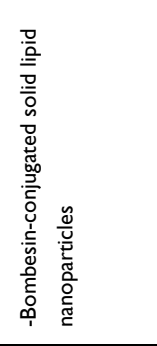 & 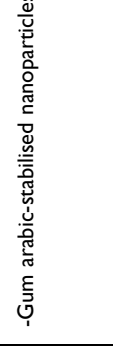 & \multicolumn{2}{|l|}{ 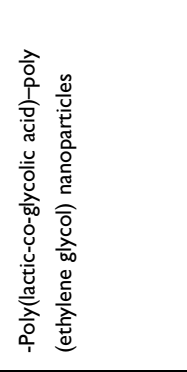 } & 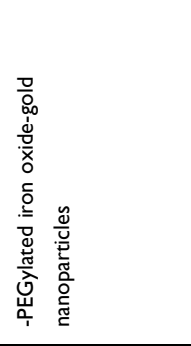 & 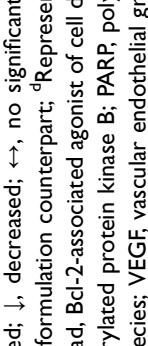 \\
\hline 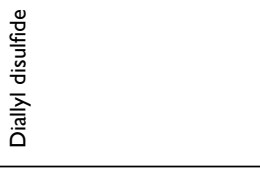 & & 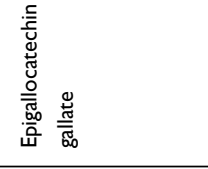 & & 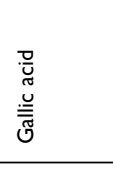 & 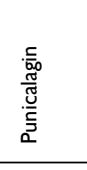 & 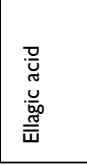 & 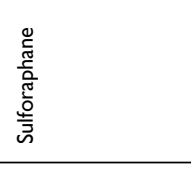 & 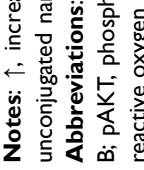 \\
\hline
\end{tabular}


established and linked to the inhibition of sphingosine kinase 1 (SK1) enzymatic activity and expression. ${ }^{209}$ SK1 catalyses the conversion of sphingosine to sphingosine-1-phosphate, the signalling of which has been implicated in cell survival, proliferation, migration and angiogenesis. ${ }^{211,212}$ SK1 overexpression has been correlated with drug resistance, worse prognosis and reduced overall survival in many cancers, thus making it a promising anti-cancer target. ${ }^{211}$ Additionally, balanocarpol's anti$\mathrm{BC}$ potential has also been linked to the induction of polyADP ribose polymerase (PARP) cleavage and the reduction of DNA synthesis. ${ }^{209}$ However, its high toxicity, low aqueous solubility and poor bioavailability have greatly hindered its clinical translation. ${ }^{210}$

To address the abovementioned limitations of balanocarpol, Obeid et $\mathrm{al}^{210}$ encapsulated balanocarpol into niosomes comprising span 80 and cholesterol (1:1). It was found that void niosomes at doses below $625 \mu \mathrm{g} / \mathrm{mL}$ were not cytotoxic to A2780 ovarian cancer cells and ZR-75-1 BC cells. Therefore, $625 \mu \mathrm{g} / \mathrm{mL}$ noisome was used to deliver balanocarpol for ensuring any observed cytotoxicity was induced solely by balanocarpol. Balanocarpolencapsulated niosomes exhibited significantly greater cytotoxicity against ZR-75-1 cells than free balanocarpol $\left(\mathrm{IC}_{50}\right.$ values of $57.97 \mu \mathrm{M}$ vs $\left.>196.6 \mu \mathrm{M}\right)$, indicating improved anti-BC efficacy.

\section{Cordycepin}

Cordyceps spp., an entomopathogenic fungus, is usually found in Asia, Europe and North America. ${ }^{213}$ Cordycepin (3-deoxyadenosine), an adenosine analogue, is the main bioactive constituent of Cordyceps spp. ${ }^{214}$ It has been extensively investigated for its pharmacological activities, including anti-BC, ${ }^{215-219}$ antimicrobial, ${ }^{220}$ anti-inflammatory, ${ }^{221}$ analgesic, ${ }^{222}$ hypoglycaemic, ${ }^{223}$ hypolipidemic ${ }^{224}$ and platelet inhibitory ${ }^{225}$ activities. As a nucleoside antagonist, cordycepin is known to exert anti-cancer effects principally by inhibiting RNA synthesis. ${ }^{217}$ Further investigations into its anti-BC mechanisms have suggested that the induction of autophagy-associated cell death, mitochondrial apoptotic pathway and caspase-dependent apoptosis; the regulation of p53 and estrogen signalling pathways; the promotion of DNA double-strand breaks and DNA damage response; the inhibition of poly(ADP)ribosylation; the suppression of hedgehog and Notch signalling pathways; the modulation of EMT markers; and the stimulation of ROS generation are also involved. ${ }^{215-219}$ However, the clinical application of cordycepin has been hindered due to toxicity to normal cells as well as poor bioavailability resulting from low aqueous solubility and rapid metabolism by adenosine deaminase. ${ }^{226}$

A study reported the encapsulation of cordycepin into PLGA nanoparticles (CPNPs) and observed that CPNPs had a higher uptake by MCF-7 cells than free cordycepin. ${ }^{227}$ This translated to a significantly greater cytotoxic effect of CPNPs on MCF-7 cells ( $\mathrm{IC}_{50}$ values of $16.79 \mu \mathrm{g} / \mathrm{mL}$ vs $47.84 \mu \mathrm{g} / \mathrm{mL}$ ). In addition, CPNPs also enabled the sustained release of cordycepin (65\% release in ten days), thus prolonging its anti-BC action. Importantly, while free cordycepin elicited hemolytic activity against rat red blood cells at 50 to $100 \mu \mathrm{g} /$ $\mathrm{mL}, \mathrm{CPNPs}$ of equivalent doses did not cause hemolysis. As opposed to free cordycepin, these findings suggest that CPNPs can exert marked and prolonged anti-BC activity at a nonhemotoxic concentration.

\section{Curcumin}

Curcumin [1,7-bis(4-hydroxy-3-methoxyphenyl)-1,6-heptadiene-3,5-dione] is a major natural polyphenol found in the rhizome of Curcuma longa (turmeric). ${ }^{228}$ It has shown benefits in diseases such as inflammatory conditions, kidney conditions, metabolic syndrome and pain, most of which have been attributed to its anti-inflammatory and antioxidant activities. ${ }^{228}$ Importantly, it has also demonstrated anti-cancer potentials both preclinically and clinically in oral, ${ }^{229}$ breast, ${ }^{230-233}$ colorectal, ${ }^{234}$ pancreatic, ${ }^{235}$ $\operatorname{skin}^{236}$ as well as head and neck ${ }^{237}$ cancers. Specifically, the anti-BC activities of curcumin have been linked to the modulation of cell cycle regulators and metastasis-related markers; the induction of caspase-dependent apoptosis and mitochondrial apoptotic pathway; the suppression of PI3K/ AKT/mammalian target of rapamycin (mTOR), extracellular signal-regulated kinase (ERK), NF- $\mathrm{BB}$ and $\beta$-catenin signalling pathways; the activation of p53 signalling pathway; as well as the inhibition of angiogenesis. ${ }^{230-233}$ However, the clinical applicability of curcumin is challenged by its poor bioavailability resulting from low aqueous solubility, poor absorption, extensive metabolism, rapid degradation at physiological $\mathrm{pH}$ and rapid systemic elimination. ${ }^{238,239}$

Different NDDS classes (eg, dendrosomes, liposomes, polymer-based nanocarriers, protein-based nanocarriers, metallic nanoparticles and MSNs) have been employed to overcome the poor bioavailability of curcumin. For example, Farhangi et al ${ }^{240}$ prepared dendrosomal curcumin (DNC) and tested its effects on both in vitro and in vivo metastatic $\mathrm{BC}$ models. While free curcumin caused 
an obvious reduction in $4 \mathrm{~T} 1$ cell viability only at $72 \mathrm{~h}$, DNC dose- and time-dependently suppressed 4T1 cell viability from 24 to $72 \mathrm{~h}\left(\mathrm{IC}_{50}\right.$ values of $32.5 \mu \mathrm{M}$ at 24 h, $25 \mu \mathrm{M}$ at $48 \mathrm{~h}$ and $17.5 \mu \mathrm{M}$ at $72 \mathrm{~h}$ ). Furthermore, DNC also dose-dependently elicited greater anti-migratory and anti-adhesive effects on 4T1 cells than free curcumin. Interestingly, DNC only demonstrated slight cytotoxic effects on normal mouse embryonic fibroblastic cells at high doses, indicating its biocompatible nature. When mice bearing 4T1 xenografts were subjected to intraperitoneal injection of DNC for seven days, it was found that doses up to $80 \mathrm{mg} / \mathrm{kg}$ were remarkably safe whereas 160 and $320 \mathrm{mg} / \mathrm{kg}$ DNC caused mild symptoms of hematotoxicity, hepatotoxicity and renal toxicity. These suggest that $\leq 80 \mathrm{mg} / \mathrm{kg}$ DNC may be more physiologically relevant in treating $\mathrm{BC}$. In comparison to untreated controls, DNC-treated mice (40-80 mg/kg; 35 days) showed higher survival rates, lower tumour incidence, smaller tumour volume and tumour weight as well as lower incidence of metastasis. In addition, these mice also had lower mRNA levels of NF- $\mathrm{KB}$ p105 and its downstream effectors (eg, matrix metalloproteinase [MMP]-9, vascular endothelial growth factor [VEGF] and cyclooxygenase-2 [COX-2]) in $\mathrm{BC}$ xenografts, brain, liver, lungs and spleen. Taken together, DNC is both biocompatible and capable of enhancing the anti-BC efficacy of curcumin, and its observed in vitro and in vivo anti-BC activities are likely correlated with the suppression of NF- $\kappa \mathrm{B}$ signalling.

Hasan et $\mathrm{al}^{241}$ loaded curcumin into nanoliposomes derived from salmon, soya or rapeseed lecithins. While free curcumin, soya curcumin-loaded nanoliposomes and rapeseed curcumin-loaded nanoliposomes induced an obvious reduction in MCF-7 cell index only from 12 to $20 \mu \mathrm{M}$, salmon curcumin-loaded nanoliposomes could significantly reduce MCF-7 cell index from 5 to $20 \mu \mathrm{M}$. Interestingly, void salmon nanoliposomes were reported to exert greater anti-proliferative effect on MCF-7 cells than void soya and rapeseed nanoliposomes. Lipid profiling revealed that salmon lecithins uniquely contained a high proportion of eicosapentaenoic acid (EPA) and docosahexanoic acid (DHA), ${ }^{241}$ both of which have previously been reported to possess anti-cancer potentials. ${ }^{242}$ Collectively, these findings suggest that the observed higher anti-BC efficacy of salmon curcumin-loaded nanoliposomes may be partly attributed to the synergistic effect between EPAand DHA-containing salmon nanoliposomes and curcumin. In another study, the same research group coated lecithin nanoliposomes with chitosan and found that chitosan-coated curcumin-loaded nanoliposomes exhibited greater anti-proliferative activity against MCF-7 cells than their uncoated counterparts. ${ }^{243}$ This improvement in antiBC efficacy offered by chitosan coating is potentially linked to enhanced permeation and encapsulation efficiency of nanoliposomes.

Besides, gum arabic-based nanoformulations have also been developed. For instance, a study reported the preparation of curcumin loaded-gum arabic aldehyde-gelatin (Cur/GA Ald-Gel) nanogels. ${ }^{244}$ In the study, free curcumin was found to significantly reduce $\mathrm{MCF}-7$ cell viability from 3.125 to $50 \mu \mathrm{g} / \mathrm{mL}$. In contrast, Cur/GA Ald-Gel nanogels could only induce significant cytotoxic effects on MCF-7 cells from 12.5 to $50 \mu \mathrm{g} / \mathrm{mL}$, and these effects were less significant than those induced by equivalent doses of free curcumin. This lower in vitro anti-BC efficacy of Cur/GA Ald-Gel nanogels may be explained by the slow release of curcumin (ie, $<65 \%$ during the treatment period of $24 \mathrm{~h}$ ). Nonetheless, the nano-range size $(452 \pm 8 \mathrm{~nm})$ of Cur/GA Ald-Gel nanogels may promote their in vivo tumour accumulation via the EPR effect, and their large negative zeta potential $(-27 \pm 4 \mathrm{mV})$ may confer good in vivo stability. Additionally, the release rate of curcumin was observed to be higher under an acidic condition ( $\mathrm{pH}$ ) than a neutral condition $(\mathrm{pH} 7.4)$, which is suggestive of preferential curcumin release at the tumour sites. Although Cur/GA Ald-Gel nanogels induced dose-dependent hemolysis, the observed percentages of hemolysis was $<5 \%$; ${ }^{244}$ thus classifying them as "hemocompatible" according to the ISO/TR 7406 standard. ${ }^{245}$ Overall, these findings suggest that although Cur/GA Ald-Gel nanogels did not demonstrate superior in vitro anti-BC efficacy as compared to free curcumin, they are hemocompatible and their nano-range size, large negative zeta potential and $\mathrm{pH}$-dependent release property may lead to superior in vivo anti-BC efficacy. Another study reported the encapsulation of curcumin into gum arabicsodium alginate (Cur/GA-Alg) nanoparticles. ${ }^{239}$ Cytotoxicity assay revealed that the $\mathrm{IC}_{50}$ values of $\mathrm{Cur} /$ GA-Alg nanoparticles against MCF-7 cells were consistently lower than those of free curcumin at $24 \mathrm{~h}(48.40 \mu \mathrm{g} /$ $\mathrm{mL}$ vs $68.20 \mu \mathrm{g} / \mathrm{mL}), 48 \mathrm{~h}(33.26 \mu \mathrm{g} / \mathrm{mL}$ vs $55.86 \mu \mathrm{g} / \mathrm{mL})$ and $72 \mathrm{~h}(16.84 \mu \mathrm{g} / \mathrm{mL}$ vs $32.10 \mu \mathrm{g} / \mathrm{mL})$. Importantly, void GA-Alg nanoparticles showed no significant cytotoxicity against MCF-7 cells, indicating that this NDDS is capable of enhancing the anti-BC efficacy of curcumin while being biocompatible. 
Poly(vinyl alcohol)/cellulose nanocrystal (PVA/CNC) hydrogel membranes, another type of polymer-based nanocarrier, have also been developed. ${ }^{246}$ Curcumin-loaded PVA/ CNC hydrogel membranes were found to induce significant morphological changes (eg, cell shrinkage and increased apoptotic bodies) and dose-dependent reduction in viability in MCF-7 cells. Furthermore, while free curcumin demonstrated greater cytotoxicity in normal HFB-4 human melanocytes than in MCF-7 cells, curcumin-loaded PVA/CNC hydrogel membranes were not cytotoxic to HFB-4 cells. These findings collectively indicate that curcumin-loaded $\mathrm{PVA} / \mathrm{CNC}$ hydrogel membranes are biocompatible and BC cell-selective. Another study reported a novel water-soluble nanomicelle that is formed via the self-assembly of pectincurcumin conjugates, with hydrophobic curcumin sitting in the core and hydrophilic pectin polymer backbone forming the outer shell. ${ }^{247}$ It was observed that pectin-curcumin conjugates elicited greater cytotoxicity against MCF-7 cells than free curcumin $\left(\mathrm{IC}_{50}\right.$ values of $12.0 \pm 3.0 \mu \mathrm{M}$ vs $48.3 \pm 2.9$ $\mu \mathrm{M})$. This enhancement in cytotoxicity is likely attributed to improved aqueous solubility and stability. Notably, pectincurcumin conjugates also demonstrated lower cytotoxicity against normal 293A human kidney cells than free curcumin $\left(\mathrm{IC}_{50}\right.$ values of $139.4 \pm 2.1 \mu \mathrm{M}$ vs $70.7 \pm 1.5 \mu \mathrm{M}$ ). Taken together, conjugation to pectin can enhance the anti-BC efficacy of curcumin (via solubility and stability improvement) while minimising its toxicity to normal cells.

Different protein-based nanoformulations of curcumin have also been developed. For example, Jithan et $\mathrm{al}^{248}$ developed curcumin-encapsulated albumin nanoparticles (CEANs) and found that CEANs $(20-120 \mu \mathrm{M})$ exhibited greater anti-proliferative effect on MDA-MB-231 cells than free curcumin. This enhancement in anti-BC efficacy may be a result of enhanced dissolution rate and aqueous solubility. Furthermore, it was observed in rats following a single intravenous injection of $10 \mathrm{mg}$ CAENs that CAENs tended to accumulate in brain and lungs, which are the common sites of $\mathrm{BC}$ metastases. These observations collectively reflect the potentials of CAENs in enhancing the anti-BC efficacy of curcumin and in treating metastatic BC. Metwally et $\mathrm{al}^{206}$ encapsulated curcumin into gelatin (Cur/Gel) nanoparticles and found that $\mathrm{Cur} / \mathrm{Gel}$ nanoparticles exhibited cytotoxicity against MCF-7 cells after $48 \mathrm{~h}\left(\mathrm{IC}_{50}=64.8 \mu \mathrm{g} / \mathrm{mL}\right)$. This $\mathrm{IC}_{50}$ value is close to but higher than that of $48 \mathrm{~h}$ free curcumin treatment $\left(\mathrm{IC}_{50}=53.18 \mu \mathrm{g} / \mathrm{mL}\right)$ observed in another study, ${ }^{249}$ which may be explained by the slow release of curcumin from nanoparticles (ie, only $40-60 \%$ after 48 h). ${ }^{206}$ Moreover, void Gel nanoparticles yielded a high $\mathrm{IC}_{50}$ value of $2.9 \mathrm{mg} / \mathrm{mL}$ against MCF-7 cells. These findings collectively suggest that Gel nanoparticles are biocompatible and capable of prolonging curcumin action, although they do not significantly improve the anti-BC efficacy of curcumin.

Curcumin has also been encapsulated into metallic nanoparticles. In a study, curcumin-encapsulated PEGylated iron oxide-gold nanoparticles (Cur/PEGylated $\mathrm{Fe}_{3} \mathrm{O}_{4} @$ @uNPs; 0-15 $\mu \mathrm{M}$ ) elicited greater cytotoxicity against SKBR3 BC cells than free curcumin, possibly attributable to improved stability and preferential curcumin release under acidic conditions. ${ }^{250}$ Cur/PEGylated $\mathrm{Fe}_{3} \mathrm{O}_{4} @$ AuNPs also demonstrated pro-apoptotic activity against SKBR3 cells. Subsequent gene expression analysis linked this pro-apoptotic activity to Bax upregulation and Bcl-2 downregulation. Additionally, MMP-9 downregulation was also observed. Taken together, Cur/PEGylated $\mathrm{Fe}_{3} \mathrm{O}_{4} @$ AuNPs mediate enhanced cytotoxic effect on BC cells by upregulating $\mathrm{Bax} / \mathrm{Bcl}-2$ ratio and inducing apoptosis; and they may potentially inhibit $\mathrm{BC}$ cell migration by downregulating MMP-9.

Folic acid (FA) has a strong binding affinity for folate receptors, which are glycosylphosphatidylinositolanchored membrane proteins often overexpressed in BC. ${ }^{251}$ Therefore, J. Wang et $\mathrm{al}^{252}$ loaded curcumin into calcium-doped dendritic MSNs conjugated with FA (CurCa@DMSNs-FA) for achieving active BC cell targeting and facilitating cellular uptake of nanoparticles. In the study, Cur-Ca@DMSNs-FA demonstrated improved aqueous solubility and in vivo bioavailability as compared to free curcumin, and showed a remarkably higher curcumin release rate under acidic $(80 \%$ in $0.5 \mathrm{~h})$ than neutral $(35 \%$ in $12 \mathrm{~h}$ ) conditions. Unsurprisingly, it was further observed that Cur-Ca@DMSNs-FA (5-20 $\mu \mathrm{M})$ exhibited more significant cytotoxicity ( $9 \%$ vs $33 \%$ cell viability), pro-apoptotic activity ( $25.85 \%$ vs $12.5 \%$ of total apoptosis ratio) and $\mathrm{G} 2 / \mathrm{M}$-phase arrest-inducing activity $(41.07 \%$ vs $24.54 \%$ of cells in $\mathrm{G} 2 / \mathrm{M}$ phase) against MCF-7 cells than comparable doses of free curcumin. Interestingly, void Ca@DMSNs-FA (320 $\mu \mathrm{g} / \mathrm{mL})$ was non-toxic to MCF-7 cells and had a hemolytic ratio of $4.38 \%(<5 \%)$. Taken together, this NDDS is biocompatible and capable of enhancing the anti-BC efficacy of curcumin via enhanced cellular uptake, improved aqueous solubility and bioavailability as well as $\mathrm{pH}$-dependent curcumin release. The same study reported higher ROS production in MCF-7 cells treated with Cur-Ca@DMSNs-FA than those treated with free curcumin. Further protein expression analysis revealed that Cur-Ca@DMSNs-FA also 
induced greater upregulation of caspase-3, caspase-9, cyto-

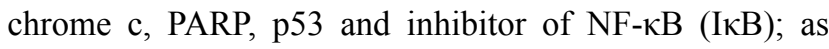
well as greater downregulation of Bcl-2, $\beta$-catenin, NF- $\kappa B$ p65, PI3K, phosphorylated AKT and phosphorylated mTOR in MCF-7 cells than free curcumin. Collectively, these findings linked the anti-BC activities of Cur$\mathrm{Ca} @$ DMSNs-FA to the induction of oxidative stress and mitochondrial apoptotic pathway, as well as the suppression of PI3K/AKT/mTOR, $\beta$-catenin and NF- $\kappa \mathrm{B}$ signalling pathways.

\section{Diallyl Disulfide}

Allium sativum (garlic), native to Central Asia and northeastern Iran, is now widely cultivated throughout the world. $^{253,254}$ It has commonly been used as both a spice and a medicinal plant in treating bone diseases, cancer, cardiovascular diseases, diabetes, gastric diseases, hypertension, metabolic disorders, microbial infections, skin diseases, etc. ${ }^{253,254}$ These health benefits of $A$. sativum are attributed to its diverse range of bioactive compounds.255 Its major organosulfur compound, diallyl disulfide, has been reported to mediate anti-BC activities by inducing caspase-dependent apoptosis and mitochondrial apoptotic pathway, inhibiting histone deacetylation, modulating metastasis-related and EMT markers, suppressing $\beta$-catenin and SRC/rat sarcoma virus (Ras)/ERK signalling pathways, activating c-Jun N-terminal kinase (JNK) and p38 signalling pathways, upregulating miR-34a and tristetraprolin (TTP) as well as downregulating urokinase-type plasminogen activator (uPA). ${ }^{256-260}$ Diallyl disulfide has also demonstrated superior anti-BC efficacy in comparison to conventional chemotherapeutic agents (eg, 5-fluorouracil and cyclophosphamide), thus suggesting its potential to be developed as an anti-BC agent. $^{261}$

Although the clinical translation of diallyl disulfide has been restricted by its low water solubility, poor bioavailability and short half-life, these problems have been tackled by NDDSs. Talluri et $\mathrm{al}^{262}$ reported the loading of diallyl disulfide into SLNs (DADS-SLNs). DADSSLNs were found to have higher uptake by MCF-7 cells than free diallyl disulfide. DADS-SLNs could also preferentially release diallyl disulfide under acidic conditions $(\mathrm{pH} 4.5)$ and enable sustained diallyl disulfide release up to $48 \mathrm{~h}$. As expected, DADS-SLNs $(1.562-100 \mu \mathrm{M})$ were capable of eliciting greater cytotoxic and pro-apoptotic effects on MCF-7 cells than free diallyl disulfide. This enhancement in anti-BC efficacy was further reflected by changes in cellular oxidative status and apoptotic marker expression. For instance, DADS-SLN-treated MCF-7 cells had higher ROS production; higher levels of pro-apoptotic proteins (eg, Bax, Bcl-2-associated agonist of cell death [Bad], caspase-3 and caspase-9); and lower level of antiapoptotic protein (Bcl-2) than diallyl disulfide-treated MCF-7 cells. Importantly, DADS-SLNs were not cytotoxic to normal MCF-10A human breast epithelial cells. Taken together, this nanoformulation is biocompatible and capable of enhancing the anti-BC efficacy of diallyl disulfide by exhibiting enhanced cellular uptake as well as enabling both $\mathrm{pH}$-dependent and sustained release of diallyl disulfide.

Receptor for advanced glycation end products (RAGE), a multi-ligand single transmembrane receptor belonging to the immunoglobulin superfamily, is frequently overexpressed in late-stage BC. ${ }^{263}$ Therefore, the same research group further conjugated DADS-SLNs with anti-RAGE antibody (RAGE-DADS-SLNs) to enable active BC cell targeting. ${ }^{10}$ As expected, RAGE-DADS-SLNs (1.562-100 $\mu \mathrm{M})$ exhibited significantly higher cellular uptake and cytotoxicity in MDA-MB-231 cells than DADS-SLNs. RAGEDADS-SLNs also showed higher pro-apoptotic activity, as reflected by their ability to induce a greater increase in the level of pro-apoptotic protein (eg, caspase-9) and a greater decrease in the levels of anti-apoptotic proteins (eg, Bcl-2 and survivin) than DADS-SLNs. Furthermore, it has been reported that RAGE activation can lead to the stimulation of signalling pathways (eg, ras-related $\mathrm{C} 3$ botulinum toxin substrate 1 [Rac1], MAPK and NF- $\kappa$ B) implicated in cell migration and invasion, thereby contributing to tumour progression. $^{264}$ This indicates that the observed greater cytotoxicity and pro-apoptotic activity of RAGE-DADSSLNs than DADS-SLNs may be the consequence of both cellular uptake enhancement and RAGE inhibition. ${ }^{10}$

\section{Epigallocatechin Gallate}

Green tea, one of the most widely consumed beverages worldwide, is obtained from the leaves of Camellia sinensis tea plant. ${ }^{265}$ Green tea consumption has long been associated with health-promoting properties in atherosclerosis, bacterial and viral infections, cancers of the breast, colon, oesophagus, kidney, lung, mouth, pancreas, small intestine and stomach, diabetes, heart diseases, liver diseases, obesity, etc. ${ }^{265}$ Epigallocatechin gallate (EGCG), the major green tea catechin, is believed to contribute to the majority of green tea-associated health benefits. ${ }^{266}$ Specifically, EGCG has been reported to mediate anti-BC effects preclinically via the modulation of metastasis- 
related markers; the suppression of PI3K/AKT and $\beta$-catenin signalling pathways; the suppression of hypoxia-inducible factor-1 alpha (HIF-1 $\alpha$ ) and NF- $\mathrm{KB}$ signalling pathways and consequent inhibition of angiogenesis; the induction of mitochondrial apoptotic pathway, death receptor apoptotic pathway, miR-25-dependent apoptosis and autophagy; as well as the inhibition of glucose metabolism and human telomerase reverse transcriptase (hTERT) transcription. ${ }^{267-272}$ Despite these promising preclinical findings, the clinical application of EGCG is hindered due to its poor bioavailability and low stability at physiological $\mathrm{pH}^{270}$

Radhakrishnan et $\mathrm{al}^{273}$ encapsulated EGCG (5\% w/w) into SLNs, and found that this nanoformulation enabled sustained EGCG release (ie, $>90 \%$ release in $24 \mathrm{~h}$ ) and improved EGCG stability. Expectedly, EGCG-SLNs could induce a more significant dose-dependent reduction in MDA-MB-231 cell viability than free EGCG $\left(\mathrm{IC}_{50}\right.$ values of $9.7 \pm 0.6 \mu \mathrm{g} / \mathrm{mL}$ vs $78.9 \pm 4.3 \mu \mathrm{g} / \mathrm{mL}$ ). Moreover, EGCG-SLNs also elicited greater pro-apoptotic activity against MDA-MB-231 cells than free EGCG, as evidenced by the observations of more extensive morphological changes (eg, cell shrinkage and elongated-to-spherical cell shape), nuclear shrinkage and apoptotic body formation in EGCG-SLN-treated MDA-MB-231 cells. Importantly, void SLNs $(10-100 \mu \mathrm{g} / \mathrm{mL})$ lacked observable cytotoxicity against MDA-MB-231 cells, suggesting that this NDDS is biocompatible and capable of enhancing the anti-BC efficacy of EGCG via its sustained release and stability improvement.

Bombesin (BBN; a 14-amino acid peptide) is a natural ligand for gastrin-releasing peptide receptor, which is a G-protein coupled receptor that is overexpressed in various cancers, including BC. ${ }^{274}$ The same research group thus further conjugated EGCG-SLNs with BBN to achieve active BC cell targeting. ${ }^{275}$ In the study, increased cellular uptake of BBN-conjugated EGCG-SLNs relative to unconjugated EGCG-SLNs was observed. Consequently, BBNconjugated EGCG-SLNs could exert greater cytotoxicity $\left(\mathrm{IC}_{50}\right.$ values of $3.2 \pm 1.7 \mu \mathrm{g} / \mathrm{mL}$ vs $6.9 \pm 1.1 \mu \mathrm{g} / \mathrm{mL}$ ) and pro-apoptotic activity against MDA-MB-231 cells than unconjugated EGCG-SLNs. Although both EGCG-SLNs and BBN-conjugated EGCG-SLNs exhibited greater antimigratory effect on MDA-MB-231 cells than pure EGCG, the effect of the latter was more intensive. Collectively, the results indicate that enhanced cellular uptake mediated by $\mathrm{BBN}$ conjugation can improve the anti-BC efficacy of EGCG-SLNs.

\section{Gallic Acid}

Gallic acid (3,4,5-trihydroxybenzoic acid), one of the most common plant phenolic acids, can be found in a variety of medicinal plants and fruits such as Quercus spp. and Punica spp. ${ }^{276}$ It has been associated with tremendous health benefits owing to the wide range of its pharmacological activities, including anti-BC, ${ }^{277-281}$ anti-inflammatory, ${ }^{282}$ antimicrobial, ${ }^{283}$ antioxidant, ${ }^{284}$ cardioprotective, ${ }^{285}$ gastroprotective $^{286}$ and neuroprotective ${ }^{287}$ activities. Specifically, the anti-BC activities of gallic acid have been linked to various mechanisms such as the modulation of $\mathrm{p} 53$, Mcl-1 and p21 expression and consequent induction of mitochondrial apoptotic pathway; the activation of $\mathrm{p} 38$ signalling pathway as well as consequent modulation of cell cycle regulators and induction of caspase-dependent apoptosis; the modulation of metastasis-related markers; as well as the suppression of NF- $\mathrm{KB}$ signalling pathway and consequent downregulation of NF- $\mathrm{KB}$ target genes signifying antiinflammatory (ie, interleukin [IL]-6, IL-8 and COX-2), anti-angiogenic (ie, VEGF), pro-apoptotic (ie, Bcl-2 and $\mathrm{X}$-linked inhibitor of apoptosis protein [XIAP]) and antimetastatic (ie, C-X-C chemokine receptor type 4 [CXCR4]) effects. ${ }^{277-281}$ However, the therapeutic potential of gallic acid as an anti-BC agent is restricted by its low bioavailability resulting from poor absorption and rapid metabolism. ${ }^{288}$

Hassani et $\mathrm{al}^{288}$ reported the preparation of gum arabicstabilised gallic acid nanoparticles (GANPs). It was observed that GANPs could exert more significant cytotoxicity against MCF-7 and MDA-MB-231 cells than free gallic acid, as well as retard the migratory capacity of MCF-7 and MDA-MB-231 cells. Interestingly, GANPs demonstrated differential cellular uptake in different BC cell lines, whereby a significantly higher uptake was seen in MCF-7 than MDA-MB-231 cells. This may potentially explain the greater cytotoxic and anti-migratory effects of GANPs on MCF-7 than MDA-MB-231 cells. Importantly, GANPs showed negligible cytotoxicity against normal MCF-10A human breast epithelial cells and preferentially released gallic acid under acidic condition ( $\mathrm{pH} 4.8 ; 95.96 \%)$ rather than neutral condition ( $\mathrm{pH} 7.4 ; 74.56 \%)$, reflecting the biocompatibility and $\mathrm{BC}$ cell selectivity of this nanoformulation.

In the same study, various in vitro antioxidant assays (ie, 2.2-diphenyl-1-picrylhydrazyl radical [DPPH], nitric oxide scavenging and $\beta$-carotene bleaching assays) consistently suggested that GANPs exhibited greater antioxidant activity than free gallic acid. ${ }^{288}$ This activity enhancement may partly 
be attributed to the synergistic effect between gallic acid and gum arabic, both of which have previously been reported as potent antioxidants. ${ }^{284,289}$ Cancer cells are often in a prooxidative state. ${ }^{290}$ ROS is implicated in cancer initiation and progression as it can induce gene mutations and changes in various signalling pathways involved in cell differentiation, survival, growth, proliferation, protein synthesis and glucose metabolism. ${ }^{291,292}$ Using antioxidants to deplete cancer cells from these ROS-induced cellular events may thus have preventive and therapeutic effects. Taken together, GANPs are biocompatible and can improve the anti-BC efficacy of gallic acid by enhancing its BC cell selectivity and antioxidant activity.

\section{Punicalagin and Ellagic Acid}

Punicalagin [2,3-(S)-hexahydroxydiphenoyl-4,6-(S,S)-gallagyl-D-glucose], the major $P$. granatum polyphenol, is an ellagitannin that has been reported to mediate anti-BC effects via the downregulation of golgi phosphoprotein 3 (GOLPH3) and consequent modulation of metastasisrelated and EMT markers, as well as its antioxidant activity and consequent inhibition of oxidative DNA damage. $^{293,294}$ However, ellagitannins are not absorbable in the gastrointestinal tract. ${ }^{295}$ They usually undergo physiological $\mathrm{pH}$ - and/or gut microbiota-facilitated hydrolysis in the stomach or small intestine to yield ellagic acid (2,3,7,8-tetrahydroxychromeno[5,4,3-cde]chromene-5,10dione). ${ }^{295}$ Ellagic acid can be subjected to further metabolism by colonic microbiota to yield bioavailable urolithins. $^{296}$ Similar to punicalagin, ellagic acid has demonstrated anti-BC activities preclinically, with the associated molecular mechanisms being the inhibition of angiogenesis via vascular endothelial growth factor receptor 2 (VEGFR2) signalling pathway suppression; ${ }^{297}$ the regulation of transforming growth factor-beta (TGF$\beta) /$ Smads signalling pathway; ${ }^{298}$ the suppression of $\beta$ catenin signalling pathway via actinin alpha 4 (ACTN4) downregulation and consequent downregulation of stemlike markers, cyclins and mesenchymal markers; ${ }^{299}$ as well as the inhibition of CDK6 expression and activity. ${ }^{300}$ However, the poor absorption and bioavailability of punicalagin and ellagic acid, together with the short elimination half-life of ellagic acid, can limit their in vivo antiBC efficacies. ${ }^{301,302}$

A polymer-based nanoformulation of punicalagin and ellagic acid has been reported by Shirode et al. ${ }^{189}$ In the study, it was found that punicalagin- and ellagic acidencapsulated PLGA-PEG nanoparticles could exert significantly greater growth-inhibitory effects on MCF-7 and Hs578T cells than free punicalagin and ellagic acid. Interestingly, punicalagin-encapsulated PLGA-PEG nanoparticles were more potent than ellagic acid-encapsulated PLGA-PEG nanoparticles in both MCF-7 ( $\mathrm{IC}_{50}$ values of $7.5 \mu \mathrm{M}$ vs $50.5 \mu \mathrm{M})$ and $\mathrm{Hs} 578 \mathrm{~T}\left(\mathrm{IC}_{50}\right.$ values of $4.1 \mu \mathrm{M}$ vs $83.5 \mu \mathrm{M})$ cell lines.

\section{Sulforaphane}

Sulforaphane [1-isothiocyanato-4-(methylsulfinyl)butane] is an isothiocyanate organosulfur compound that naturally occurs in the form of biologically inactive glucoraphanin in cruciferous vegetables, especially Brassica oleracea (broccoli). ${ }^{303}$ The conversion of glucoraphanin to sulforaphane occurs via myrosinase-catalysed hydrolysis and/or gut microbiota-mediated degradation. ${ }^{303}$ Sulforaphane has been extensively investigated for a range of pharmacological properties, including anti-aging, ${ }^{304}$ anti-inflammatory, ${ }^{305}$ antimicrobial, $^{306}$ antioxidant, ${ }^{307}$ hypoglycemic ${ }^{308}$ and neureportective $^{309}$ activities. Sulforaphane has also been preclinically recognised as a promising anti-BC candidate. ${ }^{310-313}$ Its anti-BC effects have been proposed to be mediated via the targeting of heat shock response and consequent modulation of tumour suppressors and induction of caspase-dependent apoptosis; ${ }^{310}$ the suppression of PI3K/AKT/mTOR/ribosomal protein S6 kinase 1 (S6K1) signalling pathway and consequent induction of autophagy and inhibition of protein synthesis; ${ }^{311}$ the disruption of histone deacetylase 5-lysine-specific histone demethylase 1A (HDAC5-LSD1) axis and consequent upregulation of tumour suppressor genes; ${ }^{312}$ as well as the modulation of markers associated with aggressive phenotype (eg, downregulation of EMT markers, metastasis-related markers, pro-inflammatory cytokines and pro-angiogenic growth factors). ${ }^{313}$ However, the industralisation of sulforaphane has been hindered due to its low aqueous solubility as well as instability resulting from high sensitivity to light, $\mathrm{pH}$, temperature and oxygen. ${ }^{314}$

In a study, it was found that sulforaphane-encapsulated PEGylated $\mathrm{Fe}_{3} \mathrm{O}_{4} @$ AuNPs (SF/PEGylated $\mathrm{Fe}_{3} \mathrm{O}_{4} @$ @unPs; $0-15 \mu \mathrm{M}$ ) could exert greater cytotoxicity against SKBR3 cells than free sulforaphane, possibly due to enhanced stability of sulforaphane and its preferential release under acidic conditions provided by this nanoformulation. ${ }^{250}$ The cytotoxicity of SF/PEGylated $\mathrm{Fe}_{3} \mathrm{O}_{4} @$ AuNPs against SKBR3 cells was mediated by apoptosis induction, whereby downregulation of Bcl-2 and upregulation of Bax were observed. The further observation of MMP-9 downregulation reflected the anti-migratory potential of SF/PEGylated 
$\mathrm{Fe}_{3} \mathrm{O}_{4} @$ AuNPs in SKBR3 cells. Collectively, these findings suggest that the encapsulation of sulforaphane into PEGylated $\mathrm{Fe}_{3} \mathrm{O}_{4} @$ AuNPs can enhance its anti-BC efficacy, and this nanoformulation exhibits pro-apoptotic and antimigratory activities against $\mathrm{BC}$ cells.

\section{Future Perspectives}

Plant-based natural products have long been recognised as a vital source of anti-cancer drugs. This review introduces nine selected medicinal plants, including A. capillus-veneris, $P$. quadriaurita, A. muricata, I. turpethum, M. jalapa, P. amboinicus, $P$. granatum, $P$. roxburghii and $Z$. multiflora, the extracts/essential oils of which have been evaluated for anti-BC potentials. Another nine natural bioactive compounds that have previously demonstrated anti-BC potentials, including balanocarpol, cordycepin, curcumin, diallyl disulfide, EGCG, gallic acid, punicalagin, ellagic acid and sulforaphane, have also been highlighted. Mechanistic studies have linked the anti-BC activities of these natural products to a wide range of molecular targets or mechanisms, including the modulation of angiogenesis, apoptotic pathways, autophagy, cell cycle regulators, cellular eicosanoid profile, DNA structure, synthesis, repair genes and damage response, EMT markers, enzymes, epigenetic mechanisms, glucose metabolism, heat shock response, immune system, inflammation, markers associated with aggressive phenotype, metastasis-related markers, miRNA, oxidative status, proliferation markers, protein synthesis, RNA synthesis, signalling pathways, stem-like markers and tumour suppressors. However, there is a lack of investigation into the anti-BC mechanisms of I. turpethum, M. jalapa, P. amboinicus and $P$. roxburghii extracts, which represents a future research direction to be addressed.

Although the abovementioned natural products have shown promising anti-BC activities in preclinical studies, they have not been advanced further into clinical settings. This may be attributed to their undesirable physicochemical properties, which may result in poor stability, aqueous solubility and bioavailability that can adversely influence their anti-BC efficacies in humans. There have been attempts to resolve these issues, particularly via the employment of NDDSs. Carbon-based nanocarriers, dendrimers, lipid-based nanocarriers, polymer-based nanocarriers, protein-based nanocarriers, metallic nanoparticles and MSNs represent the major classes of NDDSs that have been exploited for BC therapy. As each of these NDDS classes is associated with different advantages and disadvantages, the selection of the best suited delivery system for a specific natural product is critical.

The development of nanoformulation has been reported for all selected natural products. In particular, curcumin has attracted the greatest research interests, where dendrosomes, liposomes, polymer-based nanocarriers, proteinbased nanocarriers, metallic nanoparticles and MSNs have all been employed as NDDSs for curcumin. Generally, an enhancement in anti-BC efficacy and a reduction in toxicity to normal cells have been observed with nanoformulations as opposed to their free counterparts. These observed benefits are intensified when the surface of nanoformulations are conjugated with targeting ligands (eg, anti-RAGE antibody and BBN) to achieve active $\mathrm{BC}$ cell targeting. In addition, nanoformulations of curcumin (ie, Cur/GA Ald-Gel nanogels, Cur/PEGylated $\mathrm{Fe}_{3} \mathrm{O}_{4} @$ AuNPs and Cur-Ca@DMSNs-FA), diallyl disulfide (ie, DADS-SLNs), gallic acid (ie, GANPs) and sulforaphane (ie, SF/PEGylated $\mathrm{Fe}_{3} \mathrm{O}_{4} @$ @ AuNPs) also have the tendency to release encapsulated natural products under acidic conditions, which enables the targeting of breast tumours with acidic TME. Furthermore, nanoformulations of cordycepin (ie, CPNPs), curcumin (ie, Cur/GA Ald-Gel nanogels and Cur/Gel nanoparticles), diallyl disulfide (ie, DADS-SLNs) and EGCG (ie, EGCG-SLNs) exhibit sustained release properties, thus prolonging the anti-BC actions of these natural products. Notably, nanoformulated I. turpethum extract (ie, I. turpethum extract-loaded NIPAAM-VP-AA co-polymeric nanoparticles), P. granatum extract (ie, $P$. granatum extract-loaded PLGA-PEG nanoparticles), $P$. roxburghii extract (ie, PJSNPs) and ZEO (ie, CP-ZEO NE) as well as nanoformulated curcumin (ie, DNC and CEANs), diallyl disulfide (ie, DADSSLNs and RAGE-DADS-SLNs), EGCG (ie, EGCG-SLNs and BBN-conjugated EGCG-SLNs), gallic acid (ie, GANPs), punicalagin and ellagic acid (ie, punicalaginand ellagic acid-encapsulated PLGA-PEG nanoparticles) have shown anti-cancer activities in preclinical TNBC models, and thus are highly promising for further development. Of note, in addition to the surface modification and release properties of nanoformulations mentioned above, other aspects such as the efficiency and cost of their preparation should also be considered to ensure the feasible development of these nanoformulations.

Despite the abovementioned promising preclinical findings, however, it is of the utmost importance to establish the biocompatibility or safety profiles of these nanoformulated natural products. While AMSNPs, 
unconjugated and anti-EpCAM antibody-conjugated RIPMJ nanoparticles, $P$. granatum extract-loaded SLNs, PJSNPs, CP-ZEO NE, CPNPs, DNC, Cur/GA Ald-Gel nanogels, curcumin-loaded PVA/CNC hydrogel membranes, pectin-curcumin conjugates, DADS-SLNs and GANPs have been confirmed to be biocompatible with preclinical models by current studies, further studies are required to ascertain the biocompatibility of other nanoformulations in preclinical models and subsequently, all nanoformulations in humans. Additionally, strategies that may further improve the functionality of nanoformulated natural products in humans should also be considered. ${ }^{315}$ For example, nanoformulations could be tailored to be responsive to biological cues in the TME (eg, $\mathrm{pH}$ and redox status) or external cues (eg, magnetic field and ultrasound) for enhancing precision in the delivery and release of natural products. Moreover, the TME could also be reprogrammed to enhance the tumour accumulation of nanoformulations. For instance, passive and active tumour targeting of nanoformulations may be improved via the promotion of tumour vascular permeability and the upregulation of receptor expression, respectively. Furthermore, the development of nanoformulations with transcytosis capability may also facilitate deep tumour penetration. These represent some interesting aspects that may be important for the future development of more functional nanoformulated natural products.

\section{Consent for Publication}

The final version of the manuscript was reviewed by all the authors who consented to its submission and publication.

\section{Acknowledgments}

The authors acknowledge Faculty of Pharmacy, AIMST University, Kedah, Malaysia and Universiti Kuala Lumpur Royal College of Medicine Perak, Ipoh, Perak, Malaysia for providing the facilities and services required to complete the study. The figures and graphical abstract in this manuscript were created with BioRender.com (with the support of https://biorender.com under a paid subscription).

\section{Author Contributions}

All the authors made substantial contributions to conception and design, acquisition of data, or analysis and interpretation of data; took part in drafting the article or revising it critically for important intellectual content; agreed to submit to the current journal; gave final approval of the version to be published; and agree to be accountable for all aspects of the work.

\section{Funding}

There is no funding to report.

\section{Disclosure}

The authors have no conflicts of interest associated with this work nor the publication. There was also no significant financial support for this work.

\section{References}

1. Sun YS, Zhao Z, Yang ZN, et al. Risk factors and preventions of breast cancer. Int $J$ Biol Sci. 2017;13(11):1387-1397. doi:10.7150/ijbs. 21635

2. Sung H, Ferlay J, Siegel RL, et al. Global cancer statistics 2020: GLOBOCAN estimates of incidence and mortality worldwide for 36 cancers in 185 countries. CA Cancer J Clin. 2021;71(3):209249. doi:10.3322/caac. 21660

3. Wang L. Early diagnosis of breast cancer. Sensors. 2017;17 (7):1572. doi:10.3390/s17071572

4. Hattori M, Iwata $\mathrm{H}$. Advances in treatment and care in metastatic breast cancer (MBC): are there MBC patients who are curable? Chin Clin Oncol. 2018;7(3):23. doi:10.21037/cco.2018.05.01

5. Jin X, Mu P. Targeting breast cancer metastasis. Breast Cancer Basic Clin Res. 2015;9(Suppl 1):23-34. doi:10.4137/BCBCR. S25460

6. Peart O. Metastatic breast cancer. Radiol Technol. 2017;88 (5):519M-539M.

7. Dai X, Li T, Bai Z, et al. Breast cancer intrinsic subtype classification, clinical use and future trends. Am J Cancer Res. 2015;5 (10):2929-2943.

8. Yersal O, Barutca S. Biological subtypes of breast cancer: prognostic and therapeutic implications. World J Clin Oncol. 2014;5 (3):412-424. doi:10.5306/wjco.v5.i3.412

9. Mehanna J, Haddad FG, Eid R, Lambertini M, Kourie HR. Triplenegative breast cancer: current perspective on the evolving therapeutic landscape. Int $J$ Womens Health. 2019;11:431-437. doi:10.2147/IJWH.S178349

10. Talluri SV, Pindiprolu SKSS, Chintamaneni PK, Tummala S, Nandha Kumar S. RAGE receptor targeted bioconjuguate lipid nanoparticles of diallyl disulfide for improved apoptotic activity in triple negative breast cancer: in vitro studies. Artif Cells Nanomedicine Biotechnol. 2017;46(2):387-397. doi:10.1080/ 21691401.2017.1313267

11. Cheung KL. Treatment strategies and survival outcomes in breast cancer. Cancers (Basel). 2020;12(3):735. doi:10.3390/ cancers 12030735

12. Waks AG, Winer EP. Breast cancer treatment: a review. $J \mathrm{Am}$ Med Assoc. 2019;321(3):288-300. doi:10.1001/jama.2018.19323

13. Anampa J, Makower D, Sparano JA. Progress in adjuvant chemotherapy for breast cancer: an overview. BMC Med. 2015;13:113. doi:10.1186/s12916-015-0439-8

14. Luque-Bolivar A, Pérez-Mora E, Villegas VE, Rondón-Lagos M. Resistance and overcoming resistance in breast cancer. Breast Cancer Targets Ther. 2020;12:211-229. doi:10.2147/BCTT. S270799

15. Dias DA, Urban S, Roessner U. A historical overview of natural products in drug discovery. Metabolites. 2012;2(2):303-336. doi: $10.3390 /$ metabo2020303 
16. Atanasov AG, Zotchev SB, Dirsch VM, Supuran CT. Natural products in drug discovery: advances and opportunities. Nat Rev Drug Discov. 2021;20(3):200-216. doi:10.1038/s41573-02000114-z

17. Cragg GM, Pezzuto JM. Natural products as a vital source for the discovery of cancer chemotherapeutic and chemopreventive agents. Med Princ Pract. 2016;25(Suppl 2):41-59. doi:10.1159/ 000443404

18. Beutler JA. Natural products as a foundation for drug discovery. Curr Protoc Pharmacol. 2009;46:9-11. doi:10.1002/0471141755. ph0911s46

19. Kooti W, Servatyari K, Behzadifar M, et al. Effective medicinal plant in cancer treatment, part 2: review study. J Evid Based Complementary Altern Med. 2017;22(4):982-995. doi:10.1177/ 2156587217696927

20. Kapinova A, Kubatka P, Golubnitschaja O, et al. Dietary phytochemicals in breast cancer research: anticancer effects and potential utility for effective chemoprevention. Environ Health Prev Med. 2018;23:1-18. doi:10.1186/s12199-018-0724-1

21. Rezadoost MH, Kumleh HH, Ghasempour A. Cytotoxicity and apoptosis induction in breast cancer, skin cancer and glioblastoma cells by plant extracts. Mol Biol Rep. 2019;46(5):5131-5142. doi:10.1007/s11033-019-04970-w

22. Gautam N, Mantha AK, Mittal S. Essential oils and their constituents as anticancer agents: a mechanistic view. Biomed Res Int. 2014;2014:154106. doi:10.1155/2014/154106

23. Bayala B, Bassole IH, Scifo R, et al. Anticancer activity of essential oils and their chemical components - a review. Am $J$ Cancer Res. 2014;4(6):591-607.

24. Sharifi-Rad J, Sureda A, Tenore GC, et al. Biological activities of essential oils: from plant chemoecology to traditional healing systems. Molecules. 2017;22(1):70. doi:10.3390/molecules22 010070

25. Turek C, Stintzing FC. Stability of essential oils: a review. Compr Rev Food Sci Food Saf. 2013;12(1):40-53. doi:10.1111/15414337.12006

26. Aung TN, Qu Z, Kortschak RD, Adelson DL. Understanding the effectiveness of natural compound mixtures in cancer through their molecular mode of action. Int J Mol Sci. 2017;18(3):656. doi:10.3390/ijms18030656

27. Kesarwani K, Gupta R, Mukerjee A. Bioavailability enhancers of herbal origin: an overview. Asian Pac J Trop Biomed. 2013;3 (4):253-266. doi:10.1016/S2221-1691(13)60060-X

28. Sulaiman GM, Waheeb HM, Jabir MS, Khazaal SH, Dewir YH, Naidoo Y. Hesperidin loaded on gold nanoparticles as a drug delivery system for a successful biocompatible, anti-cancer, anti-inflammatory and phagocytosis inducer model. Sci Rep. 2020;10(1):9362. doi:10.1038/s41598-020-66419-6

29. Jabir M, Sahib UI, Taqi Z, et al. Linalool-loaded glutathionemodified gold nanoparticles conjugated with CALNN peptide as apoptosis inducer and NF- $\mathrm{KB}$ translocation inhibitor in SKOV-3 cell line. Int $J$ Nanomedicine. 2020;2020(15):9025-9047. doi:10.2147/IJN.S276714

30. Mohammed HA, Sulaiman GM, Anwar SS, et al. Quercetin against MCF7 and CAL51 breast cancer cell lines: apoptosis, gene expression and cytotoxicity of nano-quercetin. Nanomedicine. 2021;16(22):1937-1961. doi:10.2217/nnm2021-0070

31. Li J, Ge Z, Toh K, et al. Enzymatically transformable polymersome-based nanotherapeutics to eliminate minimal relapsable cancer. Adv Mater. 2021;e2105254. doi:10.1002/adma.202105254

32. Patra JK, Das G, Fraceto LF, et al. Nano based drug delivery systems: recent developments and future prospects. $J$ Nanobiotechnology. 2018;16(1):71. doi:10.1186/s12951-0180392-8
33. Attia MF, Anton N, Wallyn J, Omran Z, Vandamme TF. An overview of active and passive targeting strategies to improve the nanocarriers efficiency to tumour sites. J Pharm Pharmacol. 2019;71(8):1185-1198. doi:10.1111/jphp.13098

34. Ho BN, Pfeffer CM, Singh ATK. Update on nanotechnologybased drug delivery systems in cancer treatment. Anticancer Res. 2017;37(11):5975-5981. doi:10.21873/anticanres.12044

35. Byrne JD, Betancourt T, Brannon-Peppas L. Active targeting schemes for nanoparticle systems in cancer therapeutics. $A d v$ Drug Deliv Rev. 2008;60(15):1615-1626. doi:10.1016/j. addr.2008.08.005

36. Rosenblum D, Joshi N, Tao W, Karp JM, Peer D. Progress and challenges towards targeted delivery of cancer therapeutics. Nat Commun. 2018;9(1):1410. doi:10.1038/s41467-018-03705-y

37. Nishida $N$, Yano $H$, Nishida $T$, Kamura $T$, Kojiro $M$. Angiogenesis in cancer. Vasc Health Risk Manag. 2006;2 (3):213-219. doi:10.2147/vhrm.2006.2.3.213

38. Kalyane D, Raval N, Maheshwari R, Tambe V, Kalia K, Tekade RK. Employment of enhanced permeability and retention effect (EPR): nanoparticle-based precision tools for targeting of therapeutic and diagnostic agent in cancer. Mater Sci Eng C. 2019;98:1252-1276. doi:10.1016/j.msec.2019.01.066

39. Colone M, Calcabrini A, Stringaro A. Drug delivery systems of natural products in oncology. Molecules. 2020;25(19):4560. doi:10.3390/molecules25194560

40. Uthaman S, Huh KM, Park IK. Tumor microenvironment-responsive nanoparticles for cancer theragnostic applications. Biomater Res. 2018;22:1-11. doi:10.1186/s40824-018-0132-z

41. Sakurai Y, Akita H, Harashima H. Targeting tumor endothelial cells with nanoparticles. Int $J$ Mol Sci. 2019;20(23):5819. doi:10.3390/ijms20235819

42. Liu CG, Han YH, Kankala RK, Wang SB, Chen AZ. Subcellular performance of nanoparticles in cancer therapy. Int $J$ Nanomedicine. 2020;15:675-704. doi:10.2147/IJN.S226186

43. Markman JL, Rekechenetskiy A, Holler E, Ljubimova JY. Nanomedicine therapeutic approaches to overcome cancer drug resistance. Adv Drug Deliv Rev. 2013;65(13-14):1866-1879. doi:10.1016/j.addr.2013.09.019

44. Wu D, Si M, Xue HY, Wong HL. Nanomedicine applications in the treatment of breast cancer: current state of the art. Int $J$ Nanomedicine. 2017;12:5879-5892. doi:10.2147/IJN.S123437

45. Rauti R, Musto M, Bosi S, Prato M, Ballerini L. Properties and behavior of carbon nanomaterials when interfacing neuronal cells: how far have we come? Carbon N Y. 2018;143430-143446. doi:10.1016/j.carbon.2018.11.026

46. Cha C, Shin SR, Annabi N, Dokmeci MR, Khademhosseini A. Carbon-based nanomaterials: multi-functional materials for biomedical engineering. ACS Nano. 2013;7(4):2891-2897. doi:10.1021/nn401196a

47. Maiti D, Tong X, Mou X, Yang K. Carbon-based nanomaterials for biomedical applications: a recent study. Front Pharmacol. 2018;9:1401. doi:10.3389/fphar.2018.01401

48. Garriga R, Herrero-Continente T, Palos M, et al. Toxicity of carbon nanomaterials and their potential application as drug delivery systems: in vitro studies in Caco-2 and MCF-7 cell lines. Nanomaterials. 2020;10(8):1617. doi:10.3390/nano100 81617

49. Yang Q, Wang XD, Chen J, et al. A clinical study on regional lymphatic chemotherapy using an activated carbon nanoparticleepirubicin in patients with breast cancer. Tumor Biol. 2012;33 (6):2341-2348. doi:10.1007/s13277-012-0496-y

50. Madaan K, Kumar S, Poonia N, Lather V, Pandita D. Dendrimers in drug delivery and targeting: drug-dendrimer interactions and toxicity issues. J Pharm Bioallied Sci. 2014;6(3):139-150. doi:10.4103/0975-7406.130965 
51. Abbasi E, Aval SF, Akbarzadeh A, et al. Dendrimers: synthesis, applications, and properties. Nanoscale Res Lett. 2014;9(1):247. doi:10.1186/1556-276X-9-247

52. Chis AA, Dobrea C, Morgovan C, et al. Applications and limitations of dendrimers in biomedicine. Molecules. 2020;25 (17):3982. doi: $10.3390 /$ molecules 25173982

53. Chauhan AS. Dendrimers for drug delivery. Molecules. 2018;23 (4):938. doi:10.3390/molecules23040938

54. Wolinsky JB, Grinstaff MW. Therapeutic and diagnostic applications of dendrimers for cancer treatment. Adv Drug Deliv Rev. 2008;60(9):1037-1055. doi:10.1016/j.addr.2008.02.012

55. Palmerston Mendes L, Pan J, Torchilin VP. Dendrimers as nanocarriers for nucleic acid and drug delivery in cancer therapy. Molecules. 2017;22(9):1401. doi:10.3390/molecules22091401

56. Janaszewska A, Lazniewska J, Trzepiński P, Marcinkowska M, Klajnert-Maculewicz B. Cytotoxicity of dendrimers. Biomolecules. 2019;9(8):330. doi:10.3390/biom9080330

57. Starpharma. DEP ${ }^{\circledR}$ docetaxel positive Phase 1 results; Phase 2 commences; 2017. Available from: https://starpharma.com/news/ 339. Accessed August 2, 2021.

58. Starpharma. DEP ${ }^{\circledR}$ irinotecan phase 2 commences after positive phase 1 results; 2020. Available from: https://www.starpharma. $\mathrm{com} /$ news/story/dep-irinotecan-phase-2-commences-after-posi tive-phase-1-results. Accessed August 2, 2021.

59. Arias JL, Clares B, Morales ME, Gallardo V, Ruiz MA. Lipid-based drug delivery systems for cancer treatment. Curr Drug Targets. 2011;12(8):1151-1165. doi:10.2174/138945011795906570

60. García-Pinel B, Porras-Alcalá C, Ortega-Rodríguez A, et al. Lipid-based nanoparticles: application and recent advances in cancer treatment. Nanomaterials. 2019;9(4):638. doi:10.3390/ nano9040638

61. Yingchoncharoen P, Kalinowski DS, Richardson DR. Lipid-based drug delivery systems in cancer therapy: what is available and what is yet to come. Pharmacol Rev. 2016;68(3):701-787. doi: $10.1124 /$ pr. 115.012070

62. Habib S, Singh M. Recent advances in lipid-based nanosystems for gemcitabine and gemcitabine-combination therapy. Nanomaterials. 2021;11(3):597. doi:10.3390/nano11030597

63. Barenholz Y. Doxil ${ }^{\circledR}$-the first FDA-approved nano-drug: lessons learned. J Control Release. 2012;160(2):117-134. doi:10.1016/j. jconrel.2012.03.020

64. Ventola CL. Progress in nanomedicine: approved and investigational nanodrugs. Pharm Ther. 2017;42(12):742-755.

65. Bulbake U, Doppalapudi S, Kommineni N, Khan W. Liposomal formulations in clinical use: an updated review. Pharmaceutics. 2017;9(2):12. doi:10.3390/pharmaceutics9020012

66. Salehi B, Selamoglu Z, Mileski KS, et al. Liposomal cytarabine as cancer therapy: from chemistry to medicine. Biomolecules. 2019;9(12):773. doi:10.3390/biom9120773

67. Le Rhun E, Wallet J, Mailliez A, et al. Intrathecal liposomal cytarabine plus systemic therapy versus systemic chemotherapy alone for newly diagnosed leptomeningeal metastasis from breast cancer. Neuro Oncol. 2020;22(4):524-538. doi:10.1093/neuonc/noz201

68. Chen S, Hanning S, Falconer J, Locke M, Wen J. Recent advances in non-ionic surfactant vesicles (niosomes): fabrication, characterization, pharmaceutical and cosmetic applications. Eur $J$ Pharm Biopharm. 2019;144:18-39. doi:10.1016/j.ejpb.20 19.08.015

69. Bartelds R, Nematollahi MH, Pols T, et al. Niosomes, an alternative for liposomal delivery. PLoS One. 2018;13(4):e0194179. doi:10.1371/journal.pone.0194179

70. Kanaani L, Javadi I, Ebrahimifar M, Ebrahimi Shahmabadi H, Akbarzadeh Khiyav A, Mehrdiba T. Effects of cisplatin-loaded niosomal nanoparticles on BT-20 human breast carcinoma cells. Asian Pacific J Cancer Prev. 2017;18(2):365-368. doi:10.22034/ APJCP.2017.18.2.365
71. Nowroozi F, Dadashzadeh S, Soleimanjahi H, et al. Theranostic niosomes for direct intratumoral injection: marked enhancement in tumor retention and anticancer efficacy. Nanomedicine. 2018;13(17):2201-2219. doi:10.2217/nnm-2018-0091

72. Salem HF, Kharshoum RM, Abo El-Ela FI, Amr Gamal F, Abdellatif KRA. Evaluation and optimization of $\mathrm{pH}$-responsive niosomes as a carrier for efficient treatment of breast cancer. Drug Deliv Transl Res. 2018;8(3):633-644. doi:10.1007/s13346-018-0499-3

73. Duan Y, Dhar A, Patel C, et al. A brief review on solid lipid nanoparticles: part and parcel of contemporary drug delivery systems. RSC Adv. 2020;10:26777-26791. doi:10.1039/ D0RA03491F

74. Kang KW, Chun MK, Kim O, et al. Doxorubicin-loaded solid lipid nanoparticles to overcome multidrug resistance in cancer therapy. Nanomedicine. 2010;6(2):210-213. doi:10.1016/j. nano.2009.12.006

75. Garg NK, Singh B, Jain A, et al. Fucose decorated solid-lipid nanocarriers mediate efficient delivery of methotrexate in breast cancer therapeutics. Colloids Surfaces B Biointerfaces. 2016;146:114-126. doi:10.1016/j.colsurfb.2016.05.051

76. $\mathrm{Xu} \mathrm{W}, \mathrm{Bae} \mathrm{EJ}$, Lee MK. Enhanced anticancer activity and intracellular uptake of paclitaxel-containing solid lipid nanoparticles in multidrug-resistant breast cancer cells. Int J Nanomedicine. 2018;13:7549-7563. doi:10.2147/IJN.S182621

77. Guney Eskiler G, Cecener G, Dikmen G, Egeli U, Tunca B. Solid lipid nanoparticles: reversal of tamoxifen resistance in breast cancer. Eur J Pharm Sci. 2018;120:73-88. doi:10.1016/j. ejps.2018.04.040

78. Ghasemiyeh P, Mohammadi-Samani S. Solid lipid nanoparticles and nanostructured lipid carriers as novel drug delivery systems: applications, advantages and disadvantages. Res Pharm Sci. 2018;13(4):288-303. doi:10.4103/1735-5362.235156

79. Pandey P, Dureja H. Recent patents on polymeric nanoparticles for cancer therapy. Recent Pat Nanotechnol. 2018;12(2):155-169. doi: $10.2174 / 1872210512666180327120648$

80. Dadwal A, Baldi A, Kumar Narang R. Nanoparticles as carriers for drug delivery in cancer. Nanomed Biotechnol. 2018;46:295305. doi:10.1080/21691401.2018.1457039

81. Gutierrez Cisneros C, Bloemen V, Mignon A. Synthetic, natural, and semisynthetic polymer carriers for controlled nitric oxide release in dermal applications: a review. Polymers. 2021;13 (5):760. doi:10.3390/polym 13050760

82. Sithole MN, Choonara YE, Du Toit LC, Kumar P, Pillay V. A review of semi-synthetic biopolymer complexes: modified polysaccharide nano-carriers for enhancement of oral drug bioavailability. Pharm Dev Technol. 2017;22(2):283-295. doi:10.1080/ 10837450.2016.1212882

83. Wong $\mathrm{KH}$, Lu A, Chen X, Yang Z. Natural ingredient-based polymeric nanoparticles for cancer treatment. Molecules. 2020;25(16):3620. doi:10.3390/molecules25163620

84. Avramović N, Mandić B, Savić-Radojević A, Simić T. Polymeric nanocarriers of drug delivery systems in cancer therapy. Pharmaceutics. 2020;12(4):298. doi:10.3390/pharmace utics 12040298

85. Liu Z, Jiao Y, Wang Y, Zhou C, Zhang Z. Polysaccharides-based nanoparticles as drug delivery systems. Adv Drug Deliv Rev. 2008;60(15):1650-1662. doi:10.1016/j.addr.2008.09.001

86. El-Say KM, El-Sawy HS. Polymeric nanoparticles: promising platform for drug delivery. Int J Pharm. 2017;528(1-2):675691. doi:10.1016/j.ijpharm.2017.06.052

87. Park IH, Sohn JH, Kim SB, et al. An open-label, randomized, parallel, phase III trial evaluating the efficacy and safety of polymeric micelle-formulated paclitaxel compared to conventional Cremophor EL-based paclitaxel for recurrent or metastatic HER2-negative breast cancer. Cancer Res Treat. 2017;49 (3):569-577. doi:10.4143/crt.2016.289 
88. Sevastre A-S, Horescu C, Baloi SC, et al. Benefits of nanomedicine for therapeutic intervention in malignant diseases. Coatings. 2019;9:628. doi:10.3390/coatings9100628

89. Bernabeu E, Cagel M, Lagomarsino E, Moretton M, Chiappetta DA. Paclitaxel: what has been done and the challenges remain ahead. Int $J$ Pharm. 2017;526(1-2):474-495. doi:10.1016/j. ijpharm.2017.05.016

90. Northfelt DW, Allred JB, Liu H, et al.; North Central Cancer Treatment Group. Phase 2 trial of paclitaxel polyglumex with capecitabine for metastatic breast cancer. Am J Clin Oncol. 2014;37(2):167-171. doi:10.1097/COC.0b013e31826e0550

91. Sandra F, Khaliq NU, Sunna A, Care A. Developing proteinbased nanoparticles as versatile delivery systems for cancer therapy and imaging. Nanomaterials. 2019;9(9):1329. doi:10.3390/ nano9091329

92. Diaz D, Care A, Sunna A. Bioengineering strategies for proteinbased nanoparticles. Genes. 2018;9(7):370. doi:10.3390/ genes 9070370

93. Hong S, Choi DW, Kim HN, Park CG, Lee W, Park HH. Proteinbased nanoparticles as drug delivery systems. Pharmaceutics. 2020;12(7):604. doi:10.3390/pharmaceutics 12070604

94. Jain A, Singh SK, Arya SK, Kundu SC, Kapoor S. Protein nanoparticles: promising platforms for drug delivery. $A C S$ Biomater Sci Eng. 2018;4(12):3939-3961. doi:10.1021/ acsbiomaterials. $8 \mathrm{~b} 01098$

95. Takakura Y, Fujita T, Hashida M, Sezaki H. Disposition characteristics of macromolecules in tumor-bearing mice. Pharm Res. 1990;7(4):339-346. doi:10.1023/a:1015807119753

96. Miele E, Spinelli GP, Miele E, Tomao F, Tomao S. Albuminbound formulation of paclitaxel (Abraxane ${ }^{\circledR} \mathrm{ABI}-007$ ) in the treatment of breast cancer. Int $J$ Nanomedicine. 2009;4:99. doi:10.2147/ijn.s3061

97. Wolfram J, Ferrari M. Clinical cancer nanomedicine. Nano Today. 2019;25:85-98. doi:10.1016/j.nantod.2019.02.005

98. Gonzalez-Angulo AM, Meric-Bernstam F, Chawla S, et al. Weekly nab-rapamycin in patients with advanced nonhematologic malignancies: final results of a phase 1 trial. Clin Cancer Res. 2013;19(19):5474-5484. doi:10.1158/1078-0432.CCR-12-3110

99. Kesari S, Juarez T, Carrillo J, et al. RBTT-01. A phase 2 trial with ABI-009 (nab-sirolimus) as single-agent and combinations in recurrent high-grade glioma (rHGG) and in newly diagnosed glioblastoma (ndGBM). Neuro Oncol. 2019;21(Suppl6):vi218vi219. doi:10.1093/neuonc/noz175.913

100. Wagner AJ, Ravi V, Ganjoo KN, et al. ABI-009 (nab-sirolimus) in advanced malignant perivascular epithelioid cell tumors (PEComa): preliminary efficacy, safety, and mutational status from AMPECT, an open label phase II registration trial. $J$ Clin Oncol. 2019;37(15):11005. doi:10.1200/JCO.2019.37.15_sup pl.11005

101. Desai N, Momin M, Khan T, Gharat S, Ningthoujam RS, Omri A. Metallic nanoparticles as drug delivery system for the treatment of cancer. Expert Opin Drug Deliv. 2021;1-30. doi:10.1080/ 17425247.2021.1912008

102. Sharma A, Goyal AK, Rath G. Recent advances in metal nanoparticles in cancer therapy. J Drug Target. 2018;26(8):617-632. doi:10.1080/1061186X.2017.1400553

103. Chugh H, Sood D, Chandra I, Tomar V, Dhawan G, Chandra R. Role of gold and silver nanoparticles in cancer nano-medicine. Artif Cells Nanomedicine Biotechnol. 2018;46:1210-1220. doi:10.1080/21691401.2018.1449118

104. Vinardell MP, Mitjans M. Antitumor activities of metal oxide nanoparticles. Nanomaterials. 2015;5(2):1004-1021. doi:10.339 0/nano5021004

105. Cherukuri P, Glazer ES, Curley SA. Targeted hyperthermia using metal nanoparticles. Adv Drug Deliv Rev. 2010;62(3):339-345. doi:10.1016/j.addr.2009.11.006
106. Gobbo OL, Sjaastad K, Radomski MW, Volkov Y, Prina-Mello A. Magnetic nanoparticles in cancer theranostics. Theranostics. 2015;5(11):1249-1263. doi:10.7150/thno.11544

107. Ahmad MZ, Akhter S, Jain GK, et al. Metallic nanoparticles: technology overview \& drug delivery applications in oncology. Expert Opin Drug Deliv. 2010;7(8):927-942. doi:10.1517/ 17425247.2010.498473

108. Anderson SD, Gwenin VV, Gwenin CD. Magnetic functionalized nanoparticles for biomedical, drug delivery and imaging applications. Nanoscale Res Lett. 2019;14:1-16. doi:10.1186/s11671019-3019-6

109. Anselmo AC, Mitragotri S. A review of clinical translation of inorganic nanoparticles. AAPS J. 2015;17(5):1041-1054. doi:10.1208/s12248-015-9780-2

110. Libutti SK, Paciotti GF, Byrnes AA, et al. Phase I and pharmacokinetic studies of CYT-6091, a novel PEGylated colloidal goldrhTNF nanomedicine. Clin Cancer Res. 2010;16(24):6139-6149. doi:10.1158/1078-0432.CCR-10-0978

111. Schrand AM, Rahman MF, Hussain SM, Schlager JJ, Smith DA, Syed AF. Metal-based nanoparticles and their toxicity assessment. Nanomed Nanobiotechnol. 2010;2(5):544-568. doi:10.1002/ wnan. 103

112. Mohamed Isa ED, Ahmad H, Abdul Rahman MB, Gill MR. Progress in mesoporous silica nanoparticles as drug delivery agents for cancer treatment. Pharmaceutics. 2021;13(2):152. doi:10.3390/pharmaceutics13020152

113. Vallet-Regí M, Colilla M, Izquierdo-Barba I, Manzano M. Mesoporous silica nanoparticles for drug delivery: current insights. Molecules. 2018;23(1):47. doi:10.3390/molecu les 23010047

114. Lodha A, Lodha M, Patel A, et al. Synthesis of mesoporous silica nanoparticles and drug loading of poorly water soluble drug cyclosporin A. J Pharm Bioallied Sci. 2012;4:S92-S94. doi:10.4103/0975-7406.94153

115. Li T, Shi S, Goel S, et al. Recent advancements in mesoporous silica nanoparticles towards therapeutic applications for cancer. Acta Biomater. 2019;89:1-13. doi:10.1016/j.actbio.2019.02.031

116. Vallet-Regí M, Rámila A, Del Real RP, Pérez-Pariente J. A new property of MCM-41: drug delivery system. Chem Mater. 2001;13:308-311. doi:10.1021/cm0011559

117. Bhavsar DB, Patel V, Sawant KK. Design and characterization of dual responsive mesoporous silica nanoparticles for breast cancer targeted therapy. Eur J Pharm Sci. 2020;152:105428. doi:10.1016/j.ejps.2020.105428

118. Hanafi-Bojd MY, Moosavian Kalat SA, Taghdisi SM, Ansari L, Abnous K, Malaekeh-Nikouei B. MUC1 aptamer-conjugated mesoporous silica nanoparticles effectively target breast cancer cells. Drug Dev Ind Pharm. 2018;44(1):13-18. doi:10.1080/ 03639045.2017.1371734

119. Wang Y, Xie Y, Kilchrist KV, Li J, Duvall CL, Oupický D. Endosomolytic and tumor-penetrating mesoporous silica nanoparticles for siRNA/miRNA combination cancer therapy. ACS Appl Mater Interfaces. 2020;12(4):4308-4322. doi:10.1021/acsami.9b21214

120. Ngamcherdtrakul W, Morry J, Gu S, et al. Cationic polymer modified mesoporous silica nanoparticles for targeted siRNA delivery to HER2+ breast cancer. Adv Funct Mater. 2015;25 (18):2646-2659. doi:10.1002/adfm.201404629

121. Hozayen WG, Mahmoud AM, Desouky EM, El-Nahass ES, Soliman HA, Farghali AA. Cardiac and pulmonary toxicity of mesoporous silica nanoparticles is associated with excessive ROS production and redox imbalance in Wistar rats. Biomed Pharmacother. 2019;109:2527-2538. doi:10.1016/j.biopha.2018.11.093

122. Li L, Liu T, Fu C, Tan L, Meng X, Liu H. Biodistribution, excretion, and toxicity of mesoporous silica nanoparticles after oral administration depend on their shape. Nanomedicine. 2015;11(8):1915-1924. doi:10.1016/j.nano.2015.07.004 
123. Zhang Q, Xu H, Zheng S, Su M, Wang J. Genotoxicity of mesoporous silica nanoparticles in human embryonic kidney 293 cells. Drug Test Anal. 2015;7(9):787-796. doi:10.1002/ dta. 1773

124. Herranz-López M, Losada-Echeberría M, Barrajón-Catalán E. The multitarget activity of natural extracts on cancer: synergy and xenohormesis. Medicines. 2019;6(1):6. doi:10.3390/ medicines 6010006

125. Dehdari S, Hajimehdipoor H. Medicinal properties of Adiantum capillus-veneris Linn. in traditional medicine and modern phytotherapy: a review article. Iran J Public Health. 2018;47(2):188-197.

126. Ibraheim ZZ, Ahmed AS, Gouda YG. Phytochemical and biological studies of Adiantum capillus-veneris L. Saudi Pharm J. 2011;19(2):65-74. doi:10.1016/j.jsps.2011.01.007

127. Ranjan V, Vats M, Gupta N, Sardana S. Antidiabetic potential of whole plant of Adiantum capillus veneris linn. in streptozotocin induced diabetic rats. Int J Pharm Clin Res. 2014;6(4):341-347.

128. Khoramian L, Sajjadi SE, Minaiyan M. Anti-inflammatory effect of Adiantum capillus-veneris hydroalcoholic and aqueous extracts on acetic acid-induced colitis in rats. Avicenna $J$ Phytomed. 2020;10(5):492-503.

129. Singh M, Singh N, Khare PB, Rawat AK. Antimicrobial activity of some important Adiantum species used traditionally in indigenous systems of medicine. J Ethnopharmacol. 2008;115 (2):327-329. doi:10.1016/j.jep.2007.09.018

130. Haider S, Nazreen S, Alam MM, Gupta A, Hamid H, Alam MS. Anti-inflammatory and anti-nociceptive activities of ethanolic extract and its various fractions from Adiantum capillus veneris Linn. J Ethnopharmacol. 2011;138(3):741-747. doi:10.1016/j. jep.2011.10.012

131. Al-Hallaq EK, Litescu SC, Kasabri V, Abdul-Razzak KK, Afifi F. Hypocholesterolemic effects of Adiantum capillus veneris L. aqueous extract in high cholesterol diet-fed rats and HPLC-MS determination of its polyphenolics. Rev Roum Chim. 2015;6(23):355-363.

132. Nilforoushzadeh MA, Javanmard SH, Ghanadian M, et al. The effects of Adiantum capillus-veneris on wound healing: an experimental in vitro evaluation. Int J Prev Med. 2014;5(10):1261-1268.

133. Roy SC, Sajeeb BK, Muhit MA, Bachar SC. Evaluation of antioxidant and cytotoxic activities of aerial parts of Adiantum capillus-veneris L. growing in Bangladesh. Dhaka Univ J Pharm Sci. 2019;18(2):217-222. doi:10.3329/dujps.v18i2.43264

134. Zhang L, Zhang LB. Phylogeny and systematics of the brake fern genus Pteris (Pteridaceae) based on molecular (plastid and nuclear) and morphological evidence. Mol Phylogenet Evol. 2018;118:265-285. doi:10.1016/j.ympev.2017.09.011

135. Cao H, Chai TT, Wang X, et al. Phytochemicals from fern species: potential for medicine applications. Phytochem Rev. 2017;16(3):379-440. doi:10.1007/s11101-016-9488-7

136. Rautray S, Panikar S, Amutha T, Rajananthini AU. Anticancer activity of Adiantum capillus veneris and Pteris quadriureta L. in human breast cancer cell lines. Mol Biol Rep. 2018;45(6):18971911. doi:10.1007/s11033-018-4337-y

137. Rautray S, Panikar S, Sofia A, Rajananthini AU. Anti-oxidant and anti-microbial study of Adiantum capillus veneris and Pteris quadriureta L. J Med Plants Res. 2018;12(23):359-368. doi:10.5897/JMPR2018.6635

138. Gavamukulya Y, Wamunyokoli F, El-Shemy HA. Annona muricata: is the natural therapy to most disease conditions including cancer growing in our backyard? A systematic review of its research history and future prospects. Asian Pac J Trop Med. 2017;10(9):835-848. doi:10.1016/j.apjtm.2017.08.009

139. Moghadamtousi SZ, Fadaeinasab M, Nikzad S, Mohan G, Ali HM, Kadir HA. Annona muricata (Annonaceae): a review of its traditional uses, isolated acetogenins and biological activities. Int J Mol Sci. 2015;16(7):15625-15658. doi:10.3390/ijms160715625
140. Chan P, Ah R, Mh K. Anti-arthritic activities of Annona muricata L. Leaves extract on complete freund's adjuvant (CFA)-induced arthritis in rats. Planta Med. 2010;76:P166. doi:10.1055/s-00301264464

141. N'Gouemo P, Koudogbo B, Tchivounda HP, Akono-Nguema C, Etoua MM. Effects of ethanol extract of Annona muricata on pentylenetetrazol-induced convulsive seizures in mice. Phyther Res. 1997;11(3):243-245. doi:10.1002/(SICI)1099-1573(199705) 11:3<243::AID-PTR66>3.0.CO;2-A

142. Adeyemi DO, Komolafe OA, Adewole OS, Obuotor EM, Adenowo TK. Anti hyperglycemic activities of Annona muricata (Linn). African J Tradit Complement Altern Med. 2008;6 (1):62-69.

143. Ola-Davies OE, Oyagbemi AA, Omobowale TO, Akande I, Ashafa A. Ameliorative effects of Annona muricata Linn. (Annonaceae) against potassium dichromate-induced hypertension in vivo: involvement of Kim-1/p38 MAPK/Nrf2 signaling. J Basic Clin Physiol Pharmacol. 2019;30(4):1-21. doi:10.1515/ jbcpp-2018-0172

144. George VC, Kumar DR, Suresh PK, Kumar RA. Antioxidant, DNA protective efficacy and HPLC analysis of Annona muricata (soursop) extracts. J Food Sci Technol. 2015;52(4):2328-2335. doi:10.1007/s13197-014-1289-7

145. Miranda NC, Araujo ECB, Justino AB, et al. Anti-parasitic activity of Annona muricata L. leaf ethanolic extract and its fractions against Toxoplasma gondii in vitro and in vivo. $J$ Ethnopharmacol. 2021;273:114019. doi:10.1016/j.jep.20 21.114019

146. de La Cruz AMA, Catabay AP. Hypolipidemic effect of the lyophilized fruit pulp of guyabano, Annona muricata Linn. (Fam. Annonaceae) in atherogenic diet-induced hyperlipidemia in albino rats. $J$ Asian Assoc Sch Pharm. 2016;5:351-359.

147. Moghadamtousi SZ, Rouhollahi E, Hajrezaie M, Karimian H, Abdulla MA, Kadir HA. Annona muricata leaves accelerate wound healing in rats via involvement of Hsp70 and antioxidant defence. Int $J$ Surg. 2015;18:110-117. doi:10.1016/j. ijsu.2015.03.026

148. Moghadamtousi SZ, Rouhollahi E, Karimian H, Fadaeinasab M, Abdulla MA, Kadir HA. Gastroprotective activity of Annona muricata leaves against ethanol-induced gastric injury in rats via Hsp70/Bax involvement. Drug Des Devel Ther. 2014;8:20992110. doi:10.2147/DDDT.S70096

149. Padma P, Chansouria JP, Khosa RL. Hepatoprotective activity of Annona muricata Linn. and Polyalthia cerasoides bedd. Anc Sci Life. 1999;19(1-2):7-10.

150. Ishola IO, Awodele O, Olusayero AM, Ochieng CO. Mechanisms of analgesic and anti-inflammatory properties of Annona muricata Linn. (Annonaceae) fruit extract in rodents. J Med Food. 2014;17 (12):1375-1382. doi:10.1089/jmf.2013.0088

151. Syed Najmuddin SUF, Romli MF, Hamid M, Alitheen NB, Nik Abd Rahman NMA. Anti-cancer effect of Annona Muricata Linn leaves crude extract (AMCE) on breast cancer cell line. BMC Complement Altern Med. 2016;16(1):311. doi:10.1186/s12906-016-1290-y

152. Prasad SK, Veeresh PM, Ramesh PS, Natraj SM, Madhunapantula SV, Devegowda D. Phytochemical fractions from Annona muricata seeds and fruit pulp inhibited the growth of breast cancer cells through cell cycle arrest at G 0/G 1 phase. $J$ Cancer Res Ther. 2020;16(6):1235-1249. doi:10.4103/jcrt.JCRT_494_19

153. Alshaeri HK, Alasmari MM, Natto ZS, Pino-Figueroa A. Effects of Annona muricata extract on triple-negative breast cancer cells mediated through EGFR signaling. Cancer Manag Res. 2020;12:12519-12526. doi:10.2147/CMAR.S278647

154. Naik AV, Sellappan K. In vitro evaluation of Annona muricata L. (Soursop) leaf methanol extracts on inhibition of tumorigenicity and metastasis of breast cancer cells. Biomarkers. 2020;25 (8):701-710. doi:10.1080/1354750X.2020.1836025 
155. Sabapati M, Palei NN, Ashok Kumar CK, Molakpogu RB. Solid lipid nanoparticles of Annona muricata fruit extract: formulation, optimization and in vitro cytotoxicity studies. Drug Dev Ind Pharm. 2019;45(4):577-586. doi:10.1080/03639045.2019.15 69027

156. Jabir MS, Saleh YM, Sulaiman GM, et al. Green synthesis of silver nanoparticles using Annona muricata extract as an inducer of apoptosis in cancer cells and inhibitor for NLRP3 inflammasome via enhanced autophagy. Nanomaterials. 2021;11(2):384. doi:10.3390/nano11020384

157. Gupta S, Ved A. Operculina turpethum (Linn.) Silva Manso as a medicinal plant species: a review on bioactive components and pharmacological properties. Pharmacogn Rev. 2017;11(22):158166. doi:10.4103/phrev.phrev_6_17

158. Ignatius V, Narayanan M, Subramanian V, Periyasamy BM. Antiulcer activity of indigenous plant Operculina turpethum Linn. Evid-Based Complement Altern Med. 2013;2013:272134. doi:10.1155/2013/272134

159. Anbuselvam C, Vijayavel K, Balasubramanian MP. Protective effect of Operculina turpethum against 7,12-dimethyl benz(a) anthracene induced oxidative stress with reference to breast cancer in experimental rats. Chem Biol Interact. 2007;168(3):229236. doi:10.1016/j.cbi.2007.04.007

160. Mughees M, Wajid S. Evaluation of cytotoxicity of different part extracts of Ipomoea turpethum against breast cancer cell lines. $J$ Environ Pathol Toxicol Oncol. 2020;39(1):51-60. doi:10.1615/ JEnvironPatholToxicolOncol.2020031451

161. Mughees M, Samim M, Sharma Y, Wajid S. Identification of protein targets and the mechanism of the cytotoxic action of Ipomoea turpethum extract loaded nanoparticles against breast cancer cells. J Mater Chem B. 2019;7(39):6048-6063. doi:10.1039/c9tb00824a

162. Zhang W, Yu L, Ji T, Wang C. Tumor microenvironment-responsive peptide-based supramolecular drug delivery system. Front Chem. 2020;8:549. doi:10.3389/fchem.2020.00549

163. Polito L, Bortolotti M, Maiello S, Battelli MG, Bolognesi A. Plants producing ribosome-inactivating proteins in traditional medicine. Molecules. 2016;21(11):1560. doi:10.3390/molecules 21111560

164. Stirpe F. Ribosome-inactivating proteins: from toxins to useful proteins. Toxicon. 2013;67:12-16. doi:10.1016/j.toxicon.2013.0 2.005

165. Zhu F, Zhou YK, Ji ZL, Chen X. The plant ribosome-inactivating proteins play important roles in defense against pathogens and insect pest attacks. Front Plant Sci. 2018;9:146. doi:10.3389/ fpls.2018.00146

166. Sismindari SU, Mae Sri Hartati W, Adhyatmika A, Retno Sunarminingsih S. Cytotoxic selectivity of MJC0.3 and MJC0.5, acidic ribosome-inactivating proteins isolated from Mirabilis jalapa L. leaves against various cancer cell-lines. J Med Sci. 2010;42(1):39-43.

167. Wicaksono PA, Name S, Martien R, Ismail H. Formulation and cytotoxicity of ribosome-inactivating protein Mirabilis Jalapa L. nanoparticles using alginate-low viscosity chitosan conjugated with anti-Epcam antibodies in the T47D breast cancer cell line. Asian Pacific J Cancer Prev. 2016;17(4):2277-2284. doi:10.7314/ apjcp.2016.17.4.2277

168. Cimino A, Halushka M, Illei P, Wu X, Sukumar S, Argani P. Epithelial cell adhesion molecule (EpCAM) is overexpressed in breast cancer metastases. Breast Cancer Res Treat. 2010;123 (3):701-708. doi:10.1007/s10549-009-0671-z

169. Brandao EM, Brandão PH, Souza IA, Paiva GS, de C Carvalho M, Lacerda CM. Antineoplasic effect of aqueous extract of Plectranthus amboinicus in Ehrlich ascites carcinoma. $J$ Cancer. 2013;4(7):573-576. doi:10.7150/jca.6730
170. Gurgel AP, da Silva JG, Grangeiro AR, et al. In vivo study of the anti-inflammatory and antitumor activities of leaves from Plectranthus amboinicus (Lour.) Spreng (Lamiaceae). $J$ Ethnopharmacol. 2009;125(2):361-363. doi:10.1016/j. jep.2009.07.006

171. Almalki A, Abutaha N, Al-Doaiss AA, Mohammed AZ, Wadaan MA. Cytotoxicity, in vivo toxicity, and chemical composition of the hexane extract of Plectranthus amboinicus (Lour.) Spreng. Environ Sci Pollut Res. 2021;28(35):48141-48153. doi:10.1007/ s11356-021-13796-8

172. Hasibuan PAZ, Sitorus P, Satria D, Sibuea RD. Antioxidant properties and cytotoxic activity of ethyl acetate fraction of Plectranthus amboinicus (Lour.) Spreng. leaves on HeLa and T47D cell lines. Indones $J$ Cancer Chemoprevention. 2019;10 (1):37-45. doi:10.14499/indonesianjcanchemoprev10iss1pp37-45

173. Rai V, Pai VR, Kedilaya P. A preliminary evaluation of anticancer and antioxidant potential of two traditional medicinal plants from Lamiaceae-Pogostemon heyneanus and Plectranthus amboinicus. $J$ Appl Pharm Sci. 2016;6(8):73-78. doi:10.7324/ JAPS.2016.60811

174. Yulianto W, Andarwulan N, Giriwono PE, Pamungkas J. HPLCbased metabolomics to identify cytotoxic compounds from Plectranthus amboinicus (Lour.) Spreng against human breast cancer MCF-7Cells. J Chromatogr B Anal Technol Biomed Life Sci. 2016;1039:28-34. doi:10.1016/j.jchromb.2016.10.024

175. Hasibuan PAZ, Sumaiyah S. The anti-proliferative and pro-apoptotic properties of ethanol Plectranthus amboinicus (Lour.) Spreng. leaves ethanolic extract nanoparticles on T47D cell lines. Asian Pacific J Cancer Prev. 2019;20(3):897-901. doi:10.31557/APJCP.2019.20.3.897

176. Bassiri-Jahromi S. Punica granatum (Pomegranate) activity in health promotion and cancer prevention. Oncol Rev. 2018;12 (1):345. doi:10.4081/oncol.2018.345

177. Zarfeshany A, Asgary S, Javanmard SH. Potent health effects of pomegranate. Adv Biomed Res. 2014;3:100. doi:10.4103/22779175.129371

178. Ge S, Duo L, Wang J, et al. A unique understanding of traditional medicine of pomegranate, Punica granatum L. and its current research status. $J$ Ethnopharmacol. 2021;271:113877. doi:10.1016/j.jep.2021.113877

179. Al-Zoreky NS. Antimicrobial activity of pomegranate (Punica granatum L.) fruit peels. Int $J$ Food Microbiol. 2009;134 (3):244-248. doi:10.1016/j.ijfoodmicro.2009.07.002

180. Gil MI, Tomás-Barberán FA, Hess-Pierce B, Holcroft DM, Kader AA. Antioxidant activity of pomegranate juice and its relationship with phenolic composition and processing. J Agric Food Chem. 2000;48(10):4581-4589. doi:10.1021/jf000404a

181. Lukiswanto BS, Miranti A, Sudjarwo SA, Primarizky H, Yuniarti WM. Evaluation of wound healing potential of pomegranate (Punica granatum) whole fruit extract on skin burn wound in rats (Rattus norvegicus). J Adv Vet Anim Res. 2019;6(2):202207. doi:10.5455/javar.2019.f333

182. Razani Z, Dastani M, Kazerani HR. Cardioprotective effects of pomegranate (Punica granatum) juice in patients with ischemic heart disease. Phyther Res. 2017;31(11):1731-1738. doi:10.1002/ ptr.5901

183. González-Trujano ME, Pellicer F, Mena P, Moreno DA, GarcíaViguera C. Antinociceptive and anti-inflammatory activities of a pomegranate (Punica granatum L.) extract rich in ellagitannins. Int $J$ Food Sci Nutr. 2015;66(4):395-399. doi:10.3109/ 09637486.2015.1024208

184. Khan GN, Gorin MA, Rosenthal D, et al. Pomegranate fruit extract impairs invasion and motility in human breast cancer. Integr Cancer Ther. 2009;8(3):242-253. doi:10.1177/ 1534735409341405 
185. Ahmadiankia N, Bagheri M, Fazli M. Gene expression changes in pomegranate peel extract-treated triple-negative breast cancer cells. Reports Biochem Mol Biol. 2018;7(1):102-109.

186. Bagheri M, Fazli M, Saeednia S, Kor A, Ahmadiankia N. Pomegranate peel extract inhibits expression of $\beta$-catenin, epithelial mesenchymal transition, and metastasis in triple negative breast cancer cells. Cell Mol Biol. 2018;64(7):86-91. doi: $10.14715 / \mathrm{cmb} / 2018.64 .7 .15$

187. Shirode AB, Kovvuru P, Chittur SV, Henning SM, Heber D, Reliene R. Antiproliferative effects of pomegranate extract in MCF-7 breast cancer cells are associated with reduced DNA repair gene expression and induction of double strand breaks. Mol Carcinog. 2014;53(6):458-470. doi:10.1002/mc.21995

188. Sreeja S, Santhosh Kumar TR, Lakshmi BS, Sreeja S. Pomegranate extract demonstrate a selective estrogen receptor modulator profile in human tumor cell lines and in vivo models of estrogen deprivation. $J$ Nutr Biochem. 2012;23(7):725-732. doi:10.1016/j.jnutbio.2011.03.015

189. Shirode AB, Bharali DJ, Nallanthighal S, Coon JK, Mousa SA, Reliene R. Nanoencapsulation of pomegranate bioactive compounds for breast cancer chemoprevention. Int J Nanomedicine. 2015;10:475-484. doi:10.2147/IJN.S65145

190. Badawi NM, Teaima MH, El-Say KM, Attia DA, El-Nabarawi MA, Elmazar MM. Pomegranate extract-loaded solid lipid nanoparticles: design, optimization, and in vitro cytotoxicity study. Int J Nanomedicine. 2018;13:1313-1326. doi:10.2147/IJN.S154033

191. Wansi JD, Wandji J, Sewald N, Nahar L, Martin C, Sarker SD. Phytochemistry and pharmacology of the genus Drypetes: a review. J Ethnopharmacol. 2016;190:328-353. doi:10.1016/j. jep.2016.06.060

192. Mishra S, Kumar S, Darokar MP, Shanker K. Novel bioactive compound from the bark of Putranjiva roxburghii Wall. Nat Prod Res. 2019;35(4):1-3. doi:10.1080/14786419.2019.1633650

193. Kala C, Imam SS, Taleuzzaman M, et al. Extraction, GC-MS evaluation and anti-epileptic potential of seeds ethanolic extract of Putranjiva roxburghii Wall. Cent Nerv Syst Agents Med Chem. 2020;20(3):186-193. doi:10.2174/ 1871524920999201027125743

194. Reanmongkol W, Noppapan T, Subhadhirasakul S. Antinociceptive, antipyretic, and anti-inflammatory activities of Putranjiva roxburghii Wall. leaf extract in experimental animals. $J$ Nat Med. 2009;63(3):290-296. doi:10.1007/s11418-009-0336-6

195. Shivalingegowda M, Ekambaram H, Manjunath K. Antimicrobial, antioxidant and cytotoxic activity of methanolic leaf extract of Putranjiva roxburghii: an in-vitro study. Solid State Technol. 2020;63(6):13199-13210.

196. Balkrishna A, Sharma VK, Das SK, et al. Characterization and anti-cancerous effect of Putranjiva roxburghii seed extract mediated silver nanoparticles on human colon (HCT-116), pancreatic (PANC-1) and breast (MDA-MB 231) cancer cell lines: a comparative study. Int $J$ Nanomedicine. 2020;15:573-585. doi:10.2147/IJN.S230244

197. Nayaka S, Bhat MP, Chakraborty B, et al. Seed extract-mediated synthesis of silver nanoparticles from Putranjiva roxburghii Wall.: phytochemical characterization, antibacterial activity and anticancer activity against MCF-7 cell line. Indian J Pharm Sci. 2020;82(2):260-269. doi:10.36468/pharmaceutical-sciences.646

198. Salehi F, Behboudi H, Kavoosi G, Ardestani SK. Monitoring ZEO apoptotic potential in 2D and 3D cell cultures and associated spectroscopic evidence on mode of interaction with DNA. Sci Rep. 2017;7:1-14. doi:10.1038/s41598-017-02633-z

199. Sajed H, Sahebkar A, Iranshahi M. Zataria multiflora Boiss. (Shirazi thyme) — an ancient condiment with modern pharmaceutical uses. J Ethnopharmacol. 2013;145(3):686-698. doi:10.1016/ j.jep.2012.12.018
200. Mahmoudvand H, Tavakoli Kareshk A, Nabi Moradi M, et al. Efficacy and safety of Zataria multiflora Boiss essential oil against acute toxoplasmosis in mice. Iran J Parasitol. 2020;15 (1):22-30.

201. Zomorodian K, Saharkhiz MJ, Rahimi MJ, et al. Chemical composition and antimicrobial activities of the essential oils from three ecotypes of Zataria multiflora. Pharmacogn Mag. 2011;7 (25):53-59. doi:10.4103/0973-1296.75902

202. Sharififar F, Derakhshanfar A, Dehghan-Nudeh G, et al. In vivo antioxidant activity of Zataria multiflora Boiss essential oil. Pak $J$ Pharm Sci. 2011;24(2):221-225.

203. Majlessi N, Choopani S, Kamalinejad M, Azizi Z. Amelioration of amyloid $\beta$-induced cognitive deficits by Zataria multiflora Boiss. essential oil in a rat model of Alzheimer's disease. CNS Neurosci Ther. 2012;18(4):295-301. doi:10.1111/j.17555949.2011.00237.x

204. Azadi M, Jamali T, Kianmehr Z, Kavoosi G, Ardestani SK. Invitro (2D and $3 \mathrm{D}$ cultures) and in-vivo cytotoxic properties of Zataria multiflora essential oil (ZEO) emulsion in breast and cervical cancer cells along with the investigation of immunomodulatory potential. $J$ Ethnopharmacol. 2020;257:112865. doi:10.1016/j.jep.2020.112865

205. Salehi F, Jamali T, Kavoosi G, Ardestani SK, Vahdati SN. Stabilization of Zataria essential oil with pectin-based nanoemulsion for enhanced cytotoxicity in monolayer and spheroid drugresistant breast cancer cell cultures and deciphering its binding mode with gDNA. Int J Biol Macromol. 2020;164:3645-3655. doi:10.1016/j.ijbiomac.2020.08.084

206. Metwally AA, El-Ahmady SH, Hathout RM. Selecting optimum protein nano-carriers for natural polyphenols using chemoinformatics tools. Phytomedicine. 2016;23(14):1764-1770. doi:10.1016/j.phymed.2016.10.020

207. Bharali DJ, Siddiqui IA, Adhami VM, et al. Nanoparticle delivery of natural products in the prevention and treatment of cancers: current status and future prospects. Cancers (Basel). 2011;3 (4):4024-4045. doi:10.3390/cancers3044024

208. Atun S, Aznam N, Arianingrum R, Niwa M. Balanocarpol and heimiol A, two resveratrols dimer from stem bark Hopea mengarawan (Dipterocarpaceae). Indones J Chem. 2006;6(1):75-78. doi:10.22146/ijc. 21777

209. Lim KG, Gray AI, Pyne S, Pyne NJ. Resveratrol dimers are novel sphingosine kinase 1 inhibitors and affect sphingosine kinase 1 expression and cancer cell growth and survival. $\mathrm{Br} J$ Pharmacol. 2012;166(5):1605-1616. doi:10.1111/j.14765381.2012.01862.x

210. Obeid MA, Gany SAS, Gray AI, Young L, Igoli JO, Ferro VA. Niosome-encapsulated balanocarpol: compound isolation, characterisation, and cytotoxicity evaluation against human breast and ovarian cancer cell lines. Nanotechnology. 2020;31(19):195101. doi:10.1088/1361-6528/ab6d9c

211. Alshaker H, Thrower H, Pchejetski D. Sphingosine kinase 1 in breast cancer-a new molecular marker and a therapy target. Front Oncol. 2020;10:289. doi:10.3389/fonc.2020.00289

212. Heffernan-Stroud LA, Obeid LM. Sphingosine kinase 1 in cancer. Adv Cancer Res. 2017;117:201-235. doi:10.1016/B978-0-12394274-6.00007-8

213. Tuli HS, Sandhu SS, Sharma AK. Pharmacological and therapeutic potential of Cordyceps with special reference to Cordycepin. 3 Biotech. 2014;4(1):1-12. doi:10.1007/s13205-013-0121-9

214. Ashraf SA, Elkhalifa AEO, Siddiqui AJ, et al. Cordycepin for health and wellbeing: a potent bioactive metabolite of an entomopathogenic medicinal fungus Cordyceps with its nutraceutical and therapeutic potential. Molecules. 2020;25(12):2735. doi:10.3390/molecules 25122735 
215. Choi S, Lim MH, Kim KM, Jeon BH, Song WO, Kim TW. Cordycepin-induced apoptosis and autophagy in breast cancer cells are independent of the estrogen receptor. Toxicol Appl Pharmacol. 2011;257(2):165-173. doi:10.1016/j.taap.2011.08.030

216. Lee D, Lee WY, Jung K, et al. The inhibitory effect of cordycepin on the proliferation of MCF-7 breast cancer cells, and its mechanism: an investigation using network pharmacology-based analysis. Biomolecules. 2019;9(9):414. doi:10.3390/biom9090414

217. Lee HJ, Burger P, Vogel M, Friese K, Brüning A. The nucleoside antagonist cordycepin causes DNA double strand breaks in breast cancer cells. Invest New Drugs. 2012;30(5):1917-1925. doi:10.1007/s10637-012-9859-x

218. Liu C, Qi M, Li L, Yuan Y, Wu X, Fu J. Natural cordycepin induces apoptosis and suppresses metastasis in breast cancer cells by inhibiting the Hedgehog pathway. Food Funct. 2020;11 (3):2107-2116. doi:10.1039/c9fo02879j

219. Wang D, Zhang Y, Lu J, et al. Cordycepin, a natural antineoplastic agent, induces apoptosis of breast cancer cells via caspasedependent pathways. Nat Prod Commun. 2016;11(1):63-68. doi:10.1177/1934578X1601100119

220. Jiang Q, Lou Z, Wang H, Chen C. Antimicrobial effect and proposed action mechanism of cordycepin against Escherichia coli and Bacillus subtilis. J Microbiol. 2019;57(4):288-297. doi:10.1007/s12275-019-8113-Z

221. Choi YH, Kim GY, Lee HH. Anti-inflammatory effects of cordycepin in lipopolysaccharide-stimulated RAW 264.7 macrophages through Toll-like receptor 4-mediated suppression of mitogen-

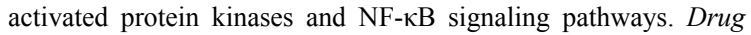
Des Devel Ther. 2014;8:1941-1953. doi:10.2147/DDDT.S71957

222. Ashraf S, Radhi M, Gowler P, et al. The polyadenylation inhibitor cordycepin reduces pain, inflammation and joint pathology in rodent models of osteoarthritis. Sci Rep. 2019;9:1-17. doi:10.1038/s41598-019-41140-1

223. Ma L, Zhang S, Du M. Cordycepin from Cordyceps militaris prevents hyperglycemia in alloxan-induced diabetic mice. Nutr Res. 2015;35(5):431-439. doi:10.1016/j.nutres.2015.04.011

224. Gao J, Lian ZQ, Zhu P, Zhu HB. Lipid-lowering effect of cordycepin (3'-deoxyadenosine) from Cordyceps militaris on hyperlipidemic hamsters and rats. Acta Pharm Sin. 2011;46(6):669-676.

225. Cho HJ, Cho JY, Rhee MH, Kim HS, Lee HS, Park HJ. Inhibitory effects of cordycepin (3'-deoxyadenosine), a component of Cordyceps militaris, on human platelet aggregation induced by thapsigargin. J Microbiol Biotechnol. 2007;17(7):1134-1138.

226. Qin P, Li X, Yang H, Wang ZY, Lu D. Therapeutic potential and biological applications of cordycepin and metabolic mechanisms in cordycepin-producing fungi. Molecules. 2019;24(12):2231. doi:10.3390/molecules24122231

227. Marslin G, Khandelwal V, Franklin G. Cordycepin nanoencapsulated in poly(lactic-co-glycolic acid) exhibits better cytotoxicity and lower hemotoxicity than free drug. Nanotechnol Sci Appl. 2020;13:37-45. doi:10.2147/NSA.S254770

228. Hewlings SJ, Kalman DS. Curcumin: a Review of Its' Effects on Human Health. Foods. 2017;6(10):92. doi:10.3390/foods6100092

229. Mishra A, Kumar R, Tyagi A, et al. Curcumin modulates cellular AP1, NF-kB, and HPV16 E6 proteins in oral cancer. Ecancermedicalscience. 2015;9:525. doi:10.3332/ecancer.2015.525

230. Sun SH, Huang HC, Huang C, Lin JK. Cycle arrest and apoptosis in MDA-MB-231/Her2 cells induced by curcumin. Eur $J$ Pharmacol. 2012;690(1-3):22-30. doi:10.1016/j.ejphar.20 12.05 .036

231. Bimonte S, Barbieri A, Palma G, et al. Dissecting the role of curcumin in tumour growth and angiogenesis in mouse model of human breast cancer. Biomed Res Int. 2015;2015:878134. doi: $10.1155 / 2015 / 878134$
232. Hu S, Xu Y, Meng L, Huang L, Sun H. Curcumin inhibits proliferation and promotes apoptosis of breast cancer cells. Exp Ther Med. 2018;16(2):1266-1272. doi:10.3892/etm.2018.6345

233. Prasad CP, Rath G, Mathur S, Bhatnagar D, Ralhan R. Potent growth suppressive activity of curcumin in human breast cancer cells: modulation of Wnt/beta-catenin signaling. Chem Biol Interact. 2009;181(2):263-271. doi:10.1016/j.cbi.2009.06.012

234. He ZY, Shi CB, Wen H, Li FL, Wang BL, Wang J. Upregulation of p53 expression in patients with colorectal cancer by administration of curcumin. Cancer Invest. 2011;29(3):208-213. doi: 10.3109/07357907.2010.550592

235. Díaz Osterman CJ, Gonda A, Stiff T, et al. Curcumin induces pancreatic adenocarcinoma cell death via reduction of the inhibitors of apoptosis. Pancreas. 2017;45(1):101-109. doi:10.1097/ MPA.0000000000000411

236. Phillips JM, Clark C, Herman-Ferdinandez L, et al. Curcumin inhibits skin squamous cell carcinoma tumor growth in vivo. Otolaryngol Neck Surg. 2011;145(1):58-63. doi:10.1177/ 0194599811400711

237. LoTempio MM, Veena MS, Steele HL, et al. Curcumin suppresses growth of head and neck squamous cell carcinoma. Clin Cancer Res. 2005;11(19 Pt 1):6994-7002. doi:10.1158/10780432.CCR-05-0301

238. Anand P, Kunnumakkara AB, Newman RA, Aggarwal BB. Bioavailability of curcumin: problems and promises. Mol Pharm. 2007;4(6):807-818. doi:10.1021/mp700113r

239. Hassani A, Mahmood S, Enezei HH, et al. Formulation, characterization and biological activity screening of sodium alginategum arabic nanoparticles loaded with curcumin. Molecules. 2020;25(9):2244. doi:10.3390/molecules25092244

240. Farhangi B, Alizadeh AM, Khodayari H, et al. Protective effects of dendrosomal curcumin on an animal metastatic breast tumor. Eur $J$ Pharmacol. 2015;758:188-196. doi:10.1016/j.ejphar.2015.03.076

241. Hasan M, Belhaj N, Benachour H, et al. Liposome encapsulation of curcumin: physico-chemical characterizations and effects on MCF7 cancer cell proliferation. Int J Pharm. 2014;461(1-2):519528. doi:10.1016/j.ijpharm.2013.12.007

242. Serini S, Fasano E, Piccioni E, Cittadini AR, Calviello G. Differential anti-cancer effects of purified EPA and DHA and possible mechanisms involved. Curr Med Chem. 2011;18 (26):4065-4075. doi:10.2174/092986711796957310

243. Hasan M, Elkhoury K, Belhaj N, et al. Growth-inhibitory effect of chitosan-coated liposomes encapsulating curcumin on MCF-7 breast cancer cells. Mar Drugs. 2020;18(4):217. doi:10.3390/md18040217

244. Sarika PR, Nirmala RJ. Curcumin loaded gum arabic aldehydegelatin nanogels for breast cancer therapy. Mater Sci Eng C. 2016;65:331-337. doi:10.1016/j.msec.2016.04.044

245. Yu SR, Zhang XP, He ZM, Liu YH, Liu ZH. Effects of Ce on the short-term biocompatibility of Ti-Fe-Mo-Mn-Nb-Zr alloy for dental materials. J Mater Sci Mater Med. 2004;15(6):687-691. doi:10.1023/b:jmsm.0000030210.83891.d4

246. Hussein Y, Loutfy SA, Kamoun EA, El-Moslamy SH, Radwan EM, Elbehairi SEI. Enhanced anti-cancer activity by localized delivery of curcumin form PVA/CNCs hydrogel membranes: preparation and in vitro bioevaluation. Int $J$ Biol Macromol. 2021;170:107-122. doi:10.1016/j.ijbiomac.2020.12.133

247. Bai F, Diao J, Wang Y, et al. A new water-soluble nanomicelle formed through self-assembly of pectin-curcumin conjugates: preparation, characterization, and anticancer activity evaluation. $J$ Agric Food Chem. 2017;65(32):6840-6847. doi:10.1021/acs.jafc.7b02250

248. Jithan AV, Madhavi K, Madhavi M, Prabhakar K. Preparation and characterization of albumin nanoparticles encapsulating curcumin intended for the treatment of breast cancer. Int J Pharm Investig. 2011;1(2):119-125. doi:10.4103/2230-973X.82432 
249. Khazaei Koohpar Z, Entezari M, Movafagh A, Hashemi M. Anticancer activity of curcumin on human breast adenocarcinoma: role of Mcl-1 gene. Iran J Cancer Prev. 2015;8(3):e2331. doi:10.17795/ijcp2331

250. Danafar H, Sharafi A, Askarlou S, Manjili HK. Preparation and characterization of PEGylated iron oxide-gold nanoparticles for delivery of sulforaphane and curcumin. Drug Res. 2017;67 (12):698-704. doi: $10.1055 / \mathrm{s}-0043-115905$

251. Cheung A, Bax HJ, Josephs DH, et al. Targeting folate receptor alpha for cancer treatment. Oncotarget. 2016;7(32):52553-52574. doi:10.18632/oncotarget.9651

252. Wang J, Wang Y, Liu Q, et al. Rational design of multifunctional dendritic mesoporous silica nanoparticles to load curcumin and enhance efficacy for breast cancer therapy. ACS Appl Mater Interfaces. 2016;8(40):26511-26523. doi:10.1021/ acsami.6b08400

253. Ansary J, Forbes-Hernández TY, Gil E, et al. Potential health benefit of garlic based on human intervention studies: a brief overview. Antioxidants. 2020;9(7):619. doi:10.3390/ antiox 9070619

254. Dorrigiv M, Zareiyan A, Garlic HH. (Allium sativum) as an antidote or a protective agent against natural or chemical toxicities: a comprehensive update review. Phyther Res. 2020;34 (8):1770-1797. doi:10.1002/ptr.6645

255. Shang A, Cao SY, Xu XY, et al. Bioactive compounds and biological functions of garlic (Allium sativum L.). Foods. 2019;8(7):246. doi:10.3390/foods8070246

256. Altonsy MO, Habib TN, Andrews SC. Diallyl disulfide-induced apoptosis in a breast-cancer cell line (MCF-7) may be caused by inhibition of histone deacetylation. Nutr Cancer. 2012;64 (8):1251-1260. doi:10.1080/01635581.2012.721156

257. Huang J, Yang B, Xiang T, et al. Diallyl disulfide inhibits growth and metastatic potential of human triple-negative breast cancer cells through inactivation of the $\beta$-catenin signaling pathway. Mol Nutr Food Res. 2015;59(6):1063-1075. doi:10.1002/mnfr.201400668

258. Lei XY, Yao SQ, Zu XY, et al. Apoptosis induced by diallyl disulfide in human breast cancer cell line MCF-7. Acta Pharmacol Sin. 2008;29(10):1233-1239. doi:10.1111/j.17457254.2008.00851.x

259. Xiao X, Chen B, Liu X, et al. Diallyl disulfide suppresses SRC/ Ras/ERK signaling-mediated proliferation and metastasis in human breast cancer by up-regulating miR-34a. PLoS One. 2014;9(11):e112720. doi:10.1371/journal.pone.0112720

260. Xiong T, Liu XW, Huang XL, et al. Tristetraprolin: a novel target of diallyl disulfide that inhibits the progression of breast cancer. Oncol Lett. 2018;15(5):7817-7827. doi:10.3892/ol.2018.8299

261. Jun Z, Suzuki M, Xiao J, et al. Comparative effects of natural and synthetic diallyl disulfide on apoptosis of human breast-cancer MCF-7 cells. Biotechnol Appl Biochem. 2009;52(Pt2):113-119. doi:10.1042/BA20070242

262. Talluri SV, Kuppusamy G, Karri VVSR, et al. Application of quality-by-design approach to optimize diallyl disulfide-loaded solid lipid nanoparticles. Artif Cells, Nanomedicine, Biotechnol. 2016;45(3):474-488. doi:10.3109/21691401.2016.1173046

263. Schröter D, Höhn A. Role of advanced glycation end products in carcinogenesis and their therapeutic implications. Curr Pharm Des. 2019;24(44):261-266. doi:10.2174/1381612825666190130145549

264. Kwak T, Drews-Elger K, Ergonul A, et al. Targeting of RAGEligand signaling impairs breast cancer cell invasion and metastasis Oncogene. 2016;36(11):1559-1572. doi:10.1038/onc.2016.324

265. Chacko SM, Thambi PT, Kuttan R, Nishigaki I. Beneficial effects of green tea: a literature review. Chin Med. 2010;5:1-9. doi:10.1186/1749-8546-5-13

266. Nagle DG, Ferreira D, Zhou YD. Epigallocatechin-3-gallate (EGCG): chemical and biomedical perspectives. Phytochemistry. 2006;67(17):1849-1855. doi:10.1016/j.phytochem.2006.06.020
267. Thangapazham RL, Passi N, Maheshwari RK. Green tea polyphenol and epigallocatechin gallate induce apoptosis and inhibit invasion in human breast cancer cells. Cancer Biol Ther. 2007;6 (12):1938-1943. doi:10.4161/cbt.6.12.4974

268. Braicu $\mathrm{C}$, Gherman $\mathrm{CD}$, Irimie $\mathrm{A}$, Berindan-Neagoe $\mathrm{I}$. Epigallocatechin-3-Gallate (EGCG) inhibits cell proliferation and migratory behaviour of triple negative breast cancer cells. $J$ Nanosci Nanotechnol. 2013;13(1):632-637. doi:10.1166/jnn.2013.6882

269. Gu JW, Makey KL, Tucker KB, et al. EGCG, a major green tea catechin suppresses breast tumor angiogenesis and growth via inhibiting the activation of HIF- $1 \alpha$ and NFKB, and VEGF expression. Vasc Cell. 2013;5(1):9. doi:10.1186/2045-824X-5-9

270. Wei R, Mao L, Xu P, et al. Suppressing glucose metabolism with epigallocatechin-3-gallate (EGCG) reduces breast cancer cell growth in preclinical models. Food Funct. 2018;9(11):56825696. doi:10.1039/c8fo01397g

271. Zan L, Chen Q, Zhang L, Li X. Epigallocatechin gallate (EGCG) suppresses growth and tumorigenicity in breast cancer cells by downregulation of miR-25. Bioengineered. 2019;10(1):374-382. doi:10.1080/21655979.2019.1657327

272. Meeran SM, Patel SN, Chan TH, Tollefsbol TO. A novel prodrug of epigallocatechin-3-gallate: differential epigenetic hTERT repression in human breast cancer cells. Cancer Prev Res. 2011;4(8):1243-1254. doi:10.1158/1940-6207.CAPR-11-0009

273. Radhakrishnan R, Kulhari H, Pooja D, et al. Encapsulation of biophenolic phytochemical EGCG within lipid nanoparticles enhances its stability and cytotoxicity against cancer. Chem Phys Lipids. 2016;198:51-60. doi:10.1016/j.chemphyslip.2016.05.006

274. Moreno P, Ramos-álvarez I, Moody TW, Jensen RT. Bombesin related peptides/receptors and their promising therapeutic roles in cancer imaging, targeting and treatment. Expert Opin Ther Targets. 2016;20(9):1055-1073. doi:10.1517/14728222.2016.1164694

275. Radhakrishnan R, Pooja D, Kulhari H, et al. Bombesin conjugated solid lipid nanoparticles for improved delivery of epigallocatechin gallate for breast cancer treatment. Chem Phys Lipids. 2019;224:104770. doi:10.1016/j.chemphyslip.2019.04.005

276. Kahkeshani N, Farzaei F, Fotouhi M, et al. Pharmacological effects of gallic acid in health and diseases: a mechanistic review. Iran J Basic Med Sci. 2019;22(3):225-237. doi:10.22038/ ijbms.2019.32806.7897

277. Rezaei-Seresht H, Cheshomi H, Falanji F, Movahedi-Motlagh F, Hashemian M, Mireskandari E. Cytotoxic activity of caffeic acid and gallic acid against MCF-7 human breast cancer cells: an in silico and in vitro study. Avicenna J Phytomed. 2019;9(6):574586. doi:10.22038/AJP.2019.13475

278. Lee HL, Lin CS, Kao SH, Chou MC. Gallic acid induces G1 phase arrest and apoptosis of triple-negative breast cancer cell MDA-MB-231 via p38 mitogen-activated protein kinase/p21/p27 axis. Anticancer Drugs. 2017;28(10):1150-1156. doi:10.1097/ CAD. 0000000000000565

279. Hsu JD, Kao SH, Ou TT, Chen YJ, Li YJ, Wang CJ. Gallic acid induces $\mathrm{G} 2 / \mathrm{M}$ phase arrest of breast cancer cell MCF-7 through stabilization of p27(Kip1) attributed to disruption of p27(Kip1)/ Skp2 complex. J Agric Food Chem. 2011;59(5):1996-2003. doi: $10.1021 / \mathrm{jf} 103656 \mathrm{v}$

280. Nowakowska A, Tarasiuk J. Comparative effects of selected plant polyphenols, gallic acid and epigallocatechin gallate, on matrix metalloproteinases activity in multidrug resistant MCF7/DOX breast cancer cells. Acta Biochim Pol. 2016;63(3):571-575. doi:10.18388/abp.2016_1256

281. García-Rivera D, Delgado R, Bougarne N, Haegeman G, Berghe WV. Gallic acid indanone and mangiferin xanthone are strong determinants of immunosuppressive anti-tumour effects of Mangifera indica L. bark in MDA-MB231 breast cancer cells. Cancer Lett. 2011;305(1):21-31. doi:10.1016/j.canlet.2011.02.011 
282. BenSaad LA, Kim KH, Quah CC, Kim WR, Shahimi M. Antiinflammatory potential of ellagic acid, gallic acid and punicalagin A\&B isolated from Punica granatum. BMC Complement Altern Med. 2017;17:1-10. doi:10.1186/s12906-017-1555-0

283. Lu J, Wang Z, Ren M, et al. Antibacterial effect of gallic acid against Aeromonas hydrophila and Aeromonas sobria through damaging membrane integrity. Curr Pharm Biotechnol. 2016;17 (13):1153-1158. doi:10.2174/1389201017666161022235759

284. Asnaashari M, Farhoosh R, Sharif A. Antioxidant activity of gallic acid and methyl gallate in triacylglycerols of Kilka fish oil and its oil-in-water emulsion. Food Chem. 2014;159:439-444. doi:10.1016/j.foodchem.2014.03.038

285. Priscilla DH, Prince PS. Cardioprotective effect of gallic acid on cardiac troponin- $\mathrm{T}$, cardiac marker enzymes, lipid peroxidation products and antioxidants in experimentally induced myocardial infarction in Wistar rats. Chem Biol Interact. 2009;179(2-3):118124. doi:10.1016/j.cbi.2008.12.012

286. Zhou D, Yang Q, Tian T, et al. Gastroprotective effect of gallic acid against ethanol-induced gastric ulcer in rats: involvement of the Nrf2/ HO-1 signaling and anti-apoptosis role. Biomed Pharmacother. 2020;126:110075. doi:10.1016/j.biopha.2020.110075

287. Maya S, Prakash T, Madhu K. Assessment of neuroprotective effects of gallic acid against glutamate-induced neurotoxicity in primary rat cortex neuronal culture. Neurochem Int. 2018;121:5058. doi:10.1016/j.neuint.2018.10.011

288. Hassani A, Azarian MMS, Ibrahim WN, Hussain SA. Preparation, characterization and therapeutic properties of gum arabic-stabilized gallic acid nanoparticles. Sci Rep. 2020;10 (1):17808. doi:10.1038/s41598-020-71175-8

289. Kaddam L, Fadl-Elmula I, Eisawi OA, et al. Gum Arabic as novel anti-oxidant agent in sickle cell anemia, phase II trial. $B M C$ Hematol. 2017;17:1-6. doi:10.1186/s12878-017-0075-y

290. Nogueira V, Hay N. Molecular pathways: reactive oxygen species homeostasis in cancer cells and implications for cancer therapy. Clin Cancer Res. 2013;19(16):4309-4314. doi:10.1158/10780432.CCR-12-1424

291. Liou GY, Storz P. Reactive oxygen species in cancer. Free Radic Res. 2010;44(5):479-496. doi:10.3109/10715761003667554

292. Nourazarian AR, Kangari P, Salmaninejad A. Roles of oxidative stress in the development and progression of breast cancer. Asian Pacific J Cancer Prev. 2014;15(12):4745-4751. doi:10.7314/ apjcp.2014.15.12.4745

293. Pan L, Duan Y, Ma F, Lou L. Punicalagin inhibits the viability, migration, invasion, and EMT by regulating GOLPH3 in breast cancer cells. J Recept Signal Transduct. 2020;40(2):173-180. doi:10.1080/10799893.2020.1719152

294. Aqil F, Munagala R, Vadhanam MV, et al. Anti-proliferative activity and protection against oxidative DNA damage by punicalagin isolated from pomegranate husk. Food Res Int. 2012;49 (1):345-353. doi:10.1016/j.foodres.2012.07.059

295. Kawabata K, Yoshioka Y, Terao J. Role of intestinal microbiota in the bioavailability and physiological functions of dietary polyphenols. Molecules. 2019;24(2):370. doi:10.3390/molecules24020370

296. Larrosa M, Tomás-Barberán FA, Espín JC. The dietary hydrolysable tannin punicalagin releases ellagic acid that induces apoptosis in human colon adenocarcinoma Caco-2 cells by using the mitochondrial pathway. J Nutr Biochem. 2006;17(9):611-625. doi:10.1016/j.jnutbio.2005.09.004

297. Wang N, Wang ZY, Mo SL, et al. Ellagic acid, a phenolic compound, exerts anti-angiogenesis effects via VEGFR-2 signaling pathway in breast cancer. Breast Cancer Res Treat. 2012;134 (3):943-955. doi:10.1007/s10549-012-1977-9

298. Chen HS, Bai MH, Zhang T, Li GD, Liu M. Ellagic acid induces cell cycle arrest and apoptosis through TGF- $\beta / \mathrm{Smad} 3$ signaling pathway in human breast cancer MCF-7 cells. Int $J$ Oncol. 2015;46(4):1730-1738. doi:10.3892/ijo.2015.2870
299. Wang N, Wang Q, Tang H, et al. Direct inhibition of ACTN4 by ellagic acid limits breast cancer metastasis via regulation of $\beta$ catenin stabilization in cancer stem cells. J Exp Clin Cancer Res. 2017;36(1):172. doi:10.1186/s13046-017-0635-9

300. Yousuf M, Shamsi A, Khan P, et al. Ellagic acid controls cell proliferation and induces apoptosis in breast cancer cells via inhibition of cyclin-dependent kinase 6. Int J Mol Sci. 2020;21 (10):3526. doi:10.3390/ijms21103526

301. Long J, Guo Y, Yang J, et al. Bioavailability and bioactivity of free ellagic acid compared to pomegranate juice. Food Funct. 2019;10(10):6582-6588. doi:10.1039/c9fo01683j

302. Seeram NP, Henning SM, Zhang Y, Suchard M, Li Z, Heber D. Pomegranate juice ellagitannin metabolites are present in human plasma and some persist in urine for up to 48 hours. $J$ Nutr. 2006;136(10):2481-2485. doi:10.1093/jn/136.10.2481

303. Bayat Mokhtari R, Baluch N, Homayouni TS, et al. The role of Sulforaphane in cancer chemoprevention and health benefits: a mini-review. J Cell Commun Signal. 2018;12(1):91-101. doi:10.1007/s12079-017-0401-y

304. Sikdar S, Papadopoulou M, Dubois J. What do we know about sulforaphane protection against photoaging? J Cosmet Dermatol. 2016;15(1):72-77. doi:10.1111/jocd.12176

305. Qi T, Xu F, Yan X, Li S, Li H. Sulforaphane exerts anti-inflammatory effects against lipopolysaccharide-induced acute lung injury in mice through the Nrf2/ARE pathway. Int $J$ Mol Med. 2016;37(1):182-188. doi:10.3892/ijmm.2015.2396

306. Johansson NL, Pavia CS, Chiao JW. Growth inhibition of a spectrum of bacterial and fungal pathogens by sulforaphane, an isothiocyanate product found in broccoli and other cruciferous vegetables. Planta Med. 2008;74(7):747-750. doi:10.1055/s2008-1074520

307. Fahey JW, Talalay P. Antioxidant functions of sulforaphane: a potent inducer of Phase II detoxication enzymes. Food Chem Toxicol. 1999;37(9-10):973-979. doi:10.1016/s0278-6915(99) 00082-4

308. Axelsson AS, Tubbs E, Mecham B, et al. Sulforaphane reduces hepatic glucose production and improves glucose control in patients with type 2 diabetes. Sci Transl Med. 2017;9(394): eaah4477. doi:10.1126/scitranslmed.aah4477

309. Morroni F, Tarozzi A, Sita G, et al. Neuroprotective effect of sulforaphane in 6-hydroxydopamine-lesioned mouse model of Parkinson's disease. Neurotoxicology. 2013;36:63-71. doi:10.1016/j.neuro.2013.03.004

310. Sarkar R, Mukherjee S, Biswas J, Roy M. Sulphoraphane, a naturally occurring isothiocyanate induces apoptosis in breast cancer cells by targeting heat shock proteins. Biochem Biophys Res Commun. 2012;427(1):80-85. doi:10.1016/j.bbrc.20 12.09.006

311. Pawlik A, Wiczk A, Kaczyńska A, Antosiewicz J, HermanAntosiewicz A. Sulforaphane inhibits growth of phenotypically different breast cancer cells. Eur J Nutr. 2013;52(8):1949-1958. doi:10.1007/s00394-013-0499-5

312. Cao C, Wu H, Vasilatos SN, et al. HDAC5-LSD1 axis regulates antineoplastic effect of natural HDAC inhibitor sulforaphane in human breast cancer cells. Int $J$ Cancer. 2018;143(6):1388-1401. doi:10.1002/ijc.31419

313. Hunakova L, Sedlakova O, Cholujova D, Gronesova P, Duraj J, Sedlak J. Modulation of markers associated with aggressive phenotype in MDA-MB-231 breast carcinoma cells by sulforaphane. Neoplasma. 2009;56(6):548-556. doi:10.4149/neo_2009_06_548

314. Zambrano V, Bustos R, Mahn A. Insights about stabilization of sulforaphane through microencapsulation. Heliyon. 2019;5(11): e02951. doi:10.1016/j.heliyon.2019.e02951

315. Li J, Kataoka K. Chemo-physical strategies to advance the in vivo functionality of targeted nanomedicine: the next generation. $\mathrm{J} \mathrm{Am}$ Chem Soc. 2021;143(2):538-559. doi:10.1021/jacs.0c09029 


\section{Publish your work in this journal}

The International Journal of Nanomedicine is an international, peerreviewed journal focusing on the application of nanotechnology in diagnostics, therapeutics, and drug delivery systems throughout the biomedical field. This journal is indexed on PubMed Central, MedLine, CAS, SciSearch ${ }^{\mathbb{B}}$, Current Contents ${ }^{\mathbb{B}} /$ Clinical Medicine, $^{2}$
Journal Citation Reports/Science Edition, EMBase, Scopus and the Elsevier Bibliographic databases. The manuscript management system is completely online and includes a very quick and fair peer-review system, which is all easy to use. Visit http://www.dovepress.com/ testimonials.php to read real quotes from published authors. 